JOHN PAUL HEMPEL LIMA

\title{
REDES NEURAIS ARTIFICIAIS APLICADAS À OTIMIZAÇÃO DE PROCESSOS DE DEPOSIÇÃO DE FILMES FINOS POLIMÉRICOS
}

\author{
Dissertação apresentada à Escola \\ Politécnica da Universidade de São \\ Paulo para a obtenção do Título de \\ Mestre em Engenharia.
}

São Paulo

2006 


\title{
JOHN PAUL HEMPEL LIMA
}

\section{REDES NEURAIS ARTIFICIAIS APLICADAS À OTIMIZAÇÃO DE PROCESSOS DE DEPOSIÇÃO DE FILMES FINOS POLIMÉRICOS}

\author{
Dissertação apresentada à Escola \\ Politécnica da Universidade de São \\ Paulo para a obtenção do Título de \\ Mestre em Engenharia. \\ Orientador: \\ Prof. Dr. Adnei Melges de Andrade
}

São Paulo

2006 
Este exemplar foi revisado e alterado em relação à versão original, sob responsabilidade única do autor e com a anuência de seu orientador.

São Paulo, 16 de maio de 2006.

Assinatura do autor

Assinatura do orientador

FICHA CATALOGRÁFICA

\section{Lima, John Paul Hempel}

Redes neurais artificiais aplicadas à otimização de processos de deposição de filmes finos poliméricos, São Paulo, São Paulo, 2006. 90 p.

Dissertação (Mestrado) - Escola Politécnica da Universidade de São Paulo. Departamento de Engenharia de Sistemas Eletrônicos.

1. Polímeros (materiais) 2. Redes Neurais 3. Dispositivos eletrônicos 4. Processos de fabricação.

I. Universidade de São Paulo. Escola Politécnica. Departamento de Sistemas Eletrônicos 


\section{DEDICATORIA}

À minha família.

À todos que passam os dias em busca de respostas.

"If I have seen farther than others, it is because $I$ was standing on the shoulder of giants." Sir Isaac Newton 


\section{AGRADECIMENTOS}

Aquele que acredita não pode deixar de agradecer a DEUS, pois sem Ele não teríamos os dons, as condições e a vida para realizarmos nosso trabalho.

Agradeço a minha mãe BERNICE e ao meu pai CHRISTIANO pela criação, pela liberdade de escolhas, pela fé em mim depositada e por estarem sempre ao meu lado em todos os momentos.

Ao meu irmão CHRISTIAN pela confiança, amizade e consideração.

Ao meu grande amigo, orientador e mentor prof. ADNEI MELGES DE ANDRADE pelas conversas, pelo apoio, pela confiança no meu trabalho e pela inestimável amizade.

Aos profs. ELY DIRANI, FERNANDO FONSECA e RODRIGO BIANCHI pelos preciosos conselhos, inúmeras conversas e pela tão boa amizade que construímos.

Ao pessoal do Grupo de Polímeros do IFSC, em especial ao dr. VALTENCIR ZUCOLOTTO, VANESSA GONÇALVES, DÉBORA BALOGH e NÍBIO por inestimáveis opiniões e ajuda na preparação de parte desse trabalho.

Ao prof. EMÍLIO DEL MORAL HERNANDEZ pelas longas conversas, sugestões e opiniões sobre redes neurais artificiais que tanto enriqueceram esse trabalho.

Aos amigos do grupo GEM, em especial a LEONARDO PATERNO, pelas suas opiniões e pelos momentos de descontração.

Aos técnicos da sala limpa do LME, pelas incontáveis contribuições na elaboração desse trabalho, ao JAIR pelas sugestões, ajuda e amizade. 
Aos meus amigos que com certeza participaram do meu trabalho, pela preciosa amizade e pelo constante incentivo. 


\section{RESUMO}

Nesse trabalho é apresentado o estudo de redes neurais artificiais (RNAs) como sistemas de aprendizado, simulação e otimização de processos de deposição de filmes finos poliméricos. Duas técnicas de deposição comumente utilizadas para a fabricação de dispositivos eletrônicos e sensores poliméricos foram escolhidas: i) spin coating ou centrifugação e ii) automontagem. Na primeira técnica, a espessura final dos filmes finos obtidos foi a característica avaliada em função da velocidade de rotação, do tempo de rotação e da concentração da solução polimérica. Como material de deposição, utilizou-se a poli(o-metoxianilina) (POMA). Com a segunda técnica analisou-se a influência sobre a espessura, sobre a condutância elétrica e sobre o espectro de absorção, do número de bicamadas, do tempo de exposição dos filmes a uma solução dopante de ácido clorídrico $(\mathrm{HCl})$ e do $\mathrm{pH}$ das mesmas. Os poliíons utilizados nessa técnica foram a polianilina (PAni) e o poli(vinil sulfato de sódio) (PVS). Os filmes obtidos pela segunda técnica de deposição constituem uma classe de sensores capazes de detectar e quantificar concentrações baixas de $\mathrm{HCl}$ diluído em água. Os treinamentos e simulações com redes neurais artificiais foram realizados apenas para a espessura dos filmes de POMA e a absorção dos filmes de PAni/PVS. Foram construídas redes neurais artificiais do tipo multilayer perceptron (MLP) utilizando o software MATLAB e o componente Neural Networks Toolbox. A reprodutibilidade e o número de neurônios contidos na camada intermediária foram avaliados. Os resultados mostram que as redes neurais artificiais treinadas fornecem boas respostas simuladas interpolando e extrapolando os valores experimentais utilizados. Como conclusão mostra-se que é possível a utilização dessa ferramenta para auxiliar a engenharia de processos, as técnicas e análises de deposições de filmes finos poliméricos. 


\begin{abstract}
In this work it is shown a study of artificial neural networks used as learning and simulating systems to optimize polymeric thin films deposition processes. Two common layer deposition techniques to fabricate polymeric electronic devices and polymeric sensors were chosen: i) spin coating and ii) self-assembly. In the first technique the final thickness of obtained thin films was the analyzed characteristic as a function of spin speed, spin time and solution concentration. For the deposited layers we used poly(o-methoxyaniline) (POMA). In the second technique we analyzed the influence of the number of bilayers, the $\mathrm{pH}$ of deposition solutions and the dipping time in the final thickness, electrical resistance and UV-Vis absorption spectra. As polyions, we used polyaniline (PAni) and poly(vinyl sodium sulfate) (PVS). These films could be used as a sensor to detect low concentrations of $\mathrm{HCl}$ diluted in water. After obtaining the experimental data we constructed artificial neural networks using multilayer perceptrons (MLP) architecture with MATLAB and its component called Neural Networks Toolbox. The number of neurons in the hidden layer and the reproducibility were analyzed. The results show that the trained artificial neural networks used in this work provide good simulation responses interpolating and extrapolating the experimental data. As a conclusion we show that it is possible to utilize this tool to aid the process engineering and the polymeric thin film deposition techniques and analysis.
\end{abstract}




\section{SUMÁRIO}

1 INTRODUCÃ̃

1

1.1 OBJETIVO DO TRABALHO

$\underline{\text { REVISÃO BIBLIOGRÁFICA }}$

\subsection{POLÍMEROS}

2.1.1.1 Polímeros condutivos e semicondutivos

2.1.1.2 A polianilina (PAni) 10

2.1.1.3 A poli(o-metoxianilina) (POMA) 12

2.1.2 DISPOSITIVOS POLIMÉRICOS 12

2.1.2.1 Diodos emissores de luz poliméricos (PLEDs) 13

2.1.2.2 Sensores químicos 17

2.1.3 PROCESSAMENTO DE FILMES FINOS POLIMÉRICOS 18

$\begin{array}{lll}2.1 .3 .1 & \text { Spin coating } & 18\end{array}$

2.1.3.2 Automontagem 21

2.2 REDES NEURAIS ARTIFICIAIS (RNA) 23

2.2.1 HISTÓRIA DAS REDES NEURAIS 25

2.2.2 PRINCÍPIOS BÁSICOS DE RNAS 26

2.2.3 REDES MULTILAYER PERCEPTRONS (MLPS) 31

2.2.4 APROXIMAÇÃO DE FUNÇÕES

$\underline{3}$ MATERIAIS E MÉTODOS

3.1 OBTENÇÃO DOS FILMES

3.1.1 SÍNTESE DE POMA E PREPARAÇÃO DE SOLUÇÕES 37

3.1.2 SÍNTESE DE PANI E PREPARAÇÃO DAS SOLUÇÕES 38

$\begin{array}{lll}3.1 .3 & \text { SPIN COATING } & 40\end{array}$

3.1.4 AUtOMONTAGEM 40

3.2 CARACTERIZAÇÃO DOS FILMES

3.2.1 PERFILOMETRIA 43

3.2.2 Microscopia de ForÇA ATÔMICA (AFM) 43

3.2.3 CONDUTÂNCIA ELÉTRICA 44 
3.2.4 ESPECTROMETRIA UV-VIS 45

3.3 REDES NEURAIS ARTIFICIAIS 4

$4 \quad$ RESULTADOS $\quad 50$

4.1 FILMES FINOS DE POMA OBTIDOS POR SPIN COATING

4.1.1 REPRODUTIBILIDADE

4.1.2 NÚMERO DE NEURÔNIOS NA CAMADA INTERMEDIÁRIA 56

4.1.3 SIMULAÇÃO DAS CURVAS EXPERIMENTAIS

4.2 FILMES DE PANI/PVS OBTIDOS POR AUTOMONTAGEM (ESA-LBL) 66

$\begin{array}{lll}\text { 4.2.1 REPRODUTIBILIDADE } & 70\end{array}$

4.2.2 NÚMERO DE NEURÔNIOS NA CAMADA INTERMEDIÁRIA 73

$\begin{array}{lll}\text { 4.2.3 SIMULAÇÃO DAS CURVAS EXPERIMENTAIS } & 75\end{array}$

$\underline{5}$ CONCLUSÕES $\quad 78$

$\underline{6}$ ANEXO I $\quad 82$

6.1 PROCEDIMENTO E COMANDOS USADOS NO MATLAB PARA A CONSTRUÇÃO DAS REDES NEURAIS ARTIFICIAIS

1 BIBLIOGRAFIA $\quad 85$ 


\section{LISTA DE FIGURAS E TABELAS}

Figura 1-1 - Displays poliméricos (CDT, Philips e Covion).

Figura 2-1 - Exemplos de polímeros conjugados.

Figura 2-2 - Defeito solitônico no trans-poliacetileno ( R. F. Bianchi).

Figura 2-3 - Estados oxidados da polianilina. a) pernigranilina b) esmeraldina c) leucoesmeraldina.

Figura 2-4 - Estrutura de um PLED simples. 13

Figura 2-5 - PLED genérico com exemplos de camadas adicionais para melhorar as propriedades do dispositivo.

Figura 2-6 - Influência da espessura da camada ativa nas propriedades do PLED a) Corrente em função da tensão para diferentes espessuras de PPV b) Emissão de luz x espessura do PPV (ref. 46).

Figura 2-7 - Eletrodo interdigitado. 16

Figura 2-8 - Deposição por spin coating. a) despejo da solução b) cobertura total do substrato c) centrifugação e expulsão do material.

Figura 2-9 - Efeito do material sólido e do material líquido da solução para a espessura final do filme (S/S0: razão entre a quantidade de sólido atual e inicial; L/LO: relação entre quantidade de líquido atual e inicial) (Ref. 51).

Figura 2-10 - Processo de automontagem. a) Substrato antes de ser mergulhado na primeira solução b) Substrato imerso na primeira solução. 22

Figura 2-11 - Exemplo de uma estrutura simples de RNA unidirecional com uma camada intermediária. 24

Figura 2-12 - Algoritmo genérico de uma RNA supervisionada. 25

Figura 2-13 - Representação de um neurônio artificial proposto por McCulloch e Pitts. 27

Figura 2-14 - Funções de ativação utilizadas no MATLAB para RNAs. 28

Figura 2-15 - Algoritmo de convergência do Perceptron. 31

Figura 2-16 - Mapa de pesos genérico (Tes - conjunto de pesos que melhor representam o conjunto de teste; Tre - pesos que melhor representam o conjunto de treinamento; 1-6 - conjunto de pesos aleatórios iniciais).

Figura 3-1 - a) o-metoxianilina b) sistema de destilação fracionada utilizado na destilação do monômero. 37

Figura 3-2 - Distribuição de massa molar da PAni sintetizada, determinada por HPSEC-GPC. 39

Figura 3-3 - a) soluções utilizadas na deposição por SA com amostras mergulhadas na primeira solução b) secagem das amostras utilizando papel toalha. 41

Figura 3-4 - a) filmes após serem depositados (dopados) b) filmes desdopados com solução de $\mathrm{NH}_{4} \mathrm{OH} 0,1 \mathrm{~N}$. 41 
Figura 3-5 - Varredura de uma amostra por perfilometria a) filme e substrato b) filme decapado com um degrau e ponta de prova iniciando a varredura c) ponta de prova varrendo a amostra. 43 Figura 3-6 - a) estação de trabalho para medidas elétricas (LME-USP) b) pontas de prova conectadas aos terminais de um sensor de $\mathrm{HCl}$. 44

Figura 3-7 - Esquema de um espectrofotômetro UV-Vis simples. 45

Figura 3-8 - Interface gráfica do Neural Networks Toolbox do MATLAB. 46

Figura 3-9 - Interfaces gráficas desenvolvidas para estudo de RNAs. 47 Figura 3-10 - Algoritmo utilizado para treinamento e análise do erro (neur=número de neurônios na camada intermediária; epo=número de épocas, rep= número da repetição (inicialização)). 48

Figura 4-1-Espessura final em função da velocidade de rotação para diferentes concentrações com tempo de rotação igual a 30 segundos.

Figura 4-2 - Traçado log-log da espessura em função da velocidade de rotação para diferentes concentrações. Aproximações lineares e coeficiente angular (n).

Figura 4-3 - Espessura em função da velocidade de rotação para diferentes tempos de rotação com concentração de $20 \mathrm{mg} / \mathrm{mL}$. 52

Figura 4-4 - Imagens de AFM da superficie de filmes de POMA obtidos com velocidades de rotação de: a) $500 \mathrm{rpm} \mathrm{b)} 3.000 \mathrm{rpm} \mathrm{c)} 6.000 \mathrm{rpm}$, (concentração de $10 \mathrm{mg} / \mathrm{mL}$, tempo de rotação $30 \mathrm{~s}$ ). 53 Figura 4-5 - Erro em função do número de épocas para diferentes inicializações. a) conjunto de treinamento b) conjunto de teste c) conjunto total.

Figura 4-6 - Média do MSE de 30 inicializações em função do número de épocas para diferentes números de neurônios na camada intermediária $(1 \leq N \leq 40)$.

Figura 4-7 - MSE médio para o conjunto de treinamento em função do número de neurônios a) 1.000 épocas b) 25.000 épocas c) 50.000 épocas.

Figura 4-8 - MSE médio para o conjunto de teste em função do número de neurônios a) 1.000 épocas b) 25.000 épocas c) 50.000 épocas. 59

Figura 4-9 - MSE médio para o conjunto total (treinamento + teste) em função do número de neurônios a) 1.000 épocas b) 25.000 épocas c) 50.000 épocas.

Figura 4-10 - MSE atual+1 em função do MSE atual para diferentes números de neurônios. 61 Figura 4-11 - Visualização circular do MSE a) conjunto de treinamento b) conjunto de teste c) conjunto total. 62

Figura 4-12 - Simulação da espessura em função da velocidade de rotação e da concentração para uma rede treinada com diferentes épocas.

Figura 4-13 - Simulação da espessura em função do número de épocas para diferentes concentrações, para tempo igual a 30 s. Simulação a partir da melhor rede neural obtida (número de neurônios: 18, inicialização: 21, época: 21.000). 65

Figura 4-14 - Espessura em função do número de bicamadas para as amostras da série 1. 66

Figura 4-15 - Condutância elétrica em função do tempo de dopagem em HCl para diferentes números de bicamadas. 67 
Figura 4-16 - Espectros de absorção em função do comprimento de onda para diferentes números de bicamadas em diferentes $\mathrm{pHs}$.

Figura 4-17 - Distribuição do conjunto de saída utilizado para treinamento e teste das RNAs. 70

Figura 4-18 - Erro em função do número de épocas para diferentes inicializações. a) conjunto de treinamento b) conjunto de teste c) conjunto total.

Figura 4-19 - Representação circular do MSE para 50 diferentes inicializações a) conjunto de treinamento b) conjunto de teste c) conjunto total.

Figura 4-20 - MSE médio em função do número de épocas para diferentes números de neurônios a) conjunto de treinamento b) conjunto de teste c) conjunto total.

Figura 4-21 - MSE atual+1 em função do MSE atual para diferentes números de neurônios a) conjunto de treinamento b) conjunto de teste c) conjunto total.

Figura 4-22 - Simulação dos espectros de absorção em função do comprimento de onda para diferentes números de bicamadas em diferentes pHs. Rede neural formada por 125 neurônios, inicialização: 6 época: 100.000.

Figura 4-23 - Espectros de absorção simulados e reais para diferentes bicamadas com pH 10 e rede “número de neurônios:125, inicialização: 6, época: 100.000”.

Tabela 2-1: Exemplo de uma tabela de dados experimentais para serem usados no treinamento e teste de uma RNA.

Tabela 2-2 - Diferentes cálculos do erro utilizados como critério de parada em redes neurais artificiais.

Tabela 3-1 - Parâmetros de deposição por spin coating utilizados. a) variação da concentração b) variação do tempo.

Tabela 3-2 - Amostras obtidas por automontagem.

Tabela 3-3 - Número de dados utilizados para treinamento e teste das RNAS. 


\section{LISTA DE ABREVIATURAS E SIGLAS}

ANN - Artificial Neural Networks

DMAc - dimetilacetamida (solvente)

ETL - electron transport layer ou camada transportadora de elétrons

ESA - electrostatic self-assembly ou automontagem por atração eletrostática

EPO - número de épocas

ITO - óxido de estanho-índio

HTL - hole transport layer ou camada transportadora de lacunas.

LEDs - light emitting diode ou diodo emissor de luz

MEH-PPV - metoxi etil hexiloxi poli(para fenileno vinileno)

MLP - Multilayer perceptron

MSE - mean squared error ou erro quadrático médio

NEUR - número de neurônios na camada intermediária

NMP - $n$-metil pirrolidona (solvente)

PA - Poliacetileno

PAni - polianilina

PLEDs - polymer light emitting diodes ou diodos emissores de luz poliméricos

POMA - poli( $o$-metoxianilina)

PPV - poli( $p$-fenileno vinileno)

PVS - poli(vinil sulfato de sódio)

RNA - rede neural artificial

REP - número da inicialização da RNA

SA - Self-assembly ou automontagem

t-PA - trans-poliacetileno

TESTE - conjunto de teste

TREIN - conjunto de treinamento

TREIN+TESTE - conjunto total 


\section{LISTA DE SIMBOLOS}

$\mathrm{D}_{\mathrm{i}}=$ valor de saída real

$\mathrm{O}_{\mathrm{i}}-$ Valor de saída obtido (simulado)

$\mathrm{W}_{\mathrm{j}}$ - Conjunto de pesos da RNA

$\mathrm{Xj}$ - Conjunto de entrada

$\mathrm{NET}$ - Somatória do produto de $\mathrm{Xj}$ e $\mathrm{Wj}$

$\theta$ - ângulo desejado para deslocar as curvas 


\section{INTRODUÇÃO}

Qual a diferença entre ciência e tecnologia? Segundo ROBERT TODD CARROLL em seu "the skeptics dictionary", ciência é um conjunto de métodos empíricos e lógicos utilizados para entender um fenômeno natural ou artificial.

Já tecnologia pode ser considerada como a aplicação de conhecimentos, métodos e materiais na resolução de um determinado problema. A grande diferença entre as duas é que geralmente no primeiro caso, o interesse é no entendimento enquanto que, no segundo caso, é na solução do problema do ponto de vista de produção e comercialização.

Na nossa sociedade hoje, há uma linha difusa que ora separa, ora funde a ciência com a tecnologia. A ciência como conhecemos hoje pode ser dividida em dois grandes grupos, o teórico e o experimental. A ciência experimental sempre foi palco de suposições, propostas, análises e modelamentos usados para explicar os diversos fenômenos da natureza. O estudo científico dos fenômenos deve e é embasado na linguagem mais fundamental, a matemática.

Para que os resultados de certo procedimento experimental expliquem um fenômeno, é preciso que esse resultado seja reproduzido. Assim, infere-se a esse fenômeno uma lei empírica baseada em dados e medidas experimentais. A lei de Wien do deslocamento ${ }^{2}$, ou a lei de Stefan-Boltzmann são leis baseadas em procedimentos e resultados experimentais.

Um exemplo de ciência e de tecnologia pode ser encontrado no ramo da microeletrônica. O primeiro passo geralmente consiste em se estudar os materiais e as técnicas a fim de conceber um dispositivo melhor, mais eficiente e mais barato. Muitos modelos teóricos são criados para explicar os fenômenos elétricos baseados em primeiros princípios e em resultados experimentais. Em seguida, os processos são concebidos para que certos dispositivos possuam as características finais desejadas. Nesse momento, a ciência se transforma em tecnologia e o objetivo passa a ser a obtenção de um produto.

Podemos afirmar que na área de processos, a ciência se encontra com a tecnologia.

Um processo é fruto da ciência e o fundamento para que uma tecnologia seja gerada e desenvolvida. O estudo dos processos fornece diversas receitas e 
procedimentos. Através de tabelas e gráficos é possível correlacionar os parâmetros de processos com as características desejadas dos filmes e dispositivos eletrônicos. Tanto na ciência quanto nas aplicações tecnológicas há a constante necessidade de que os resultados sejam extremamente reprodutivos. Há diversas referências onde é possível encontrar correlações de parâmetros de processos com as características finais, como no caso de trabalhos em silício microcristalino ${ }^{3}$.

A eletrônica sempre foi associada a materiais inorgânicos, em especial o silício e o arseneto de gálio. Esses materiais revolucionaram o nosso mundo e mudaram para sempre a forma como vivemos. Hoje, porém, uma nova onda de mudanças começa a ocorrer com a utilização de materiais orgânicos na eletrônica. Esses materiais podem ser divididos em materiais orgânicos de baixa massa molar, (que serão chamados aqui simplesmente de orgânicos) e os materiais de elevada massa molar, ou poliméricos.

Dentre as aplicações dos materiais orgânicos, o estudo de transistores 4, 5, 6 , diodos emissores de luz (LEDs) (Figura 1-1) ${ }^{7}$ e sensores são os grandes focos nos dias atuais.

Com o surgimento dos materiais poliméricos $\operatorname{condutivos}^{8} \mathrm{e}$ eletroluminescentes ${ }^{9,}{ }^{10}$ uma série de dispositivos e aplicações ${ }^{11}$ foi vislumbrada, desde displays inteiramente poliméricos e flexíveis, sensores ${ }^{12,13,14,15}$ e até sistemas de iluminação mais eficientes. Devido às propriedades únicas desses novos materiais, hoje já se consegue fabricar transistores que além de funcionarem como sistema de controle de pixels, também são responsáveis pela emissão de $l u z^{16}$, aumentando assim a integração e a redução de tamanho e custo dos dispositivos.
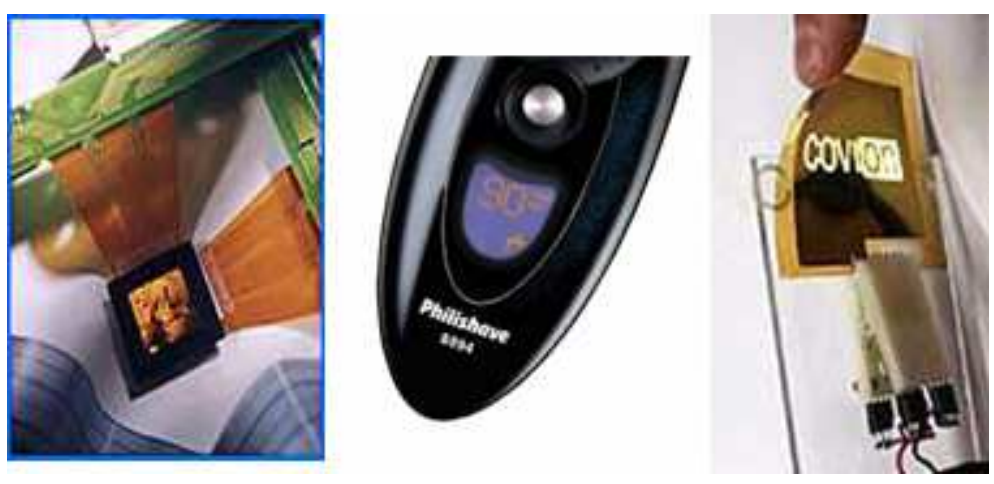

Figura 1-1 - Displays poliméricos (CDT, Philips e Covion). 
Dentre as diversas vantagens que esta nova classe de materiais apresenta, destacam-se a flexibilidade, a eletroluminescência, a facilidade de processamento e o baixo custo. Esses novos materiais aliam diversas vantagens e características dos semicondutores inorgânicos com as propriedades mecânicas dos materiais poliméricos tradicionais.

Apesar dos inúmeros trabalhos apresentados atualmente em congressos, simpósios e reuniões científicas, os dispositivos poliméricos ainda são apenas um pouco mais que uma promessa comercial. Os principais pontos fracos desses dispositivos são o seu tempo de vida e a falta de reprodutibilidade. Quando submetidos à luz, o polímero se degrada fazendo com que o dispositivo pare de funcionar. Um método para solucionar esse problema é realizar o processo de confecção em atmosfera controlada, livre de oxigênio e água (os elementos responsáveis pela degradação foto-oxidativa $)^{17}$. As características finais dos dispositivos são fortemente dependentes do processo realizado para sua obtenção, assim torna-se evidente o estudo aprofundado sobre as características macroscópicas dos materiais e dispositivos, baseados na análise dos processos de fabricação.

Para se construir um dispositivo é preciso que filmes finos poliméricos sejam obtidos com controle e reprodutibilidade. As técnicas de deposição de filmes finos poliméricos mais usadas hoje são spin coating, casting, automontagem (electrostatic self-assembly), Langmuir-Blodgett, polimerização in-situ e deposição através de impressoras jato de tinta.

Um ponto em comum entre todas essas técnicas de deposição é a necessidade de se obter as características finais dos dispositivos e filmes finos poliméricos, baseadas nos parâmetros de deposição, conseguindo obter um maior grau de reprodutibilidade. Devido à dificuldade de correlação entre os diferentes parâmetros de deposição e as características finais, um grande conjunto de dados e experimentos torna-se necessário para a otimização dos dispositivos.

Para otimizar e simular os parâmetros de deposição é necessário entender o comportamento dessa nova classe de materiais, suas peculiaridades, seu funcionamento e também o funcionamento dos dispositivos formados a partir deles. Em cada uma das etapas de fabricação, podem ser observados candidatos ideais para a aplicação da ferramenta proposta nesse trabalho. 


\subsection{OBJETIVO DO TRABALHO}

O objetivo principal desse trabalho é mostrar que uma ferramenta, como as redes neurais artificiais, pode auxiliar a área de processos de engenharia para que se consiga construir simuladores e sistemas otimizadores de parâmetros baseados em resultados experimentais previamente coletados.

Dessa maneira, trabalhos com esses materiais e métodos poderão ser previamente analisados e simulados, evitando assim que uma quantidade enorme de dados seja sempre levantada.

Devido à importância que os materiais e dispositivos eletrônicos poliméricos vem ganhando recentemente, foram escolhidos dois procedimentos experimentais distintos para a obtenção do conjunto de dados e conseqüente análise. Foi realizado o estudo de parâmetros de deposição de filmes finos poliméricos por spin coating e por automontagem, utilizando poli(o-metoxianilina) (POMA), polianilina (PAni) e poli(vinil sulfato de sódio) (PVS). 


\section{REVISÃO BIBLIOGRÁFICA}

Neste capítulo são apresentados dados sobre a ciência dos polímeros, em especial os polímeros condutivos, os dispositivos poliméricos, os materiais e as técnicas de fabricação utilizadas nesse trabalho. Em seguida é apresentada a revisão histórica das redes neurais artificiais, seus princípios básicos e uma breve revisão sobre aproximação de funções.

\subsection{POLÍMEROS}

A ciência de polímeros tem início com HERMANN STAUDIGER ${ }^{18}$ que analisando a síntese do isopreno concluiu que as teorias da época que explicavam a estrutura natural da borracha estavam incorretas. Essas teorias eram baseadas em moléculas grandes e complexas. STAUDIGER começou a analisar tais moléculas não como sistemas complexos, mas sistemas formados por unidades mais simples. Em maio de 1922, ele publicou um artigo na Helvetica Chimica Acta, introduzindo o conceito de macromoléculas e de polimerização, conceitos esses que até hoje são empregados e aceitos na química.

O próximo grande passo na ciência de polímeros aconteceu em abril de 1930 quando WALLACE HUME CAROTHERS e sua equipe sintetizaram o policloropreno, o primeiro polímero sintético produzido artificialmente. A Dupont, onde CAROTHERS trabalhava, comercializou esse polímero com o nome de Neopreno, até hoje produzido e empregado na indústria. Em seguida, CAROTHERS sintetizou outro material, conhecido como Nylon, abrindo um novo campo para que pesquisadores desenvolvessem materiais artificiais com diferentes propriedades óticas, mecânicas, térmicas e elétricas.

Em 1953, KARL ZIEGLER obteve sua mais importante descoberta a partir de seu trabalho com compósitos de organo-alumínio. Ele descobriu que substâncias obtidas pela mistura de compósitos organo-metálicos com certos metais pesados permitiam uma rápida polimerização do etileno à pressão atmosférica. Como conseqüência, foi possível produzir polietileno de alto peso molecular com cadeia de estrutura linear.

PAUL FLORY foi o seguinte grande nome dessa ciência, avançando a pesquisa em polímeros através dos seus estudos teóricos e experimentais sobre 
macromoléculas. Pelo seu trabalho, FLORY foi laureado com o premio Nobel de química em 1974.

Mas afinal, o que é um polímero? O conceito mais geral hoje é de que um polímero é um material geralmente orgânico de alta massa molar na qual há uma unidade básica e principal (chamada mero) que se repete ao longo da cadeia.

Para uma molécula ser considerada uma macromolécula, sua massa molar deve ser elevada (geralmente dezenas de milhares de gramas/mol). Caso a molécula possua massa molar inferior a 10.000, dá-se o nome de oligômero (poucos meros). Os polímeros podem ser classificados quanto à sua massa molar, ao seu comportamento ao calor, às suas características mecânicas e por diversos outros parâmetros.

Uma outra classificação que se dá aos polímeros é dizer se ele é conjugado ou não. Conjugação é o nome dado para a alternância de ligações simples e duplas entre átomos de carbono. Diz-se que um polímero é conjugado quando essa alternância ocorre ao longo da cadeia principal. Anéis de benzeno podem conferir ao polímero o caráter de conjugação, pois a alternância não é interrompida. A Figura 2-1 apresenta alguns polímeros conjugados comumente utilizados e estudados.

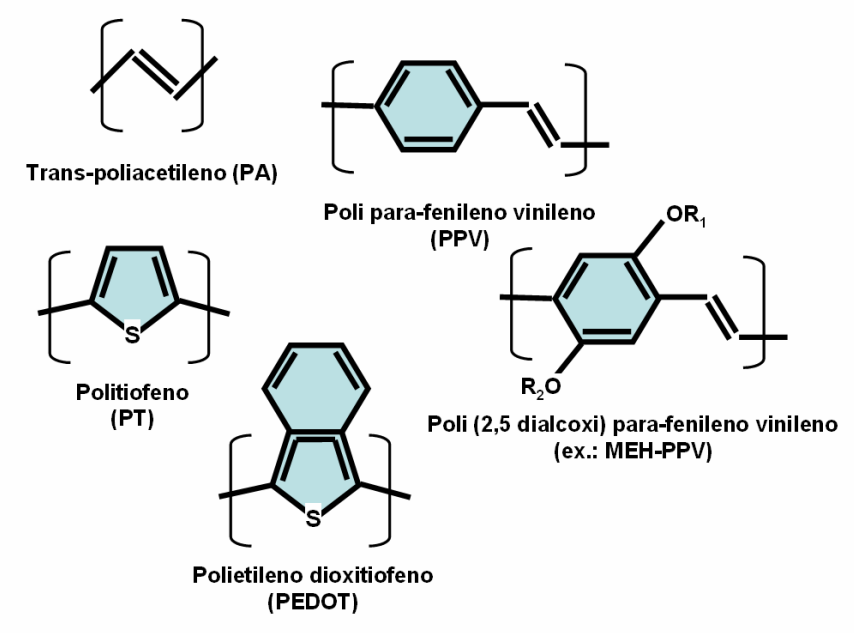

Figura 2-1 - Exemplos de polímeros conjugados.

Até a metade da década de 70 os polímeros eram vistos como materiais dielétricos e até hoje grande parte de sua produção se destina à isolação elétrica em cabos, às peças mecânicas e a utensílios domésticos. 


\subsubsection{Polímeros condutivos e semicondutivos}

Em 1975, GREENE e seus colegas ${ }^{19}$ descobriram o fenômeno da supercondutividade no primeiro polímero conjugado, o politiazil. Porém, só dois anos mais tarde, SHIRAKAWA ${ }^{20}$ e seus colaboradores deram início à era dos polímeros condutivos através do estudo dos fenômenos elétricos presentes intrinsecamente no trans-poliacetileno ( $t$-PA) dopado.

Os polímeros podem ser condutivos intrinsecamente ou extrinsecamente. Os polímeros condutivos extrínsecos são sistemas onde o material polimérico funciona apenas como matriz para que outras moléculas conduzam a eletricidade. Um exemplo típico é a utilização de negro de fumo para se conseguir um polímero condutor. O material condutor é incorporado na matriz polimérica por diversas técnicas, sendo a mais comum a mistura dos dois materiais.

Já nos polímeros condutivos intrínsecos, os processos de condução são governados pelas propriedades elétricas das próprias cadeias poliméricas. Para esses polímeros se tornarem um sistema condutivo ou semicondutivo, é necessário a realização de dopagem para que mudem do estado isolante para um estado condutivo. Este processo de dopagem é diferente do caso dos semicondutores inorgânicos, como o silício ou o arseneto de gálio. Em um polímero conjugado (sistemas que podem se tornar condutivos) o dopante não possui caráter substitucional formando ligações na cadeia, mas fica próximo a ela induzindo uma espécie de defeito topológico que se propaga ao longo da mesma.

\subsection{A semicondutividade dos polímeros}

Entender a complexidade dos processos condutivos nesses materiais é muito importante para compreender o efeito que o processamento acarreta sobre as propriedades eletrônicas finais. Para explicar porque um polímero pode ser semicondutivo, costuma-se utilizar o caso do $t$-PA, o polímero conjugado mais simples e protótipo para os primeiros modelos de condução elétrica.

O $t$-PA é um polímero conjugado que em seu estado natural (não dopado) é isolante. $\mathrm{O}$ fato de haver alternância de ligações simples e duplas na cadeia principal do $t$-PA, induz a uma diferença de comprimento entre elas. Estudos teóricos que envolvem o cálculo termodinâmico e o efeito coulombiano mostraram que a 
diferença entre o comprimento das ligações simples e duplas da cadeia do $t$-PA equivale a $0,1 \AA$. Apesar de parecer pequena, essa diferença é essencial para explicar a condutividade nesses materiais. Uma diferença de comprimento induz uma diferença de energia. Essa diferença energética é conhecida como instabilidade de Peierls. Se pensarmos em um diagrama de energia, essa instabilidade induz uma abertura, ou a formação de um gap energético. Esse fenômeno também é conhecido como dimerização.

Segundo KNOESTER ${ }^{21}$, dimerização é o parâmetro de ordem de Peierls, que pode ser definido como a diferença entre as amplitudes de salto dos elétrons nas ligações duplas e simples. Dimerização, de uma outra maneira, pode ser entendida como a abertura do gap proveniente da instabilidade de Peierls. Essa diferença implica na sobreposição dos orbitais pz, dando origem a orbitais $\pi$ (ocupados) e $\pi^{*}$ (vazios). A formação desses orbitais faz com que os elétrons estejam fracamente localizados, surgindo uma diferença energética.

A formação do gap explica o caráter semicondutivo, mas ainda não explica o comportamento das cargas ou portadores, dentro do polímero. Para explicar esses fenômenos devemos entender o que são sólitons ${ }^{22,23,24}$, polarons ${ }^{25,26}$, bipolarons e excitons.

Sóliton é o nome dado ao defeito topológico proveniente da formação dos estados degenerados a partir da dimerização da cadeia dos polímeros conjugados. $\mathrm{O}$ sóliton pode ser entendido como uma interrupção na seqüência de ligações "simplesdupla" alternadas, no meio da cadeia e da conseqüente perda de simetria energética e estrutural ao redor dela, como mostra a figura abaixo. O sóliton estável só existe no $t$ PA devido à simetria energética (Figura 2-2). Porém, em todos os outros polímeros conjugados, a existência de um sóliton cria a necessidade de haver um antisolíton e para esse par formado, caso não ocorra a aniquilação (recombinação), dá-se o nome de polaron. O spin eletrônico do polaron é $1 / 2$ e ele pode ser negativo ou positivo. Caso haja a formação de um polaron positivo e um negativo e eles se encontrarem, ocorre a aniquilação de ambos e a conseqüente formação de um éxciton singleto. Se dois pares sóliton/antisóliton se encontrarem eles podem formar um novo defeito, chamado então de bipolaron. Caso o estado no interior do gap seja ocupado por 4 
elétrons, dá-se o nome de bipolaron negativo e analogamente, se não estiver ocupado, dá-se o nome de bipolaron positivo ${ }^{27}$.

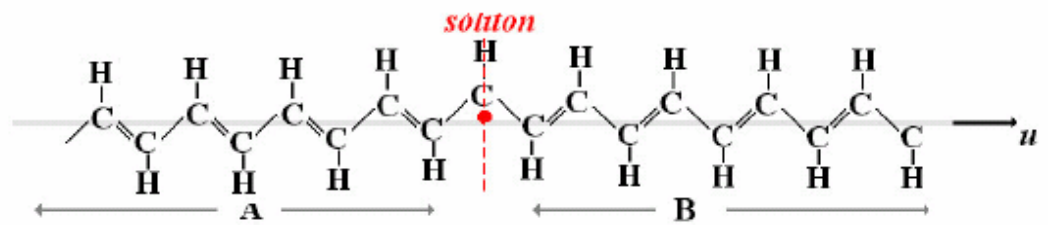

Figura 2-2 - Defeito solitônico no trans-poliacetileno ( R. F. Bianchi).

Em mecânica quântica é habitual escrever a energia de um sistema como o hamiltoniano. Em 1979, SU, SCHRIEFFER e HEEGER ${ }^{23}$ propuseram um modelo muito bem sucedido para explicar o fenômeno de condução nos polímeros conjugados. Esse modelo foi chamado de Modelo SSH e descreve através do hamiltoniano, as contribuições dos elétrons livres interagindo com a rede. A energia do sistema, segundo esse modelo, pode ser descrita como a soma da energia dos elétrons mais a contribuição da energia da rede. Imaginando uma cadeia polimérica longa, se pensarmos em um elétron que salta de sua posição para a posição seguinte, podemos imaginar que esse elétron é aniquilado na posição $x$ e é criado na posição $x+1$. Na consideração da energia, esse fenômeno possui uma probabilidade de acontecer. Esse fato também é levado em consideração no cálculo do hamiltoniano. A contribuição da rede para a energia leva em conta a energia cinética e a energia potencial elástica das ligações. Esse modelo é base para o desenvolvimento atual de cálculos teóricos do comportamento eletrônico dos polímeros condutivos e semicondutivos.

Um outro campo importante no entendimento das propriedades eletrônicas dessa nova classe de materiais está relacionado à injeção e ao transporte de cargas pelo material.

Para melhorar os diodos emissores de luz poliméricos (PLEDs), os displays e os outros dispositivos eletrônicos poliméricos, é necessário estudar os mecanismos de injeção e de transporte de portadores de carga nos polímeros a partir dos eletrodos e das interfaces. Tais estudos têm sido realizados em nosso grupo de pesquisa GEMGrupo de Eletrônica Molecular da EPUSP.

Dentre os vários modelos de injeção e transporte de portadores de carga em polímeros condutivos e semicondutivos, Fowler-Nordheim, Richardson Schottky e 
SCLC (space charge limited current) são os mais estudados ${ }^{28,29,30,31}$. Os trabalhos de PARKER $^{32}$ e BRAUN ${ }^{33}$ mostram a aplicação bem sucedida de alguns desses modelos para explicar a injeção em PLEDs.

Esses diversos modelos apontam para um problema importante na ciência dos polímeros condutivos e semicondutivos: as relações eletrônicas são complexas e ainda não completamente entendidas. Diversos podem ser os fatores que governam as propriedades elétricas, morfológicas e ópticas e muitos deles são provenientes do processo de fabricação.

\subsubsection{A polianilina (PAni)}

Dentre os polímeros condutivos, a polianilina tem se destacado, devido à facilidade de obtenção, possibilidade de controlar sua condutividade através de ácidos e bases, relativa estabilidade ao oxigênio e baixo custo. Suas aplicações atualmente vão desde camadas ativas em sensores químicos ${ }^{12,14,34,35}$ até camadas injetoras de lacunas em PLEDs e como eletrodos transparentes ${ }^{36}$.

A polianilina é um polímero formado a partir da anilina (um anel benzênico com uma ligação imina). A PAni pode apresentar diferentes estados de oxidação. Nesse caso, a oxidação pode ser entendida simplesmente como a retirada de um elétron da cadeia.

Dependendo do seu estado de oxidação é dado um nome diferente para o tetrâmero (representação de quatro meros da cadeia). A Figura 2-3 apresenta três estados de oxidação comumente encontrados. No primeiro caso, onde a oxidação é maior, o polímero é conjugado. Porém, no estado chamado esmeraldina, o polímero apresenta um grau de $50 \%$ de oxidação e a condutividade é gerada sempre por uma dopagem. 
a)

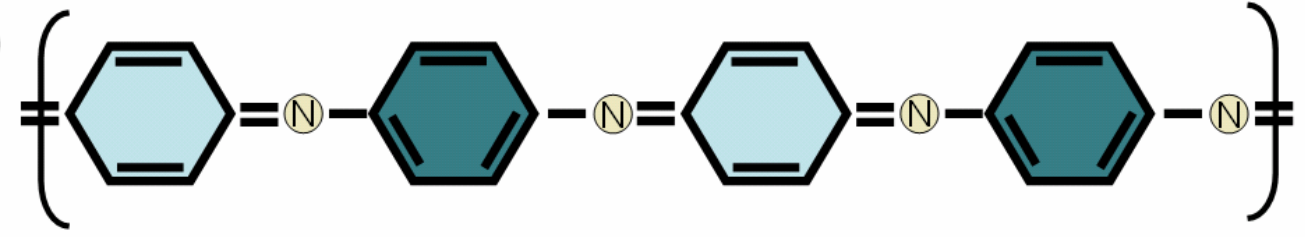

b)

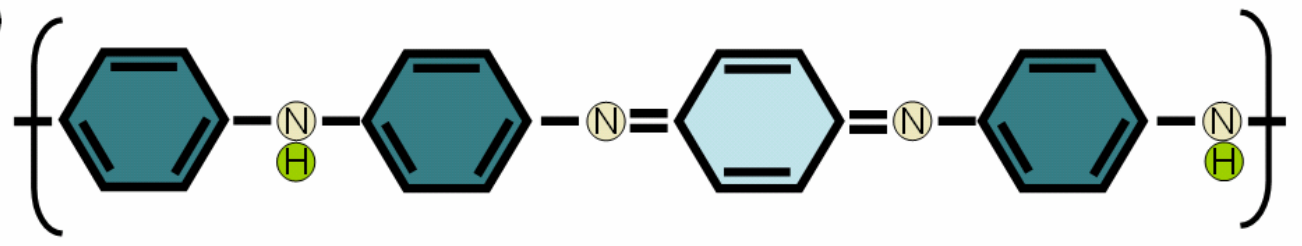

C)

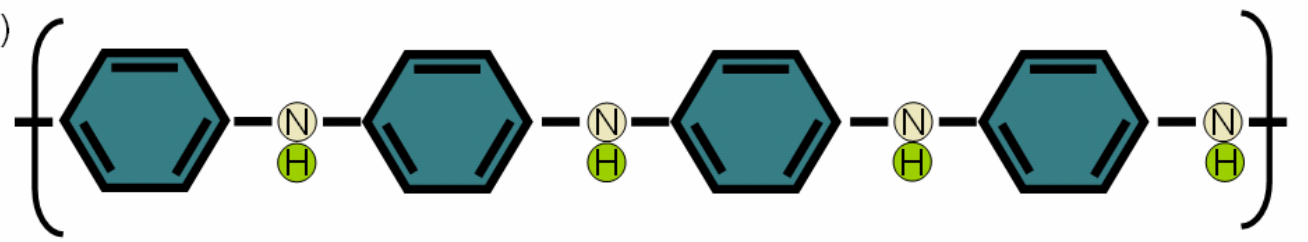

Figura 2-3 - Estados oxidados da polianilina. a) pernigranilina b) esmeraldina c) leucoesmeraldina.

A Pani possui a característica de poder ser dopada por diferentes sistemas ${ }^{37}$. O mais comum deles é a dopagem por protonação. ZOPPEI ${ }^{38}$ fornece uma boa explicação sobre o processo de protonação da PAni.

A diferença da PAni em relação a outros polímeros condutores é que em formato básico, a chamada base de esmeraldina (EB), a polianilina pode ser dopada com um ácido protônico não oxidante. Entre os dopantes possíveis, encontram-se materiais inorgânicos, orgânicos e poliácidos. O material mais comum utilizado para a dopagem da polianilina é o HCl. Devido à diferença de eletronegatividade entre os seus átomos ( $\mathrm{H}$ e o $\mathrm{Cl})$ e da afinidade com o polímero, o hidrogênio é incorporado na cadeia polimérica (dando-se o nome de protonação). O íon cloreto restante fica próximo à cadeia polimérica. A associação do hidrogênio ocorre no nitrogênio que liga os anéis benzênicos.

O processo de desdopagem ou desprotonação ocorre quando a polianilina dopada é colocada em solução aquosa básica como no caso de hidróxido de amônio $\left(\mathrm{NH}_{4} \mathrm{OH}\right)$. A base reage com o polímero removendo o hidrogênio provido pelo ácido, neutralizando seu efeito dopante. 
NECHTSCHEIN e colaboradores ${ }^{39}$ apresentaram um estudo importante sobre as propriedades condutoras da PAni, em seus diferentes estados de oxidação. Tal trabalho aponta os resultados nos espectros de absorção UV-Vis de filmes de PAni quando dopados em diferentes concentrações.

\subsubsection{A poli(o-metoxianilina) (POMA)}

A POMA é um polímero pertencente à classe das polianilinas. Sua diferença é um grupo metoxi na posição orto ligada ao anel benzeno. Como no caso da polianilina, a POMA é obtida por síntese química, um processo simples e de baixo custo. Esse polímero tem se mostrado um material promissor para a confecção de diversos dispositivos eletrônicos, como transistores ${ }^{40}$ e diodos retificadores ${ }^{41}$. Os diodos retificadores obtidos por Mergulhão ${ }^{41}$ e colaboradores apresentaram uma tensão de operação próxima a $0 \mathrm{~V}$, fornecendo novas possibilidades na utilização em dispositivos de baixa potência.

Sua principal vantagem frente à polianilina é a possibilidade de se preparar soluções utilizando o clorofórmio como solvente. Num processo de spin coating, a taxa de evaporação do solvente é um parâmetro importante na obtenção de filmes uniformes e homogêneos ${ }^{55}$. Devido ao clorofórmio ter uma taxa de evaporação muito superior ao do NMP ( $n$-metil pirrolidona), solvente geralmente empregado na solubilização da PAni, a solução formada pela POMA e por esse solvente foi utilizada nesse trabalho para a obtenção de filmes finos poliméricos por spin coating.

\subsubsection{Dispositivos poliméricos}

O estudo científico dos diferentes materiais poliméricos está sempre associado à capacidade de se produzirem dispositivos ${ }^{11}$ e novas aplicações. Os dispositivos poliméricos vão desde instrumentos mecânicos feitos com polímeros convencionais até sensores químicos e displays que utilizam polímeros condutivos e semicondutivos. Cada dispositivo polimérico apresenta um conjunto de características que devem ser avaliadas durante seu projeto e sua elaboração. Os dispositivos e sensores mais promissores nessa nova área são os displays, os sensores de paladar e olfato, os transistores e as células fotovoltaicas. 
Para se projetar um PLED, por exemplo, deve-se avaliar qual seu tempo de vida, qual sua tensão de limiar (turn-on) e o seu espectro de emissão. Um filme de polianilina que servirá como trilha entre dispositivos, por outro lado, deve apresentar uma condutividade elevada e baixa degradação. Já em um sensor de gás, a avaliação de sua condutividade (ou capacitância, dependendo do tipo de sensor) em função do gás é a principal propriedade a ser analisada. Quando um sensor é submetido ao ambiente a ser analisado, o seu tempo de resposta e a sua sensibilidade são determinantes para sua viabilidade tecnológica e comercial.

\subsubsection{Diodos emissores de luzpoliméricos (PLEDs)}

Quatorze anos depois do trabalho de SHIRAKAWA, FRIEND ${ }^{42}$ e colaboradores produziram o primeiro PLED a partir do poli( $p$-fenileno vinileno) (PPV). Apesar da baixa eficiência obtida na época, esse trabalho inspirou centenas de pesquisadores ao redor do mundo a desenvolverem displays e LEDs feitos a partir de polímeros.

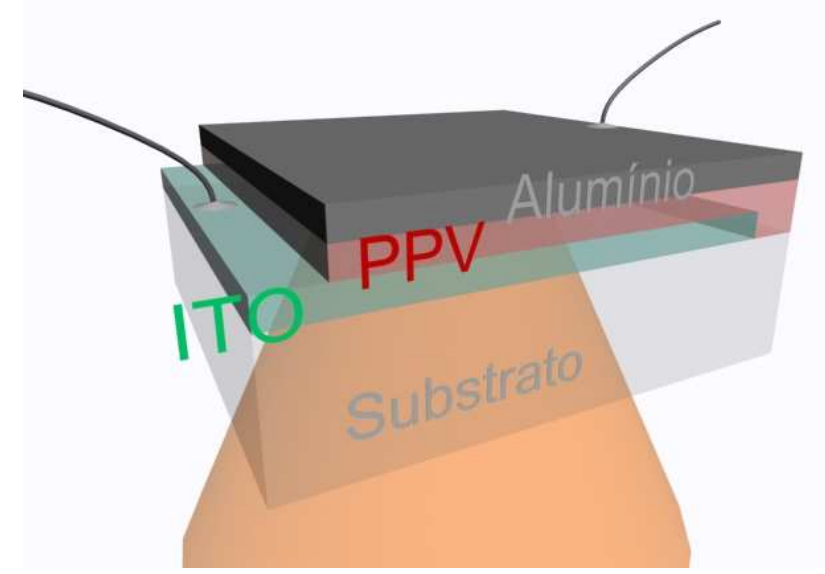

Figura 2-4 - Estrutura de um PLED simples.

Um PLED é um diodo emissor de luz cuja camada ativa é um polímero eletroluminescente. A estrutura mais simples de um PLED é formada por uma camada de polímero eletroluminescente entre dois eletrodos, onde um deles (ou os dois) é transparente (Figura 2-4).

Seu princípio de funcionamento é muito simples. Elétrons são injetados a partir de um eletrodo enquanto lacunas (ou chamados também de buracos) são injetadas por outro eletrodo quando uma tensão elétrica é aplicada entre os dois 
terminais. Essas cargas se deslocam pelas cadeias poliméricas e podem se encontrar, se recombinar e formar o que se costuma chamar de éxciton. O decaimento do éxciton pode ser radioativo emitindo luz.

Um exemplo mais genérico para um PLED é encontrado na Figura 2-5. Diferente da primeira estrutura, essa apresenta camadas adicionais para aumentar a eficiência do dispositivo. Cada camada que compõe um PLED utiliza uma técnica de processamento diferente. Para a construção de um dispositivo desse tipo, muitos são os parâmetros que governam suas características finais. A otimização de cada uma dessas técnicas pode levar a dispositivos mais reprodutivos e eficientes.

Como já dito anteriormente, o mecanismo de emissão requer que um par elétron-lacuna se recombine para emitir luz. Contudo, a mobilidade de lacunas é muito superior à dos elétrons nos materiais poliméricos e dessa forma, nesses dispositivos costuma-se ter uma alta corrente com uma baixa eficiência luminosa. A adição de camadas extras visa balancear o número de portadores para que se maximize a eficiência de recombinação e emissão.

É comum encontrarmos camadas que injetam as lacunas, as chamadas hole transport layer (HTL). Uma nova e importante aplicação de filmes automontados de PAni/PVS é na confecção de HTLs.

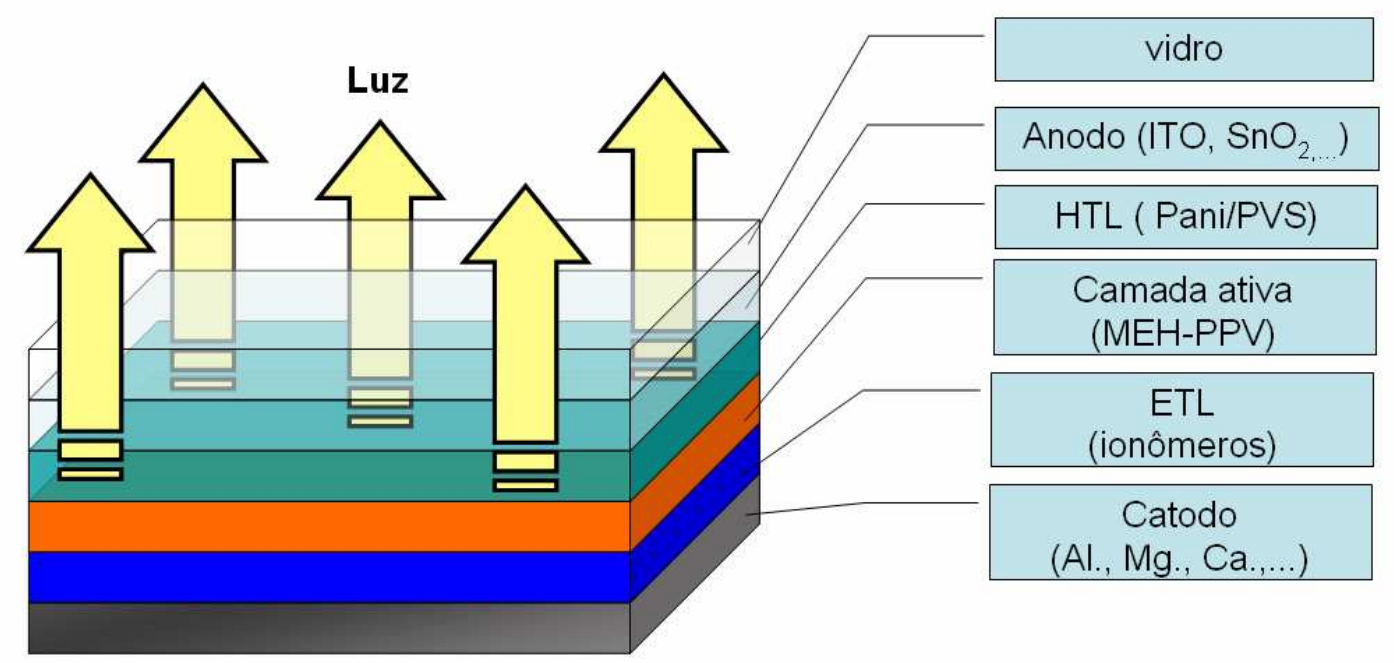

Figura 2-5 - PLED genérico com exemplos de camadas adicionais para melhorar as propriedades do dispositivo.

Electron Transport Layer (ETL) é uma camada depositada entre a camada ativa de um PLED e o catodo. Com a predominância de um portador dentro da 
camada ativa, a máxima eficiência será determinada pelo número de portadores minoritários. Como no caso dos polímeros os portadores majoritários são lacunas, utiliza-se essa camada para que mais elétrons sejam injetados na camada ativa aumentando a eficiência final do dispositivo.

Dentre os materiais que podem ser usados como camadas injetoras ou transportadoras de elétrons, o fluoreto de lítio e os ionômeros são os mais promissores. Ionômeros são polímeros que possuem uma pequena quantidade de grupos iônicos com metais complexados ao longo da cadeia ${ }^{43}$. Um exemplo de iônomero estudado na literatura é o poli(etileno-co-ácido metacrílico). Dentre os processos de deposição utilizados para a camada ETL, spin coating, automontagem e evaporação térmica são as mais empregadas (variando para cada tipo de material a ser depositado).

Olhando para as camadas que compõem um PLED, o catodo também possui um papel muito importante. O material mais comum utilizado como eletrodo transparente é o óxido de estanho-índio ou ITO, porém, não é o único que pode ser utilizado $^{44}$. Como descrito no trabalho de MARKS e colaboradores ${ }^{45}$ há diversos materiais como o ZITO (óxido de zinco-índio-estanho), o ZIO (óxido de zincoíndio), o GITO (óxido de gálio-indio-estanho), e o GIO (óxido de gálio-índio) variantes do ITO que apresentam valores diferentes de condutividade, coeficiente de absorção e função trabalho, podendo apresentar um desempenho melhor como eletrodo. O ITO é um óxido transparente e condutor e sua principal aplicação está em dispositivos mostradores de informação e em recobrimento de janelas. O estudo sistemático desses materiais importantes para a confecção de PLEDs também poderia ser feito utilizando a técnica proposta nesse trabalho.

A PAni e o PEDOT:PSS são os materiais orgânicos mais promissores para a substituição do ITO devido ao seu baixo custo e sua fácil processabilidade. A polianilina é um material relativamente estável (na presença de oxigênio), como já dito anteriormente, e apresenta boa condutividade. O PEDOT:PSS tem função trabalho mais próxima à das camadas ativas do que o ITO, aumentando assim a eficiência de injeção de portadores. Usando várias etapas da microeletrônica convencional, é possível depositar os eletrodos e para alguns casos, camadas participantes na injeção e transporte de portadores de carga. 
Uma das grandes dificuldades hoje na construção de LEDs poliméricos reside no fato de seu tempo de vida ser muito baixo. A oxidação assistida por luz, faz com que as cadeias sejam interrompidas (i.e. a conjugação) e o LED acaba por não funcionar. A avaliação do tempo de vida é um parâmetro importante para que os PLEDs se tornem economicamente viáveis.

Do ponto de vista prático, são diversos os parâmetros de processos que podem ser alterados na confecção de um PLED: A espessura da camada ativa, o material eletroluminescente, a concentração da solução polimérica, a adição de novas camadas, entre outros fatores. SEOUL e seus colaboradores ${ }^{46}$ demonstraram o efeito da espessura na característica elétrica e na eletroluminescência de um PLED feito à base de PPV (Figura 2-6). Em seu trabalho, quanto menor a espessura da camada ativa, melhor é a característica de diodo. Por outro lado, apesar de uma espessura menor aumentar a injeção de portadores devido à diminuição da resistência série, o comportamento da eficiência de emissão não é semelhante. SEOUL mostra que para seus dispositivos, uma espessura de $150 \mathrm{~nm}$ de PPV fornece a maior eficiência.

Desse modo notamos que a espessura dos filmes finos poliméricos (determinada pela técnica e pelos parâmetros de processamento) tem papel importante e central no funcionamento do dispositivo.

a)

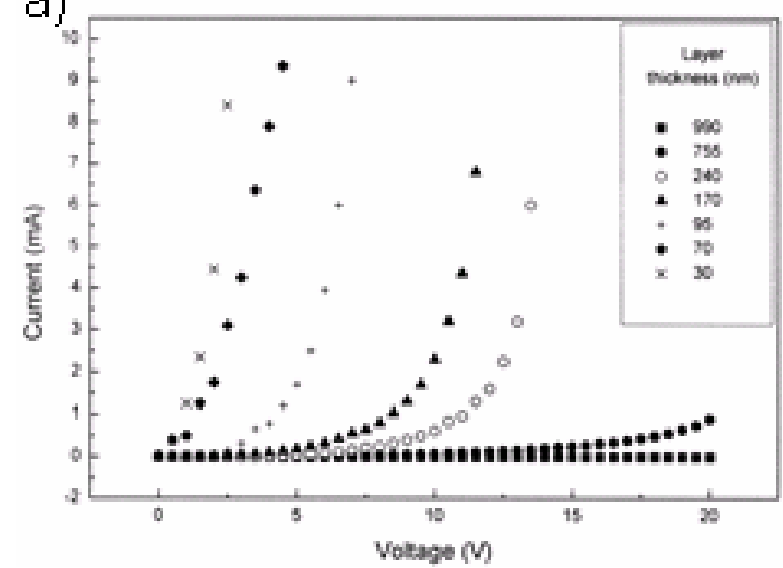

b)

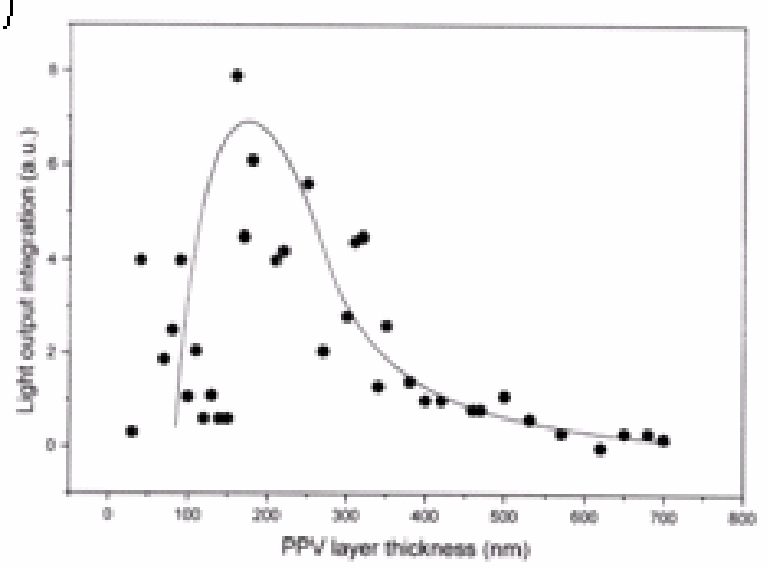

Figura 2-6 - Influência da espessura da camada ativa nas propriedades do PLED a) Corrente em função da tensão para diferentes espessuras de PPV b) Emissão de luz x espessura do PPV (ref. 46).

Os problemas envolvidos na confecção de um PLED são muitos e a variabilidade que as técnicas de fabricação atuais apresentam é elevada. Ferramentas que possibilitem a diminuição do trabalho experimental, correlacionando os 
parâmetros de processamento e as características finais podem fazer com que se consiga uma maior homogeneidade e um maior controle sobre os PLEDs.

\subsubsection{Sensores químicos}

Uma das importantes aplicações de sensores poliméricos é a possibilidade de detecção de gases e substâncias presentes em líquidos. Dentre os tipos de substâncias detectáveis, os ácidos e bases constituem uma classe importante tanto em estado líquido quanto gasoso, devido a sua periculosidade ao meio ambiente e sua elevada reatividade.

A partir do estudo das propriedades condutoras das polianilinas, fica evidente que os ácidos e as bases alteram a condutividade desse polímero, protonando ou desprotonando a cadeia. Baseado nessa característica importante, diversos sensores químicos foram propostos na literatura $^{11,12,13}$.

Há muitas propriedades que podem ser utilizadas como características sensoras. Polarizações magnéticas, mudanças estruturais, variações de massa, alterações ópticas, mudança da condutividade e capacitância são exemplos de propriedades utilizadas como variáveis de medida.

Para certos tipos de aplicação, onde sinais elétricos podem ser perigosos, mudanças na cor de sensores captados por sistemas de fibra óptica mostram-se promissores $^{47}$.

Nesse trabalho, o enfoque foi dado para os sensores onde a condutividade e a cor (i.e. espectro de absorção) são alteradas em função da presença de um ácido. Devido à elevada resistência desses polímeros quando não dopados, optou-se por utilizar eletrodos interdigitados (Figura 2-7) depositados sobre vidro e sob a camada sensora, ao invés de se utilizar o método de medidas conhecido como $4 \operatorname{pontas}^{48}$.

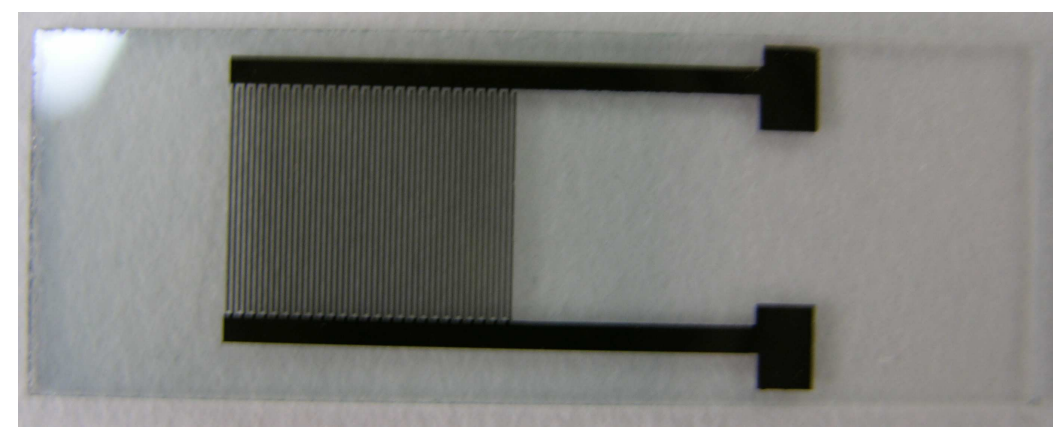

Figura 2-7 - Eletrodo interdigitado. 


\subsubsection{Processamento de filmes finos poliméricos}

Como visto anteriormente, há diversas técnicas de processamento de filmes finos poliméricos para a confecção de um dispositivo. Entre essas técnicas, spin coating e automontagem foram escolhidas por serem muito utilizadas e apresentarem um excelente controle de processamento. Outras vantagens são o baixo custo e a facilidade de utilização.

\subsubsection{Spin coating}

A técnica de spin coating é muito utilizada para se depositar uma fina camada uniforme sobre substratos planos. Dentre suas aplicações encontram-se a deposição de fotoresistes sobre laminas de silício, a cobertura de telas de televisão coloridas, a deposição de filmes finos poliméricos e de semicondutores ultrafinos ${ }^{49}$.

O processo de spin coating pode ser dividido em quatro etapas sendo elas o despejo da solução (a e b), a aceleração do substrato(c), a desaceleração e a evaporação do solvente (Figura 2-8).
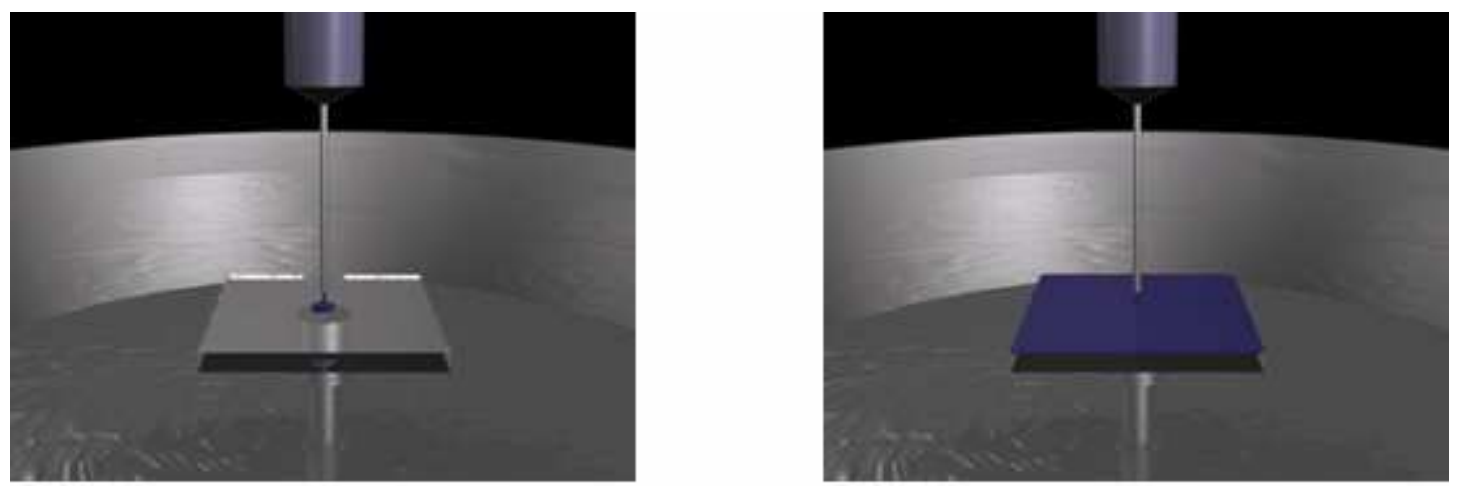

a)

b)

c)

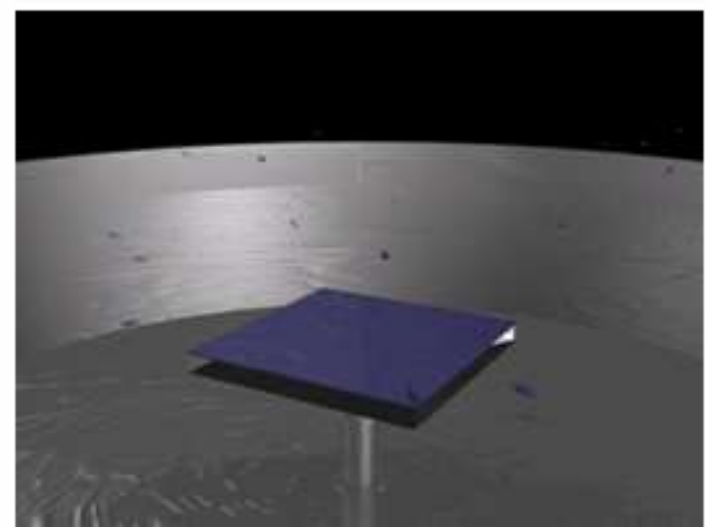

Figura 2-8 - Deposição por spin coating. a) despejo da solução b) cobertura total do substrato c) centrifugação e expulsão do material. 
Em 1958, EMSLIE, BONNER e PECK ${ }^{50}$ descreveram pela primeira vez o comportamento de um líquido viscoso sobre um disco em rotação, utilizando a idéia de um fluido newtoniano, através de equações hidrodinâmicas representativas do processo. Dentre suas conclusões, eles mostraram que a espessura final do fluido era independente de como o líquido se encontrava no instante inicial da rotação. Porém, a influência da evaporação do solvente e muitos outros fatores foram deixados de lado em seus cálculos.

Já em 1978, MEYERHOFER ${ }^{51}$ refinou o modelo anterior adicionando a taxa de evaporação do solvente. Em seu estudo, ele mostrou que até certo instante, o fator que governa a espessura do filme é a dispersão por força centrífuga. A partir de um determinado instante, a evaporação do solvente domina a espessura final do filme, como mostra a Figura 2-9. É possível notar o instante em que a influência da evaporação do solvente $\left(\mathrm{L} / \mathrm{L}_{0}\right)$ torna-se importante para a espessura.

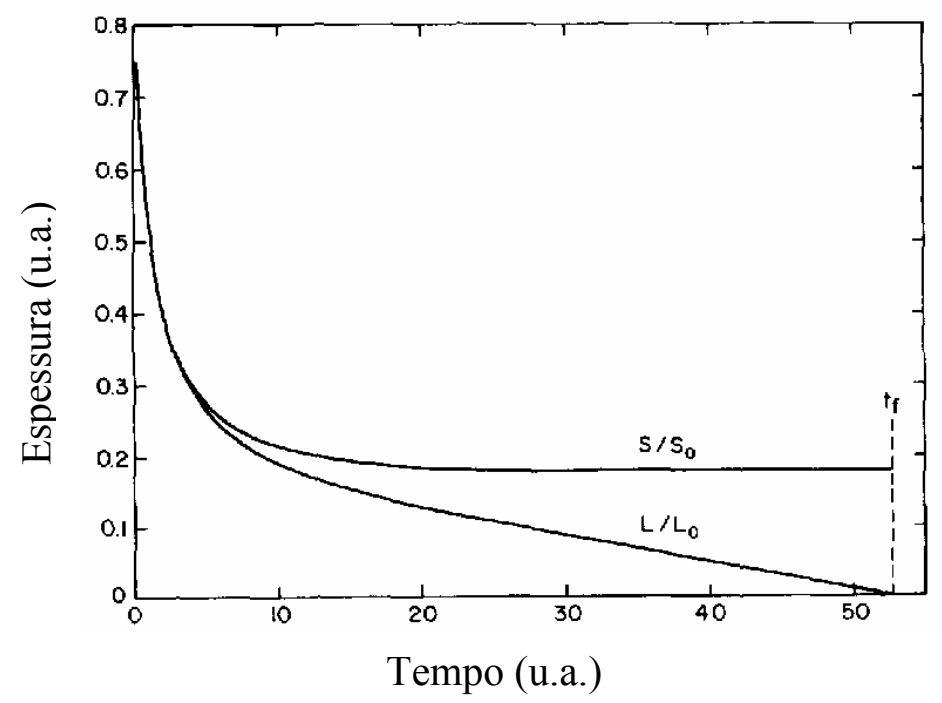

Figura 2-9 - Efeito do material sólido e do material líquido da solução para a espessura final do filme (S/SO: razão entre a quantidade de sólido atual e inicial; L/L0: relação entre quantidade de líquido atual e inicial) (Ref. 51).

DAMON $^{52}$ obteve a equação abaixo para a espessura final, que está correlacionada a diversos filmes de fotoresistes por ele obtidos (eq. 5).

$$
h=\frac{k c_{0}{ }^{2}}{\sqrt{f}}
$$

onde, $h$ é a espessura final do filme, $f$ a velocidade de rotação, $c_{0}$ a concentração da solução e $k$ uma constante do sistema. 
FLACK e seus colaboradores ${ }^{53}$ apresentaram um modelo matemático para esse processo envolvendo os efeitos não newtonianos, as mudanças na viscosidade do material e a difusividade do solvente pelo filme, com a mudança da concentração da solução polimérica. Mais tarde, LAWRENCE ${ }^{54}$ apresentou um novo trabalho, com um modelo mais elaborado e reuniu em seu artigo as principais referências e correlações existentes até então.

De uma forma geral, podemos descrever a espessura final de um filme obtido por spin coating como sendo:

$$
h=k \cdot f^{n}
$$

Onde, k é uma constante que envolve os materiais e $f$ a velocidade de rotação. Um parâmetro muito estudado empiricamente é a potência associada $(n)$ à velocidade de rotação $(f)$. Para DAMON e seus fotoresistes, o valor de $n$ era -0,5. SUKANEK ${ }^{55}$ por sua vez, analisando diversos materiais diferentes obteve valores entre - 0,4 e -1,3.

Pode-se dizer que os parâmetros mais importantes para a espessura final do filme obtido por spin coating são; a velocidade de rotação, a concentração da solução e os materiais usados (polímero, solvente). Muitos outros fatores ainda influem como a rampa de aceleração do processo, o ambiente em que o processo acontece (umidade do ar, temperatura, etc.), o tempo de rotação, entre outros. LUURTSEMA ${ }^{56}$ fez um estudo significativo da influência de se utilizar substratos retangulares em deposições por spin coating. Segundo ele, os principais efeitos de se utilizar um substrato retangular é o aparecimento do efeito coroa onde nas bordas ocorre um acúmulo de material depositado. Para evitar problemas devido a esse fenômeno, tomou-se a precaução de se utilizar um substrato de uma polegada quadrada e de se realizar a medida de espessura no centro da amostra.

Diversos trabalhos experimentais, conduzidos principalmente por SUKANEK, visam entender o efeito dos materiais e parâmetros de deposição por spin coating ${ }^{55,57,58}$. Analisando o expoente $n$ da velocidade de rotação, SUKANEK apresentou em seu trabalho com poliimidas ${ }^{59}$, que o tempo de rotação só é importante até um ponto na qual a espessura passa a não variar mais. Outro ponto importante apresentado nesse trabalho é a análise das diferentes propriedades dos solventes e soluções nas características finais dos filmes. 
São poucos os trabalhos em polímeros condutores que estudam apenas o processamento e suas variáveis. Em 2005, CHANG e colaboradores ${ }^{60}$ analisaram do ponto de vista reológico quatro polímeros conjugados (entre eles o MEH-PPV). Dentre suas conclusões, constataram que o coeficiente $n$ não variava com a concentração da solução polimérica. Para o caso do MEH-PPV, o coeficiente encontrado foi de $-0,49$, mas também foram obtidos coeficientes da ordem de $-0,37$ para outros polímeros.

Do ponto de vista morfológico, MELLO e colaboradores ${ }^{61}$ obtiveram filmes de POMA por spin coating e os analisaram utilizando técnica de AFM. Segundo eles, quanto maior a velocidade de rotação, maior é a rugosidade do filme.

STANGE e colaboradores ${ }^{62}$ analisaram a morfologia de filmes finos de poliestireno depositados por spin coating utilizando STM e AFM. Segundo eles, existe uma concentração crítica a qual, qualquer valor abaixo faz com que o substrato não seja totalmente preenchido e dessa maneira a rugosidade torna-se elevada. Podemos ver em seu artigo que abaixo dessa concentração crítica, o material polimérico tende a formar ilhas, ou aglomerados, não cobrindo assim toda a superfície do substrato.

Apesar de a teoria de spin coating já estar bastante desenvolvida, essa técnica foi escolhida nesse trabalho por possibilitar uma comparação do comportamento físico (modelos) e dos resultados encontrados. Nesse procedimento experimental, a simulação e otimização dos parâmetros de deposição poderiam ser feitos utilizando simulações numéricas dos modelos fornecidos pelos diferentes trabalhos apresentados acima, porém, validar a utilização de RNAs nesse processo permite que processos multivariáveis não-lineares mais complexos que esse possam ser também estudados por essa técnica.

\subsubsection{Automontagem}

Self-assembly (SA) ou simplesmente automontagem, é uma técnica de deposição de filmes finos poliméricos que utiliza duas espécies iônicas para formar bicamadas sucessivas ${ }^{63,64,65,66,67}$. Por esse motivo, também se costuma chamá-la de Layer-by-Layer (LBL). 
Uma variante desse processo de deposição é a técnica conhecida como electrostatic layer-by-layer self-assembly (ESA). Seu princípio se baseia na atração eletrostática de íons complementares. É uma técnica muito simples, de baixo custo e que permite formar filmes altamente ordenados ${ }^{68,69}$. Além de polímeros, podem-se depositar moléculas orgânicas de baixo peso molecular, proteínas, aglomerados inorgânicos, colóides, etc. ${ }^{70}$.
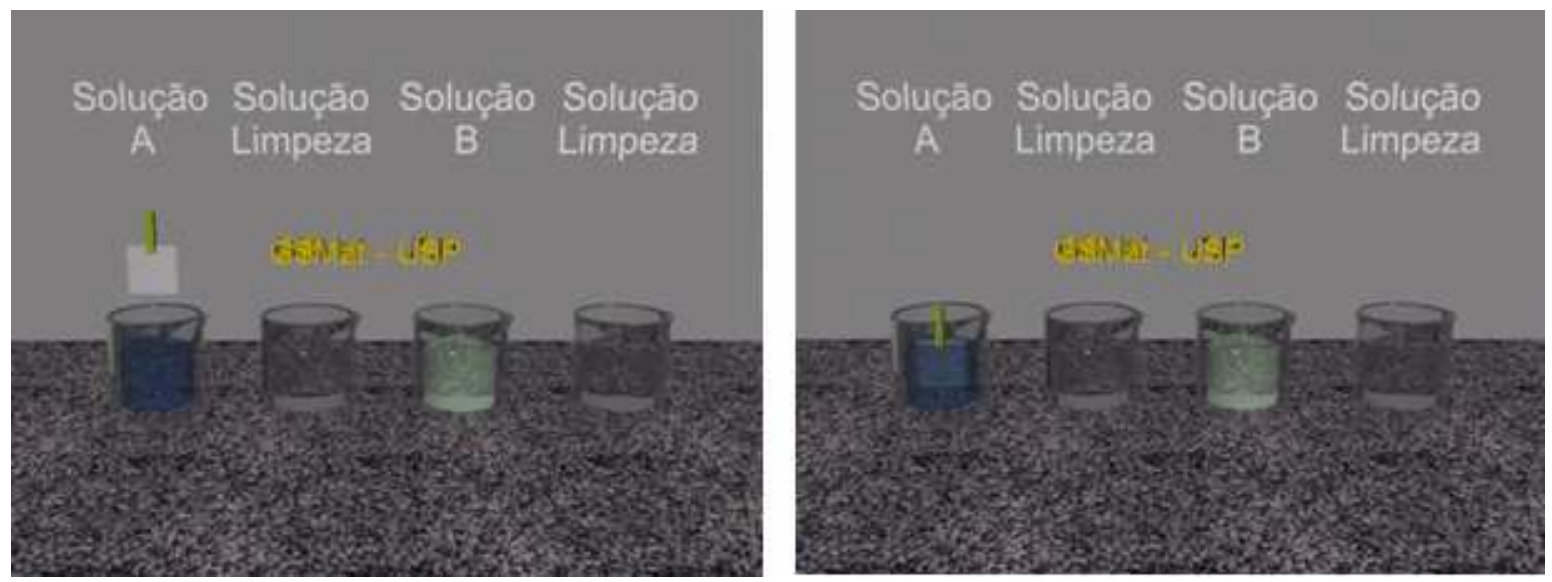

Figura 2-10 - Processo de automontagem. a) Substrato antes de ser mergulhado na primeira solução b) Substrato imerso na primeira solução.

Nessa técnica o substrato é mergulhado na solução que contém a espécie iônica onde o material é adsorvido na sua superfície. Assim, forma-se uma monocamada (Figura 2-10). A seguir, lava-se a amostra em água com o mesmo pH das soluções poliméricas. A formação das camadas se dá através de uma forte interação entre a camada já formada e as moléculas contidas na próxima solução de mergulho.

Para que as camadas sejam formadas, os dois polímeros utilizados precisam ser iônicos e com polaridades diferentes. A adsorção de polieletrólitos foi proposta inicialmente por DECHER e colaboradores ${ }^{71}{ }^{72}$. Diferentemente da formação por adsorção química, onde são formadas ligações covalentes, a adsorção se dá através de forças eletrostáticas entre os grupos iônicos encontrados nessas moléculas. O grau de adsorção por essa técnica é fortemente dependente da densidade de cargas, influenciando no crescimento do filme e em suas propriedades finais ${ }^{73}$.

$\mathrm{O}$ entendimento da cinética de crescimento e da morfologia final dos filmes ainda é motivo de estudo. LASCHWSKY e colaboradores ${ }^{74}$ propuseram um modelo no qual o crescimento do filme é governado por três mecanismos sendo eles a 
adsorção do polieletrólito, a difusão do polieletrólito nas camadas já depositadas e a complexação dos polieletrólitos difundidos. Isso nos apresenta um problema que é a interpenetração de uma camada na camada adjacente. Tal fenômeno é principalmente observado nos filmes que contém poucas bicamadas, na medida em que suas propriedades são de difícil reprodutibilidade.

Alguns trabalhos atualmente associam essa técnica de deposição com a técnica de spin coating, mostrando que é possível combinar os dois processos em um, assegurando um maior controle nas propriedades óticas e estruturais dos filmes $75,76,77$.

Devido às suas propriedades de condução, suas propriedades óticas e suas outras vantagens em dispositivos e no seu processamento, resolveu-se utilizar a polianilina como um dos polieletrólitos. Dessa maneira, um poliânion precisou ser escolhido e devido a trabalhos já realizados por DECHER ${ }^{71}$, usou-se o poli(vinil sulfato de sódio) (PVS). O PVS não é um polímero conjugado e sua utilização serve apenas como camada de combinação para a construção de um filme espesso de PAni/PVS. Seu efeito isolante pode ser benéfico quando utilizado em PLEDs, devido ao efeito bloqueador de lacunas.

Olhando para o processo de deposição, os parâmetros mais importantes para a formação de filmes com PAni e PVS seriam o número de bicamadas depositadas, o tempo de imersão, o pH das soluções e a concentração. Neste trabalho, verificou-se a influência do número de bicamadas, do tempo de imersão e do $\mathrm{pH}$ nas propriedades dos filmes.

\subsection{REDES NEURAIS ARTIFICIAIS (RNA)}

Quase toda atividade produzida pelos seres vivos requer a utilização de redes neurais. A memória, o controle motor, as sensações, os pensamentos, são todos governados pela complexa rede de neurônios ou células nervosas que compõem o nosso sistema nervoso. A motivação de desenvolver redes neurais artificiais veio do interesse de se criar sistemas que reproduzissem as habilidades que possuímos.

Rede neural artificial é o nome dado aos sistemas computacionais que procuram se basear nas redes formadas por neurônios biológicos naturais, a fim de tirar proveito de suas habilidades e características únicas. Segundo HAIKIN e outros 
pesquisadores $^{78,79}$, rede neural pode ser entendido como um processador paralelo massivo feito de unidades simples de processamento, que conseguem armazenar conhecimento e torná-las disponíveis para uso. Dentre suas vantagens, a mais importante delas para esse trabalho é sua capacidade de aprender quando um conjunto de informações é a ela fornecido. Um sistema com características (exemplo de um tipo de rede na Figura 2-11) e pesos aleatórios é treinado até que aprenda a fornecer a resposta seguindo o padrão contido no conjunto de treinamento. Essas redes conseguem aprender relações não lineares, interpolar e extrapolar os valores de treinamento, gerando um ambiente de simulação.

Podem-se classificar as tarefas que uma rede neural artificial executa em dois grandes blocos. Aquelas que necessitam de treinamento supervisionado e as que necessitam de treinamento não supervisionado. No primeiro caso, um "professor" deve dizer para a rede qual é a resposta esperada (como no caso de problemas referentes à classificação). $\mathrm{O}$ aprendizado não supervisionado é feito por comparações. Um exemplo típico é de se determinar se um dado pertence ao conjunto, baseado em comparações. Diferentemente do primeiro caso, aqui não há um "professor" para indicar se a resposta está correta ou incorreta ${ }^{78}$.

Dentre as tarefas que as redes neurais artificiais podem desempenhar, podemos citar a classificação e o agrupamento de dados, a associação de padrões (reconhecimento de imagens, por exemplo), a aproximação de funções, os sistemas de controle e as previsões ${ }^{79}$.

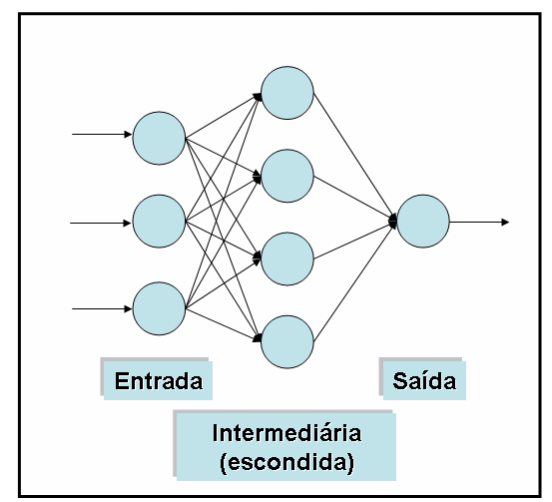

Figura 2-11 - Exemplo de uma estrutura simples de RNA unidirecional com uma camada intermediária.

De modo geral, podemos dividir as tarefas de uma rede neural para o nosso fim, em basicamente duas, sendo a primeira o treinamento e a segunda a simulação. 
Em forma seqüencial, o algoritmo padrão de uma rede neural com aprendizado supervisionado é fornecido abaixo (e na Figura 2-12):

- A RNA é inicializada de uma maneira geralmente aleatória (i.e. os pesos entre os neurônios são escolhidos aleatoriamente).

- Um conjunto de dados chamado de conjunto de treinamento é apresentado à rede.

- O erro entre os dados simulados e os conhecidos é computado.

- O erro é propagado para as camadas interiores, alterando os pesos dos neurônios a fim de minimizar o erro global.

- Uma nova simulação é realizada, o erro é computado e propagado novamente.

- Repete-se esse procedimento até que se atinja algum critério de parada.

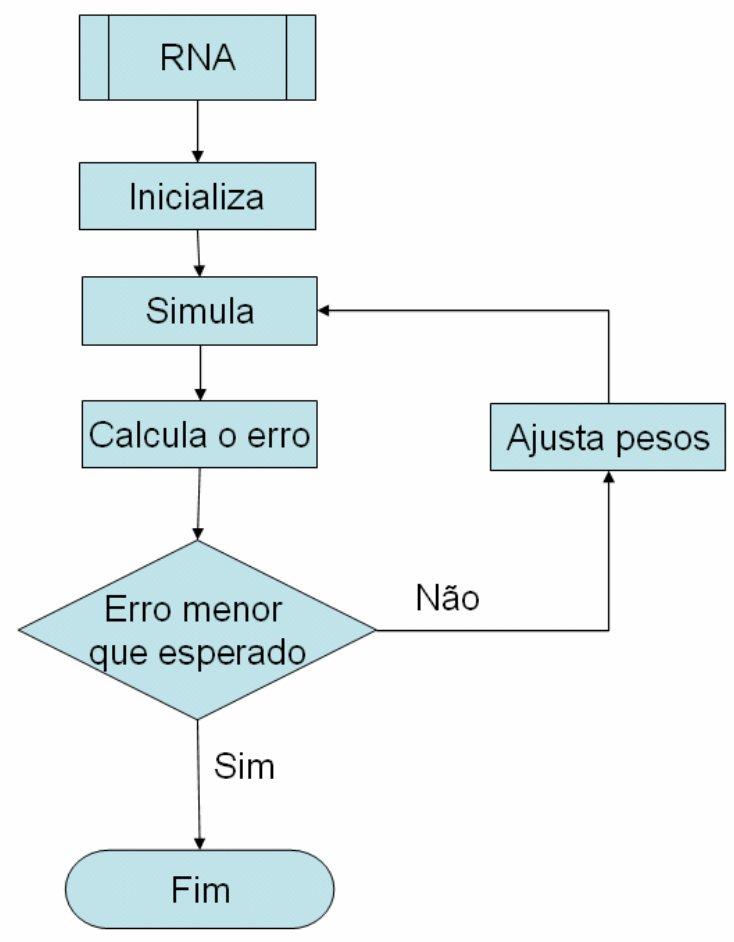

Figura 2-12 - Algoritmo genérico de uma RNA supervisionada.

\subsubsection{História das redes neurais}

Em 1943, MCCULLOCH e PITTS $^{80}$ propuseram o primeiro modelo matemático para descrever o comportamento lógico do neurônio biológico. Em seu 
trabalho, eles uniram a matemática e a neurofisiologia mostrando que esse modelo conseguia computar qualquer função computável.

O próximo grande salto em redes neurais foi dado por $\mathrm{HEBB}^{81}$ (1949) em seu livro intitulado The organization of behavior. Nesse trabalho, HEBB fundamentou pela primeira vez um mecanismo de aprendizado baseado nas modificações sinápticas dos neurônios. Na época o livro gerou um grande impacto na ciência da neurofisiologia. É importante lembrar que a utilização de redes neurais artificiais em problemas só pode ser realizada caso haja procedimentos de aprendizado estabelecidos para a realização de um treinamento, supervisionado ou não.

Mais tarde, em 1958, ROSENBLATT ${ }^{82}$ propôs seu modelo de aprendizagem supervisionada, chamado de perceptron. No modelo do perceptron, o neurônio artificial possui a capacidade de aprender segundo a idéia proposta por HEBB. Dois anos mais tarde, WIDROW ${ }^{83}$ apresentou uma variante do modelo do perceptron, chamada por ele de ADAptative LInear NEtwork (ADALINE). A diferença entre os dois modelos consiste basicamente no método de aprendizado, onde nesse novo algoritmo, a realimentação do treinamento é realizada antes da computação da função de transferência.

$\mathrm{Na}$ década de 60 parecia que as redes neurais eram capazes de realizar qualquer tarefa. Então, em 1969, MISNKY e PAPERT ${ }^{84}$ demonstraram matematicamente as limitações que os perceptrons possuíam. Esse trabalho foi tão profundo que limitou a pesquisa em redes neurais por 10 anos.

Em 1986, RUMELHART, HINTON e WILLIAMS ${ }^{85}$ apresentaram o algoritmo conhecido como "back-propagation", o qual é extremamente utilizado até hoje em redes do tipo multilayer perceptron (MLP). Esse algoritmo possibilitou a implantação de processos de treinamento em multiníveis, tornando viável a elaboração de redes mais complexas e robustas.

\subsubsection{Princípios básicos de RNAs}

Segundo MCCULLOCH e PITTS ${ }^{80}$, um neurônio pode ser modelado assumindo algumas proposições simples:

- Um neurônio possui apenas um valor de saída, 
- Ele é alimentado por $n$ entradas, relativas ao número de neurônios presentes na camada anterior.

Ele realiza uma operação matemática baseada nas entradas para fornecer o valor de saída. Tal operação é conhecida como função de ativação.

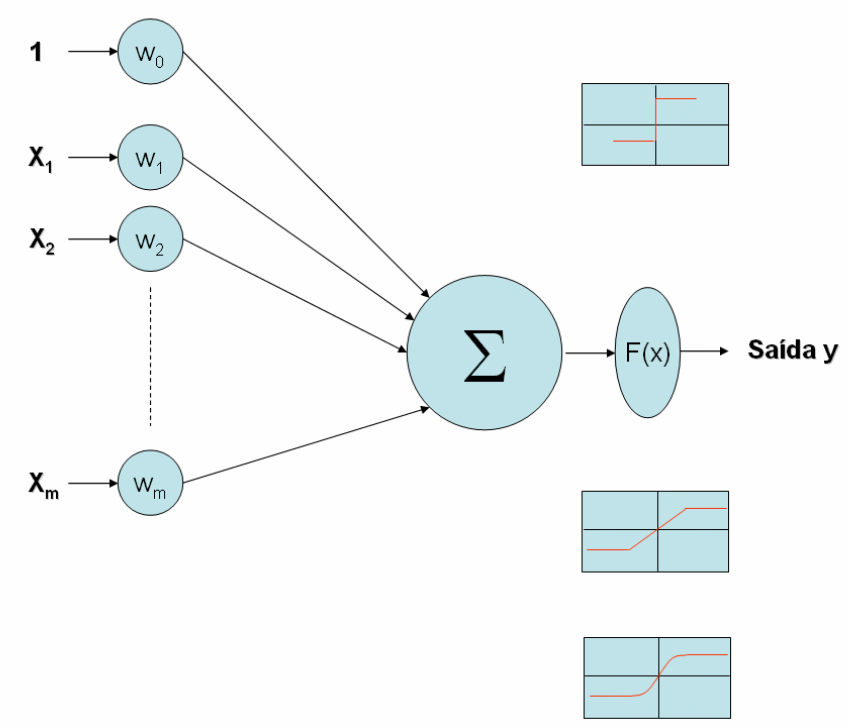

Figura 2-13 - Representação de um neurônio artificial proposto por McCulloch e Pitts.

De modo geral, podemos dizer que um neurônio artificial é o elemento mais simples que constitui uma rede neural e possui $n$ entradas com pesos individuais, uma unidade de soma, uma função de ativação e uma saída (Figura 2-13).

O processo realizado por um neurônio consiste primeiramente em somar o valor das $n$ entradas $\left(\mathrm{X}_{\mathrm{n}}\right)$ multiplicadas pelo peso $\left(\mathrm{W}_{\mathrm{n}}\right)$ associado a cada uma delas. Esse resultado é então introduzido em uma função de ativação $(\mathrm{F}(\mathrm{x}))$ que fornece a saída do neurônio.

O modelo matemático dessa operação é dado a seguir, onde w são os pesos referentes a cada entrada e x o valor da entrada:

$$
\begin{aligned}
& \text { Net }=\sum_{i=1}^{n} w_{i} x_{i} \\
& \text { Saida }=f(\text { Net })
\end{aligned}
$$

Nos primeiros modelos, a função de ativação era do tipo degrau (Figura 2-14). Essa função é útil, por exemplo, para classificar dois conjuntos de dados. Mais 
tarde, ficou claro que funções sigmoidais (que são diferenciáveis em qualquer ponto) apresentavam diversas vantagens ${ }^{79}$ sobre as funções degrau.

As funções de ativação podem ser, a priori, qualquer função conhecida. Porém, como demonstrado no livro de $\mathrm{MEHROTRA}^{79}$, a utilização de funções diferenciáveis é extremamente interessante e necessária para a minimização do erro global em diversos algoritmos de treinamento.

Dentre as funções de ativação mais usadas estão as funções gaussianas, sigmóides, funções senoidais, funções lineares, tangentes hiperbólicas, funções logarítmicas, entre outras. (Figura 2-14).

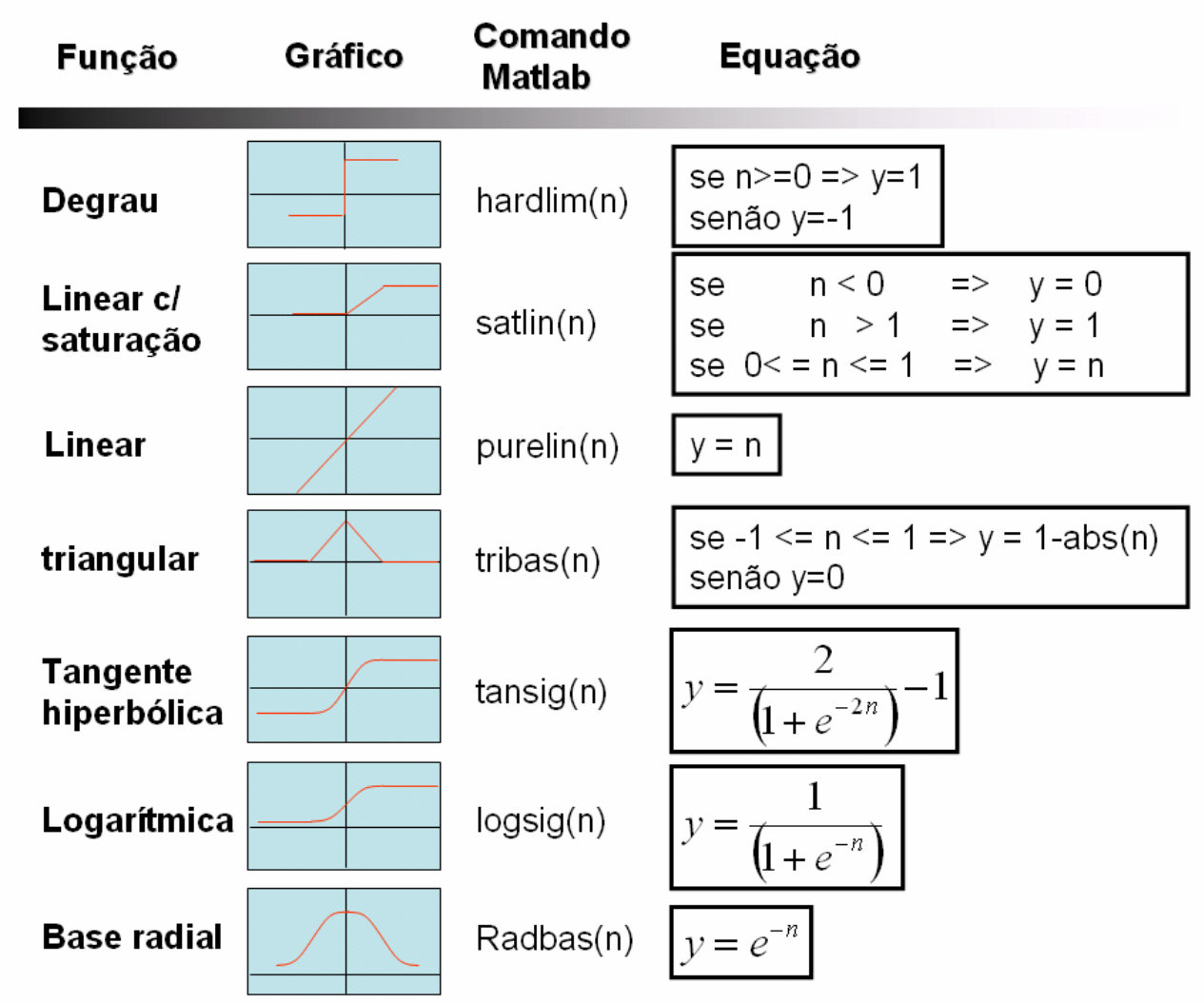

Figura 2-14 - Funções de ativação utilizadas no MATLAB para RNAs.

Para entender como funciona o processo de treinamento de uma RNA, é interessante observar o algoritmo de treinamento do perceptron, proposto por ROSENBLATT $^{82}$.

Primeiramente, devemos definir alguns conceitos e para isso utilizaremos um exemplo. Faremos uso de um exemplo fictício, uma fábrica onde frutas são selecionadas entre boas e ruins. Dois parâmetros são avaliados sendo eles; o tamanho (de 1 até 30 ) e a cor (de 0 até 10). Para treinar a RNA para realizar tal classificação, 
foram selecionadas 230 frutas e após serem medidas o tamanho e a cor, elas foram classificadas como boas ou ruins. Uma tabela foi gerada contendo todos esses valores (tabela 2-1).

Tabela 2-1: Exemplo de uma tabela de dados experimentais para serem usados no treinamento e teste de uma RNA.

ENTRADA1 ENTRADA2 SAIDA

\begin{tabular}{cccc}
\hline Fruta & Tamanho & Cor & Classificação \\
\hline 1 & 3 & 7 & Ruim \\
2 & 15 & 4 & Ruim \\
3 & 8 & 9 & Boa \\
4 & 21 & 2 & Ruim \\
5 & 24 & 7 & Boa \\
6 & 18 & 5 & Boa \\
. & & &. \\
. & & & Ruim \\
230 & 7 & 3 &
\end{tabular}

Amostra, no exemplo acima é a composição das entradas e saídas para uma única fruta. Cada amostra é um conjunto de relações entre as entradas e as saídas. Uma amostra é o conjunto de dados que caracteriza uma fruta.

Um conjunto de treinamento é a composição de todas as amostras utilizadas no treinamento. Assim, caso 120 frutas sejam usadas para o treinamento, diz-se que essas 120 amostras formam o conjunto de treinamento.

Um conjunto de teste é a composição de todas as amostras utilizadas para a validação da rede. No exemplo acima, as 110 frutas restantes formariam o conjunto de teste.

Conjunto total é a união dos conjuntos de treinamento e o de teste. No exemplo são todos os dados.

Vetor de entrada é o conjunto de todas as entradas. No exemplo acima, o vetor de entrada é formado por todos os dados de tamanho e de cor de todas as frutas (o vetor de entrada pode ser referido ao conjunto de treinamento, ao de teste ou ao total).

Vetor de saída é o conjunto de todas as saídas de todas as amostras. No exemplo acima ele é formado apenas por uma saída, a classificação de boa ou ruim.

Taxa de aprendizagem é a taxa com a qual os pesos são alterados. Para o caso mais simples do perceptron, a taxa de aprendizagem é constante e fixa. Para outros 
casos mais complexos, a taxa de aprendizagem pode ser alterada durante o treinamento.

Inicialização ou repetição é o ato de reiniciar aleatoriamente os pesos dos neurônios, deixando a rede em um estado não treinado.

Pela natureza do problema acima poderíamos utilizar como função de ativação a função degrau onde, para NET $<0$ a saída seria 0 (ruim) e para NET $\geq 0$ a saída seria 1 (boa).

Como critério de parada, podemos escolher o número de amostras classificadas incorretamente. Assim, a rede irá continuar a realizar o treinamento enquanto o número de amostras não classificadas adequadamente estiver acima do esperado.

No treinamento de uma RNA, uma série de amostras diferentes é apresentada, o erro é computado e os pesos são atualizados. Essa série de amostras faz parte do conjunto de treinamento. Quando todas as entradas forem apresentadas apenas uma vez, o erro for computado e os pesos atualizados (também uma única vez), diz-se que uma época aconteceu. Dessa maneira, uma época pode ser definida como uma única passagem por todas as entradas e uma atualização de todos os pesos da rede. Para averiguar a capacidade de uma RNA de minimizar o erro global, costuma-se utilizar o número de épocas para tal feito e não o número de cálculos computacionais ou o tempo gasto. 


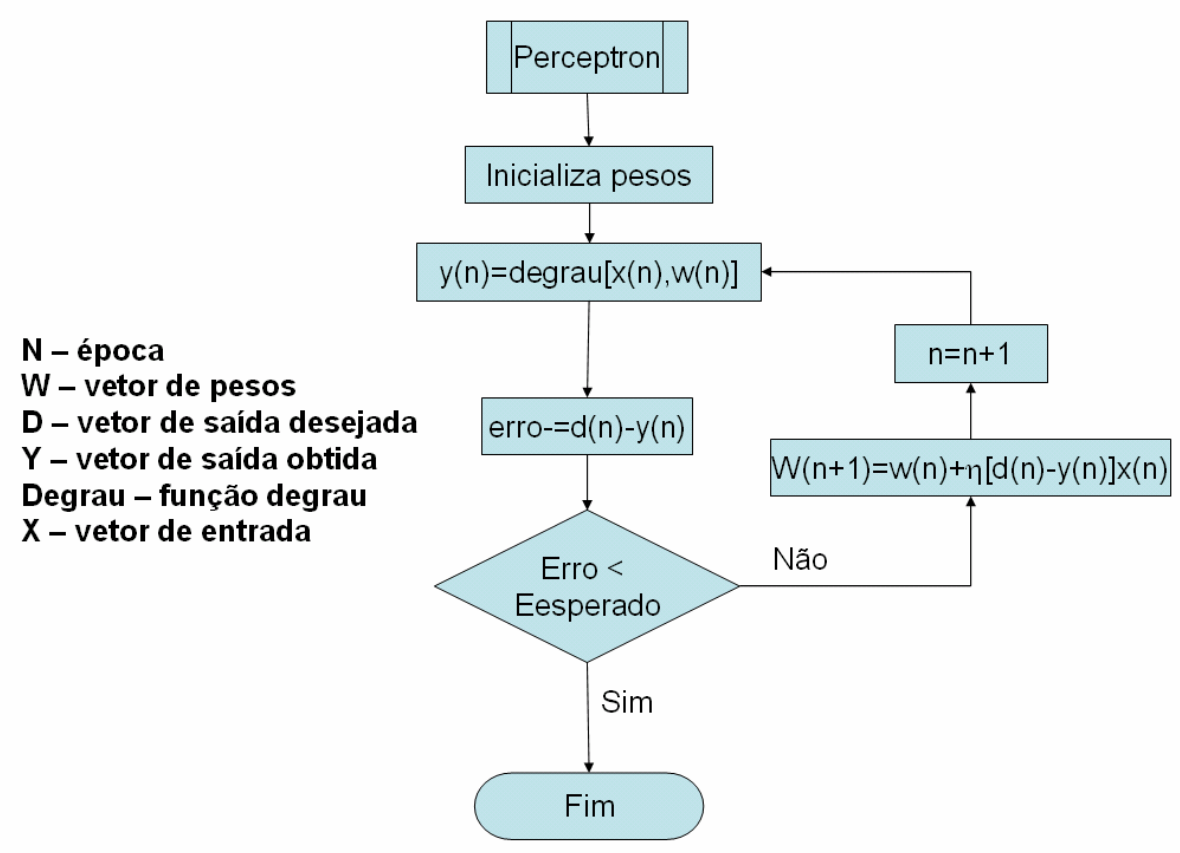

Figura 2-15 - Algoritmo de convergência do Perceptron.

No algoritmo do perceptron (Figura 2-15) só é possível distinguir duas ou mais classes quando essas são linearmente separáveis. Sua utilidade em termos práticos é pequena, porém, em termos didáticos é o algoritmo mais simples e o que fornece um bom entendimento dos conceitos fundamentais de redes neurais artificiais.

O que deve ficar claro é que na maioria dos casos, definidos os diferentes parâmetros das redes neurais, os pesos são os parâmetros modificados no treinamento.

\subsubsection{Redes multilayer perceptrons (MLPs)}

Extrapolando o conceito do perceptron proposto por ROSENBLATT ${ }^{82}$, foi proposta uma verdadeira rede, formada por vários perceptrons interligados. Essas redes são muito mais poderosas do que as formadas por apenas um perceptron. A utilização dessas redes só foi possível com a elaboração de um algoritmo de treinamento que conseguisse minimizar o erro global de forma eficiente. Esse algoritmo, como já descrito anteriormente foi denominado de retropropagação ou backpropagation. 
Desenvolvido através da generalização da regra de aprendizagem de Widrow$\operatorname{Hoff}^{83}$, RUMELHART propôs esse novo algoritmo ${ }^{85}$. Apresentando valores de entrada, gera-se saídas que são comparadas com os valores esperados. Tal comparação gera um erro, que é utilizado para corrigir os pesos dos perceptrons das camadas interiores à rede. Tal procedimento para minimizar o erro quadrático médio é geralmente conhecido como gradient descent algorithm. Os pesos da rede são alterados negativamente em relação ao gradiente do erro.

Em geral, redes retropropagadas treinadas adequadamente tendem a fornecer boas respostas a entradas nunca antes vistas. Essas redes também são conhecidas como aproximadores universais, devido às suas propriedades, que serão abordadas no próximo tópico.

O primeiro passo na construção de uma rede MLP é definir quais são as entradas e as saídas. O passo seguinte é escolher o número de camadas intermediárias (ou escondidas), o número de neurônios em cada uma delas e a função de ativação de cada um deles. Em seguida, deve-se estabelecer o critério de parada do treinamento. Dentre os critérios utilizados em MLPs, pode-se usar o número máximo de épocas, o erro global e para alguns casos, a variação da taxa de aprendizagem.

Como critério de parada, o parâmetro mais utilizado é o erro global (erro quadrático médio). $\mathrm{O}$ erro global pode ser definido como:

$$
\mathrm{E}=\frac{1}{A m} \sum_{j=1}^{A m}\left(\sum_{i \in C}\left(d_{i}(j)-o_{i}(j)\right)^{2}\right)
$$

Onde $A m$ é o número de amostras, $d_{i}$ o valor desejado, $o_{i}$ o valor encontrado e $\mathrm{C}$ o conjunto de dados (diferentes saídas, se houver).

Segundo THOMSEY ${ }^{86}$, existem três medidas comumente utilizadas para o erro, sendo elas: média do erro absoluto (MAE), raiz quadrada da média do erro ao quadrado (RMSE) e porcentagem de classificações corretas (Tabela 2-2). 
Tabela 2-2 - Diferentes cálculos do erro utilizados como critério de parada em redes neurais artificiais.
MAE
RMSE ou MSE
Porcentagem
Erro $=\frac{\sum_{p=1}^{n}\left|d_{i}-o_{i}\right|}{n}$
Erro $=\sqrt{\frac{\sum_{p=1}^{n}\left(d_{i}-o_{i}\right)^{2}}{n}}$
Erro $=\frac{\sum_{p=1}^{n}\left(Y_{p}\right)}{n} x 100$

Onde $Y p$ é 1 quando a diferença entre o real e o simulado for menor do que um valor pré-estabelecido, $d_{\mathrm{i}}$ é o valor real, $o_{i}$ o valor obtido e $n$ o número de dados.

$\mathrm{O}$ treinamento de retropropagação faz com que os pesos sejam atualizados levando a rede neural a um mínimo local do erro quadrático médio. Porém, mínimos locais não necessariamente correspondem ao mínimo global, onde a escolha dos pesos forneceria uma resposta muito mais satisfatória. Para evitar que o treinamento se torne preso a um mínimo local, adiciona-se um parâmetro à regra de mudança de pesos do algoritmo de retropropagação. Esse novo termo, chamado de momentum, corresponde a uma média do erro quadrático médio tomado em uma pequena região ao redor do ponto em si.

O erro global é calculado sobre o conjunto de treinamento, mas para melhorar a generalização, pode-se medir também o erro sobre um conjunto de testes e utilizar esse valor como critério de parada.

Em redes neurais podemos sempre entender o treinamento pensando no universo de pesos. Conforme o treinamento acontece, os pesos dos neurônios que compõem a rede são alterados. Então, em um determinado momento, um conjunto específico de pesos representa a rede neural.

Na Figura 2-16 os círculos verdes, vermelho e azul são estados específicos dos pesos que formam a rede neural. O circulo vermelho com o escrito "Tre" representa o melhor conjunto de pesos que a rede neural pode ter comparando os resultados simulados com os utilizados no treinamento.

Da mesma forma, há um conjunto de pesos que melhor representa os resultados contidos no conjunto de teste (pois os dados são diferentes dos contidos no conjunto de treinamento). Esse conjunto de pesos está representado pelo circulo azul com o escrito "Tes". 
Os círculos em verde numerados são estados dos pesos em inicializações aleatórias. Se o algoritmo de treinamento é adequado e eficiente, o conjunto de pesos inicializado tende a caminhar em direção ao conjunto de pesos representado pelo círculo vermelho ("Tre"). Nota-se que o erro sobre o conjunto de treinamento é proporcional a distância entre os estados atual (circulo verde) e o círculo vermelho.

Em um caso ideal, o conjunto de pesos inicializado deveria se tornar igual aquele representado pelo círculo vermelho. Como se observa na figura abaixo, a inicialização aleatória pode fazer com que os pesos se aproximem do conjunto de treinamento, mas que ainda estejam afastados do conjunto de teste. Assim, se analisarmos o erro apenas do conjunto de teste teremos para o mesmo número de neurônios uma falta de reprodutibilidade (inicializações aleatórias com resultados pouco parecidos). Um modo de resolver o problema é não trabalhar sobre apenas um resultado, mas ao invés disso, trabalhar sobre a média de diversas inicializações. Assim, analisando o valor médio, mínimo e máximo de um grande número de inicializações podemos observar a verdadeira influência do número de neurônios sobre a eficiência da rede.

Os círculos denominados "a", "b" e "c" indicam regiões em que os pesos se encontram em determinadas épocas, sendo que "a" engloba um número de épocas menor do que "b" que por sua vez engloba um número menor do que de "c". 


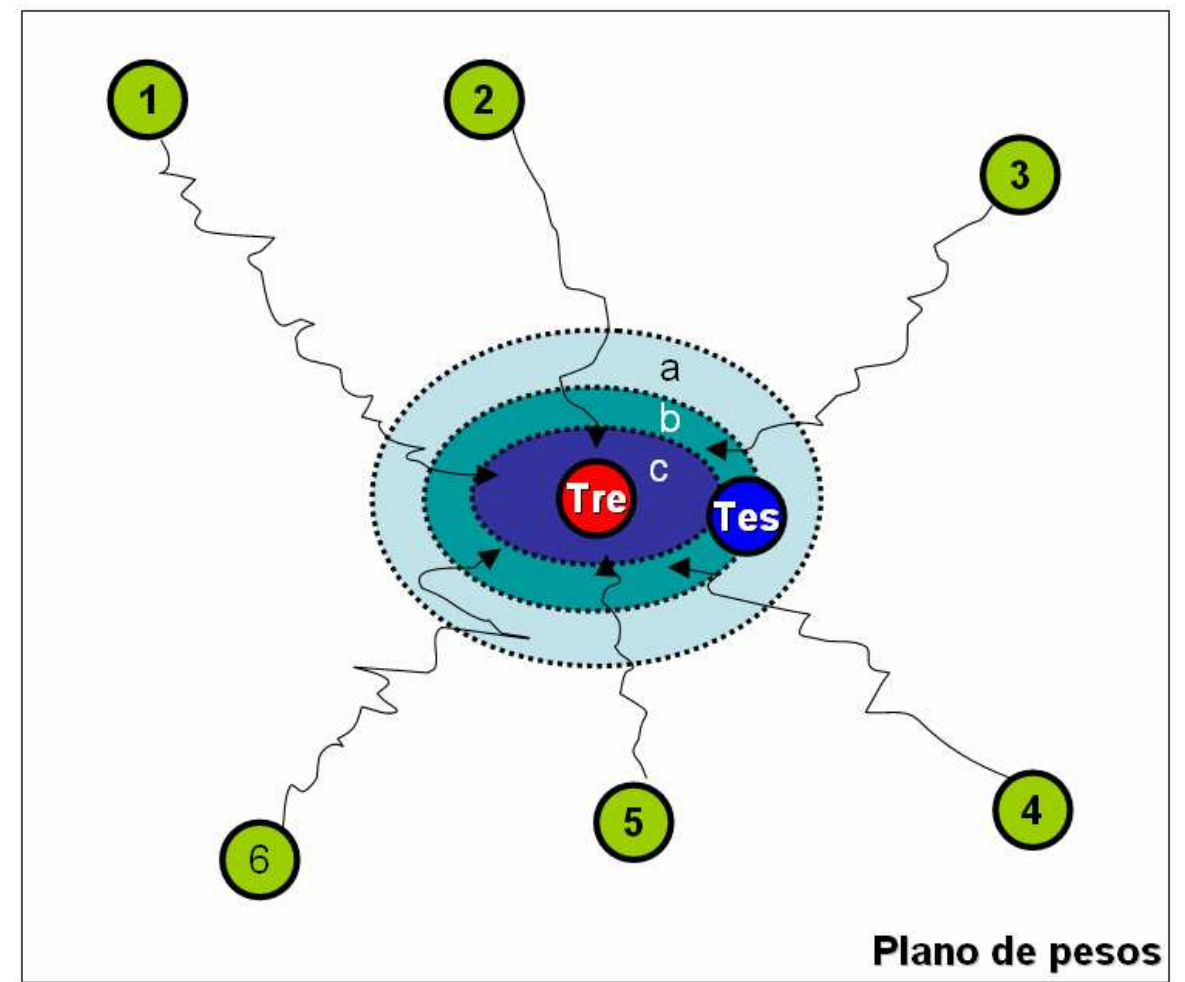

Figura 2-16 - Mapa de pesos genérico (Tes - conjunto de pesos que melhor representam o conjunto de teste; Tre - pesos que melhor representam o conjunto de treinamento; 1-6 conjunto de pesos aleatórios iniciais).

\subsubsection{Aproximação de funções}

Em 1957, KOLMOGOROV ${ }^{87}$ apresentou um artigo onde descreve como é possível representar qualquer função $f$ com $n$ variáveis por uma série de funções de uma variável. Esse artigo deu origem ao teorema de Kolmogorov, o qual diz que a função $f$ pode ser escrita como uma soma de transformações de uma soma de funções fixas dependentes apenas de uma variável (eq. 10).

$$
f\left(x_{1}, x_{2}, \ldots, x_{n}\right)=\sum_{j=1}^{2 n+1} g_{j}\left(\sum_{i=1}^{n} h_{i, j}\left(x_{i}\right)\right)
$$

$h(k)$ são funções determinadas e fixas

$\mathrm{g}(\mathrm{k})$ são funções dependentes de $f$

De uma maneira relativamente óbvia, pode-se construir uma rede neural que represente esse teorema. Uma rede com duas camadas escondidas, onde a primeira realizaria as transformações $h$ às entradas, a segunda computaria as transformações $g$ e o neurônio de saída realizaria a soma final poderia ser usada para implementar tal função. Porém, como levantado por KOLMOGOROV, a escolha das funções $g$ deve 
ser dependente da função $f$ que se pretende representar. Do ponto de vista prático, tal fato limita sua utilização.

Utilizando esse teorema, $\mathrm{CYBENKO}^{88}$ demonstrou que uma rede neural com uma camada intermediária e funções sigmoidais contínuas e arbitrárias conseguiriam aproximar qualquer função com precisão também arbitrária. Esse artigo publicado em 1989 é utilizado como base na maioria dos trabalhos de aproximação de funções por redes neurais artificiais.

As aproximações de Fourier são muito conhecidas e amplamente utilizadas nas ciências exatas para representar funções. Como se sabe, a aproximação em séries de Fourier representa a função através de uma soma de senos e cossenos com diferentes argumentos e coeficientes multiplicadores. Dessa forma, GALLANT e WHITE $^{89}$ propuseram a construção de uma rede neural de uma camada escondida com funções de ativação cossenoidais. Para esse tipo de rede, quanto menor o erro desejado, mais neurônios deverão ser adicionados à camada intermediária.

Um grande problema em se utilizar RNAs no trabalho proposto é que para o primeiro caso (spin coating), o número de dados utilizados é pequeno. Geralmente, quando se utilizam RNAs, o conjunto de treinamento e de teste possuem centenas a milhares de amostras. No presente trabalho, devido à dificuldade experimental de algumas técnicas utilizadas, a quantidade de dados obtida foi pequena. Há outros casos na ciência onde a falta de longas séries também acontece. Em 1998, SILVERT e BAPTIST $^{90}$, publicaram um artigo onde exploram o problema de poucos resultados no treinamento de redes neurais, para a área ecológica. Porém, apesar de haver um problema com conjuntos de treinamento pequenos, há poucas publicações abordando o problema. 


\section{MATERIAIS E MÉTODOS}

Para se avaliar a utilização de redes neurais artificiais como um simulador dos processos de deposição de filmes finos poliméricos, foram realizadas deposições por duas diferentes técnicas (spin coating e automontagem), utilizando três diferentes polímeros (POMA, PAni e PVS). Nesse capítulo serão discutidos os materiais utilizados, os processos de deposição e as técnicas de caracterização dos filmes.

\subsection{Obtenção dos filmes}

\subsubsection{Síntese de POMA e preparação de soluções}

O primeiro passo para a deposição dos filmes é a obtenção do polímero. Para a síntese da POMA, o monômero o-metoxianilina (Figura 3-1 a) é primeiramente destilado por destilação fracionada (Figura 3-1 b) e então é realizada a síntese.
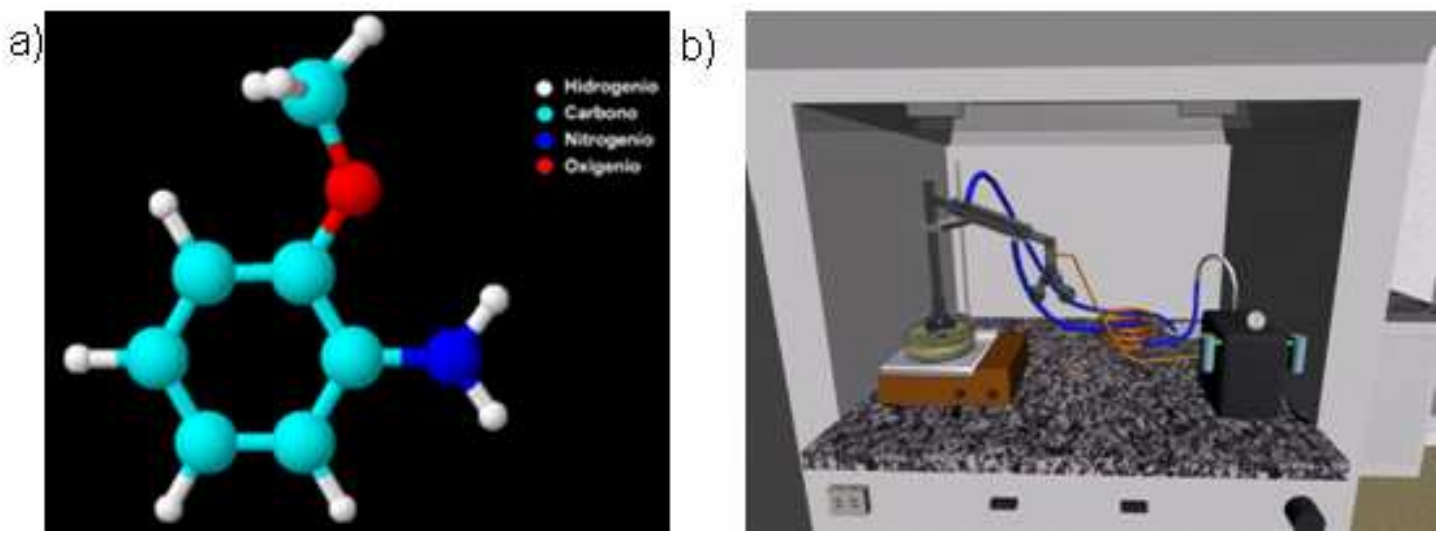

Figura 3-1 - a) o-metoxianilina b) sistema de destilação fracionada utilizado na destilação do monômero.

Os passos para a síntese desse polímero são descritos a seguir:

Prepara-se 1 litro de solução de HCl 1 molar. Em seguida pesa-se 11,52g de peróxidissulfato de amônio e então é feita a sua diluição com $200 \mathrm{~mL}$ da solução de $\mathrm{HCl}$ em um béquer de $600 \mathrm{~mL}$ (béquer 1). Coloca-se $300 \mathrm{~mL}$ de $\mathrm{HCl}$ em um béquer de $1000 \mathrm{~mL}$ (béquer 2) acrescentando o monômero destilado (28 $\mathrm{mL}$ de $o$ metoxianilina). Os dóis béqueres são colocados em recipientes com gelo e espera-se a estabilização da temperatura em torno de $0^{\circ} \mathrm{C}$. Usando um bastão de vidro, adiciona-se o conteúdo do béquer 1 no béquer 2 cuidadosamente e vagarosamente. A solução deve ser agitada com um agitador magnético. A temperatura deve ser mantida em $0^{\circ} \mathrm{C}$ por 4 horas e a solução mantida sob agitação. Após esse período é obtido o polímero na sua forma protonada (dopada, POMA-ES) como um 
precipitado verde escuro. Este é então coletado num funil de Buchner e lavado com $\mathrm{HCl} 1 \mathrm{M}$ ou acetona. Para a desprotonação, o polímero protonado é mantido sob agitação por 18 horas em uma solução de Hidróxido de Amônio $\left(\mathrm{NH}_{4} \mathrm{OH}\right)$ 0,1N. Posteriormente, o polímero desprotonado (POMA-EB) é coletado em um funil de Buchner, lavado com porções de água e seco em secador sob vácuo dinâmico por 72 h.

Com o pó desdopado foi preparada a solução polimérica, para a deposição por spin coating, segundo o seguinte procedimento:

Utilizando uma balança analítica ou semi-analítica pesa-se o pó no frasco onde estará a solução. Coloca-se a cápsula magnética dentro do frasco e com a cápsula em agitação, usa-se uma seringa para adicionar o solvente, no caso clorofórmio. A adição deve ser feita de maneira gradual e após ser colocado todo o solvente, a solução deve permanecer sob agitação por $30 \mathrm{~min}$. aproximadamente. $\mathrm{O}$ frasco deve estar fechado e é interessante que ele não fique exposto à luz.

\subsubsection{Síntese de PAni e preparação das soluçães}

A síntese da PAni é bastante similar à síntese, já descrita, da POMA. A única diferença é a utilização de $20 \mathrm{~mL}$ de anilina e não $28 \mathrm{~mL}$ de $o$-metoxianilina. A Pani utilizada nesse trabalho foi sintetizada, utilizando as instalações do Grupo de Polímeros "Prof. Bernhard Gross" no IFSC - USP. A medida de cromatografia por exclusão de tamanho (GPC) (HPSEC (High Perfomance Size Exclusion Chromatography)), medida realizada para se determinar a massa molecular do polímero (Figura 3-2), foi realizada posteriormente pela Dr. Débora Balogh pertencente àquele grupo de pesquisa. 


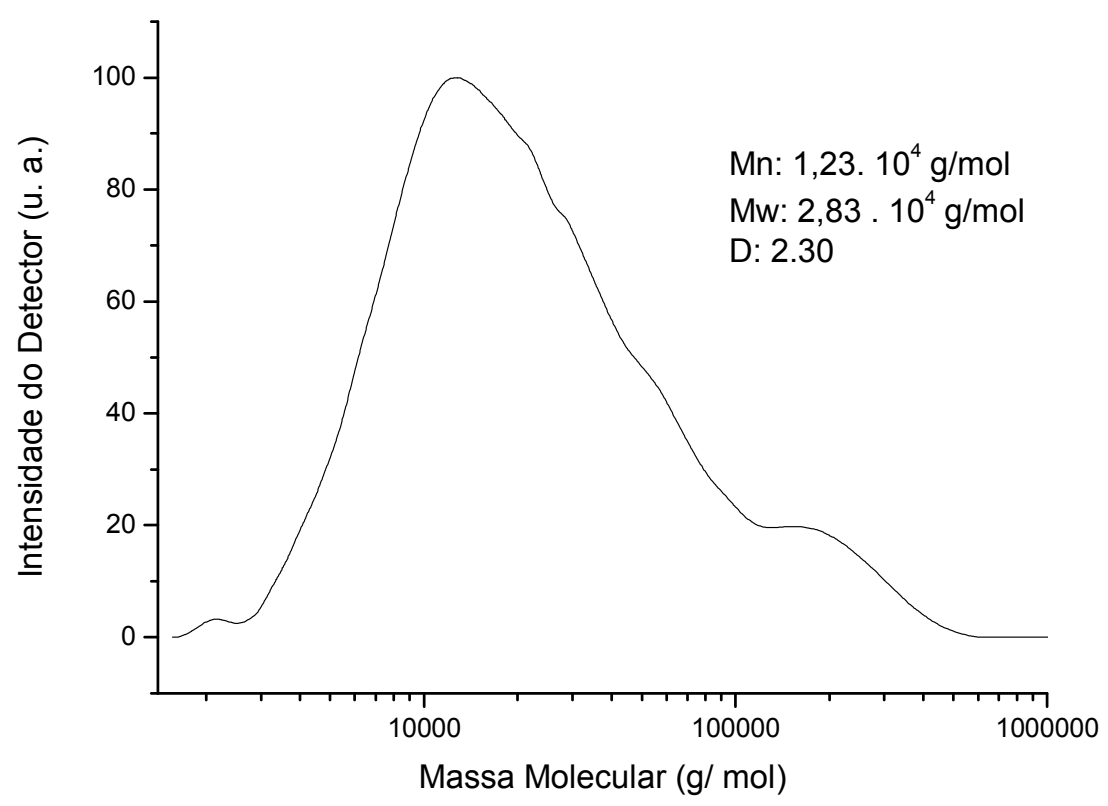
HPSEC-GPC.

Figura 3-2 - Distribuição de massa molar da PAni sintetizada, determinada por

A preparação da solução polimérica para esse polímero é diferente da descrita anteriormente. Isso porque, além do solvente ser outro esse polímero foi usado para deposições por automontagem.

A metodologia de preparação de soluções de PAni para automontagem, proposta por RUBNER ${ }^{66}$, utiliza $20 \mathrm{mg} / \mathrm{mL}$ de PAni diluídos em dimetilacetamida (DMAc). Devido a quantidade excessiva de material retido na filtragem, resolveu-se utilizar 0,4 g de pó de PAni desdopada em $25 \mathrm{~mL}$ de DMAc $(16 \mathrm{mg} / \mathrm{mL})$. A solução é preparada sob agitação e o frasco é selado e deixado ainda sob agitação por mais 24 horas. Passado esse tempo, a solução deve ser filtrada (filtração a vácuo) para a remoção de particulados não solubilizados.

Essa solução foi armazenada e utilizada conforme a demanda. Três mililitros desta são adicionados utilizando uma pipeta, a $26 \mathrm{~mL}$ de solução aquosa (de $\mathrm{HCl}$ ) com pH entre 2,5 e 3 . A adição deve ser lenta, sob agitação e deve-se observar se não há formação de precipitados. Após a adição, adiciona-se mais $29 \mathrm{~mL}$ dessa solução.

A solução de PVS (polímero utilizado como poliânion) é preparada pesando $0,4 \mathrm{~g}$ de PVS e adicionando $100 \mathrm{~mL}$ de água com $\mathrm{pH}$ igual ao utilizado na preparação da solução de PAni. 


\subsubsection{Spin Coating}

Os filmes de POMA foram obtidos em uma centrifugadora da Specialty Coating Systems, inc, modelo P6204. Tomou-se o cuidado de se depositar as amostras no mesmo dia em que as soluções foram feitas, para evitar a mudança da concentração da solução devido à volatilidade do solvente utilizado (clorofórmio).

Os parâmetros variados encontram-se na tabela 3-1.

Tabela 3-1 - Parâmetros de deposição por spin coating utilizados. a) variação da concentração b) variação do tempo.

\begin{tabular}{|c|c|c|}
\hline \multicolumn{3}{|c|}{ Variação da Concentração } \\
\hline $\begin{array}{l}\text { Velocidade de } \\
\text { rotação (rpm) }\end{array}$ & $\begin{array}{c}\text { Concentração da } \\
\text { solução (mg/ml) }\end{array}$ & $\begin{array}{c}\text { Tempo de } \\
\text { rotação (s) }\end{array}$ \\
\hline 500 & $* 0$ & 30 \\
1000 & 5 & \\
2000 & 10 & \\
3000 & 20 & \\
4000 & 25 & \\
5000 & & \\
6000 & & \\
\hline
\end{tabular}

\begin{tabular}{|c|c|c|}
\hline \multicolumn{3}{|c|}{ Variação do Tempo } \\
\hline $\begin{array}{c}\text { Velocidade de } \\
\text { rotação (rpm) }\end{array}$ & $\begin{array}{c}\text { Concentração da } \\
\text { solução (mg/ml) }\end{array}$ & $\begin{array}{c}\text { Tempo de } \\
\text { rotação (s) }\end{array}$ \\
\hline \multirow{2}{*}{500} & 20 & 2 \\
3000 & & 5 \\
6000 & & 10 \\
& & 20 \\
& & 30 \\
& & 60 \\
\hline
\end{tabular}

Para aumentar o número de dados experimentais no treinamento das redes e a fim de melhorar a extrapolação da concentração para valores menores do que 5 $\mathrm{mg} / \mathrm{mL}$ acrescentaram-se 7 valores de rotação com concentração igual a 0 e espessura final também igual a 0 .

A aceleração da centrifugadora foi ajustada no valor máximo para evitar a influência desse parâmetro no processo.

\subsubsection{Automontagem}

Utilizando as soluções preparadas como descrito no item 2.1.2, preparou-se 4 béqueres como mostrado na Figura 3-3 a), onde a solução $A$ foi a de PAni, a solução $B$ a de PVS e as soluções de limpeza, água ultra pura com pH igual a das soluções $A$ e $B$ (pH: 2,7). Após cada mergulho, os substratos com os filmes foram encostados em papel toalha para escorrer o excesso de líquido presente sobre eles (Figura 3-3 b). 

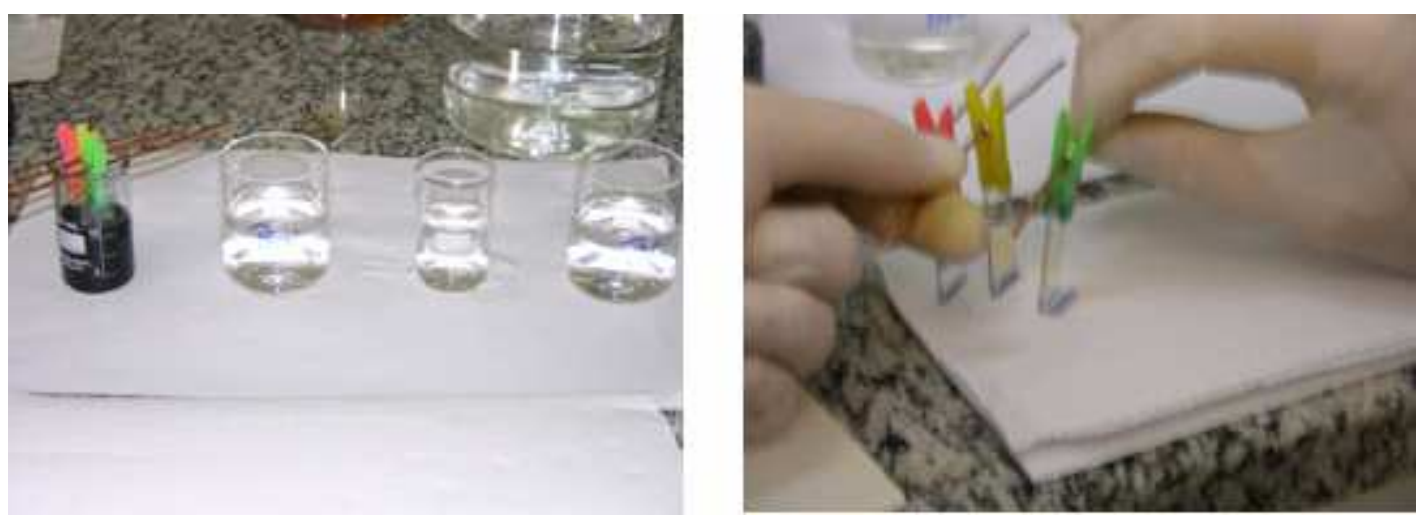

Figura 3-3 - a) soluções utilizadas na deposição por SA com amostras mergulhadas na primeira solução b) secagem das amostras utilizando papel toalha.

Após os filmes serem obtidos, eles foram armazenados dentro de placas de Petri em local escuro. Devido ao meio de preparo ser ácido, os filmes automontados encontravam-se dopados (cor esverdeada) como é mostrado na Figura 3-4 a).
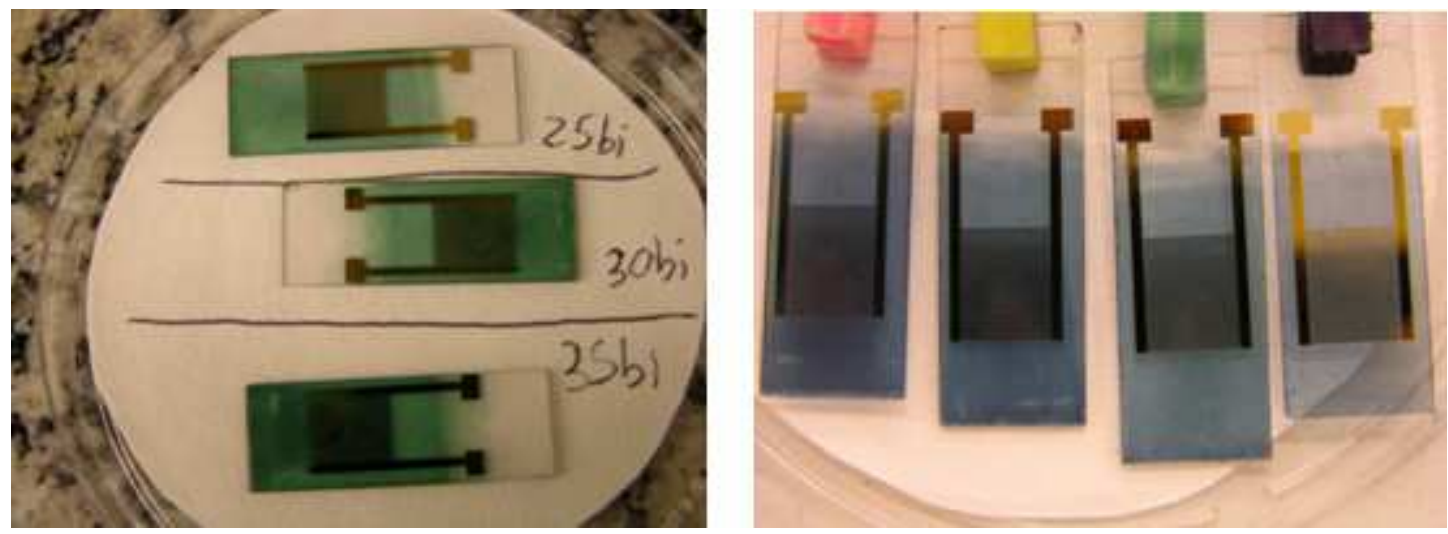

Figura 3-4 - a) filmes após serem depositados (dopados) b) filmes desdopados com solução de $\mathrm{NH}_{4} \mathrm{OH} 0,1 \mathrm{~N}$.

Os filmes finos de Pani/PVS analisados nesse trabalho compreenderam duas séries diferentes. Um primeiro conjunto de filmes foi obtido sobre vidro utilizando um equipamento automatizado de deposição de filmes finos automontados, pertencente ao Grupo de Polímeros "Prof. Bernhard Gross" do IFSC-USP. O experimento foi conduzido e as amostras cedidas (série 1) pelo Dr. Valtencir Zucolotto. Nesses filmes, variou-se o número de bicamadas de 3 até 80 (Tabela 3-2). 
Tabela 3-2 - Amostras obtidas por automontagem.

\begin{tabular}{lllllllllllll} 
Nome da série & Local & Obtenção & \multicolumn{1}{l}{ Número de bicamadas } \\
\hline série 1 (x) & GP IFSC USP & Automatizada & 3 & 5 & 10 & 15 & 20 & 40 & 60 & 80 & - & - \\
série 2 (jp) & POLI USP & Manual & 1 & 2 & 3 & 5 & 7 & 10 & 15 & 25 & 30 & 35
\end{tabular}

O segundo conjunto de amostras foi depositado no nosso laboratório, utilizando substratos de $1,00 \mathrm{~cm}$ x 2,54 cm com eletrodos interdigitados. A máscara usada para a fabricação dos eletrodos possuía espaçamento de $100 \mu \mathrm{m}$ e largura de trilha de $100 \mu \mathrm{m}$.

Os tempos de mergulho foram de 2 min em PAni e 4 min em PVS (pHs: 2,7). Os tempos de lavagem não foram controlados, pois só servem para remover parte da solução sobre os filmes e algum material não adsorvido completamente.

Tomou-se o cuidado de trocar as soluções de limpeza a cada 5 bicamadas, para evitar contaminação cruzada de soluções.

Com os filmes já depositados e armazenados, prepararam-se soluções ácidas e básicas para averiguar os efeitos da dopagem sobre a condutividade e sobre o espectro de absorção.

Os pHs utilizados foram de $10\left(\mathrm{NH}_{4} \mathrm{OH}\right), 5(\mathrm{HCl}), 4(\mathrm{HCl}), 3(\mathrm{HCl}), 2(\mathrm{HCl})$ e $1(\mathrm{HCl})$.

Os filmes foram mergulhados por 10 minutos em solução básica, retirados e secos por $30 \mathrm{~min}$.

Para a análise da condutância em função do tempo de mergulho, utilizou-se pH: 3 e tempo de $10 \mathrm{~s}$ entre cada medida.

Para a análise da influência de concentração sobre o espectro de absorção, deixou-se mergulhado os filmes por 30 segundos nas soluções com diferentes pHs, mencionados acima.

\subsection{Caracterização dos filmes}

Dentre as diferentes caracterizações que são comumente realizadas foram escolhidas técnicas de caracterização morfológica, óptica e elétrica. A seguir as técnicas utilizadas nesse trabalho serão brevemente descritas. 


\subsubsection{Perfilometria}

Talvez a técnica de caracterização mais comum relacionada à análise de filmes finos seja a perfilometria. Como o nome sugere, essa técnica consiste em se levantar o perfil de um determinado filme a partir de uma ponta de prova que varre a amostra em uma única direção (Figura 3-5).
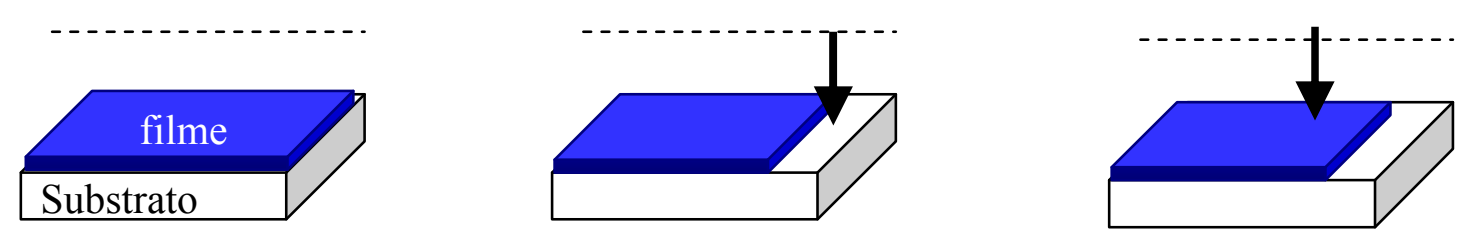

Figura 3-5 - Varredura de uma amostra por perfilometria a) filme e substrato b) filme decapado com um degrau e ponta de prova iniciando a varredura c) ponta de prova varrendo a amostra.

Devido a sua facilidade e simplicidade, é amplamente utilizada para se obter a espessura de filmes finos. Nesse caso é necessário que haja uma parte do substrato sem o filme. Em alguns processos, costuma-se cobrir uma região para que não haja a deposição do filme sobre o substrato. No caso da deposição de polímeros por spin coating ou automontagem é mais fácil e comum criar o degrau após a deposição do filme, removendo o polímero com um solvente adequado e/ou por abrasão. Nesse trabalho foi utilizado um perfilômetro Alfa Step 500 de fabricação da Tencor Instruments, do Laboratório de Microeletrônica da USP (LME).

Devido à natureza morfológica dos filmes produzidos, mais de uma medida de espessura para cada amostra foi obtida. Para os filmes de POMA, cinco medidas de espessura em pontos diferentes da mesma amostra foram realizadas e 3 amostras com a mesma condição de deposição foram preparadas a fim de se constatar a variação tanto de medida quanto do filme. Nos filmes de PAni/PVS foram realizadas 3 medidas em cada amostra.

\subsubsection{Microscopia de Força Atômica (AFM)}

A microscopia de força atômica (AFM) é uma técnica de análise morfológica muito utilizada em nanociência para se estudar diversas propriedades físicas superficiais. Ao lado do AFM encontra-se a microscopia de tunelamento (STM), outra ferramenta poderosa para explorar essas dimensões. 
O microscópio de força atômica utiliza uma ponta de prova, a qual entra em contato próximo com a superfície da amostra de estudo, gerando uma atração (ou repulsão) que faz com que um laser incidente sobre uma alavanca que apóia a ponta, seja defletido. Através da deflexão do feixe, um sinal elétrico é gerado, fazendo com que seja possível detectar a variação do feixe conforme se movimenta sobre a superfície da amostra. A amostra é fixada sobre uma peça chamada de scanner. Esse scanner é o responsável pelo movimento nos eixos x e y levantando assim o perfil da superfície do filme. O AFM apresenta uma resolução horizontal da ordem de unidades de nanômetro. Já sua resolução vertical é um pouco mais limitada, sendo da ordem de nanômetros. Nesse trabalho essa técnica foi utilizada para se estudar a rugosidade dos filmes depositados por spin coating. Utilizou-se um AFM Nanoscope III-A da Digital Instruments, pertencente ao LSI-USP. Mais informações são encontradas nas imagens.

\subsubsection{Condutância elétrica}

As medidas de condutância elétrica para os sensores de $\mathrm{HCl}$ foram realizadas utilizando eletrodos de ouro obtidos por sputtering através da obtenção de uma curva de corrente em função da tensão aplicada (VxI). Utilizou-se o analisador modelo 4145 da Hewlett-Packard para variar a tensão de 0 a 3 V (Figura 3-6). A medida da corrente em $2 \mathrm{~V}$ foi obtida e a resistência elétrica foi calculada pela lei de Ohm:

$$
\mathrm{R}=\mathrm{V} / \mathrm{I}
$$

A condutância elétrica é o inverso da resistência.
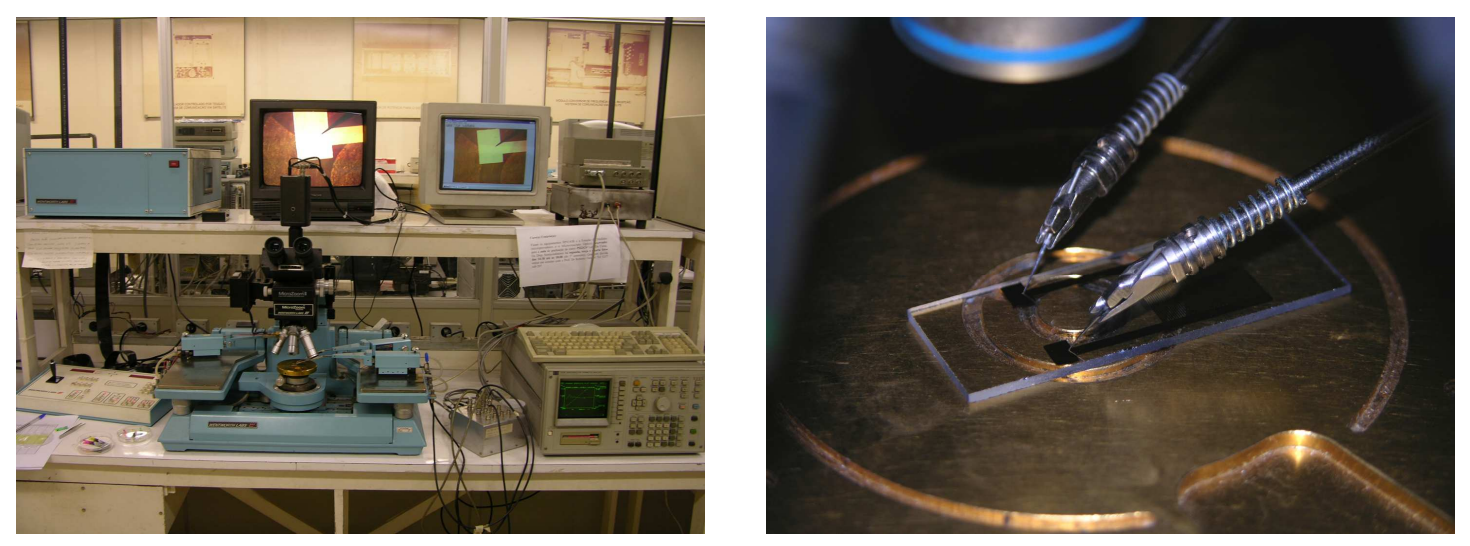

Figura 3-6 - a) estação de trabalho para medidas elétricas (LME-USP) b) pontas de prova conectadas aos terminais de um sensor de $\mathrm{HCl}$. 
Essas medidas foram realizadas apenas para a série 2, onde os filmes automontados foram depositados sobre vidros com eletrodos.

\subsubsection{Espectrometria $U V-V$ is}

Essa técnica de análise foi utilizada a fim de se averiguar os efeitos da dopagem de filmes finos automontados de PAni/PVS. Sabe-se que a dopagem influencia o espectro, deslocando os picos de absorção máxima ${ }^{39}$. A espectrometria UV-Vis está relacionada à absorção dos comprimentos de onda que compõem a região de ultravioleta (UV) e a região do visível (Vis). O princípio de medição é bastante simples $^{91}$. Uma fonte de luz é filtrada por um seletor de comprimento de onda. Esse seletor pode ser um filtro ou um monocromador (Figura 3-7). Um feixe de luz de comprimento de onda selecionado é então obtido o qual atravessa a amostra. Uma parte da energia é absorvida pela amostra, outra parte é transmitida e a última parte é refletida. O fotodetector capta a energia que é transmitida. Conhecendo a energia incidente e a transmitida, obtém-se assim a quantidade de energia que foi absorvida pela amostra.

\section{Seletor}

de comprimento

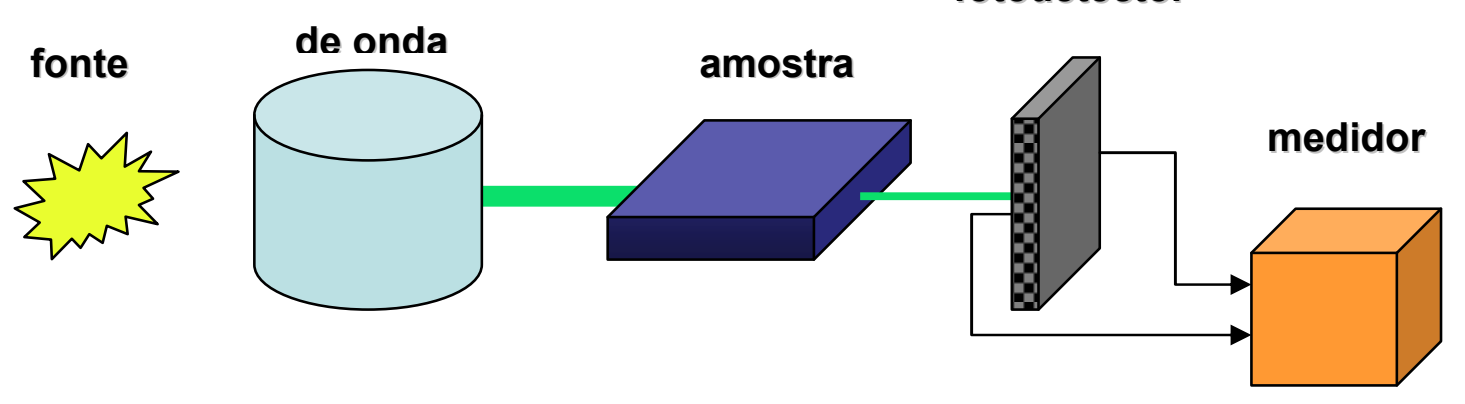

Figura 3-7 - Esquema de um espectrofotômetro UV-Vis simples.

Nesse trabalho foi utilizado um espectrofotômetro UV-Vis da marca Hitachi modelo U-2001 de propriedade do Grupo de Polímeros "Prof. Bernhard Gross" do Instituto de Física de São Carlos (USP).

Para se realizar as medidas, a linha de base foi obtida sem amostra (em ar). Variou-se o comprimento de onda de $1100 \mathrm{~nm}$ a $300 \mathrm{~nm}$ com passo de $5 \mathrm{~nm}$. Utilizou-se uma lâmina de vidro sem filme no porta-amostras de referência. 


\subsection{Redes Neurais Artificiais}

Para criar, treinar e simular as RNAs, foi utilizado o software MATLAB 6.1 da Mathworks e a ferramenta Neural Networks Toolbox. Essa ferramenta permite que uma série de tipos diferentes de RNAs seja criada e fornece um grau de liberdade relativamente grande para a alteração dos parâmetros dessas redes. Apesar de essa ferramenta permitir sua utilização via uma interface gráfica (Figura 3-8) optou-se por utilizar o acessório de programação do MATLAB, devido à sua maior robustez e facilidade na confecção de testes e análises semi-automáticas. A programação em MATLAB pode ser encontrada em livros ${ }^{92}$ ou no próprio software.

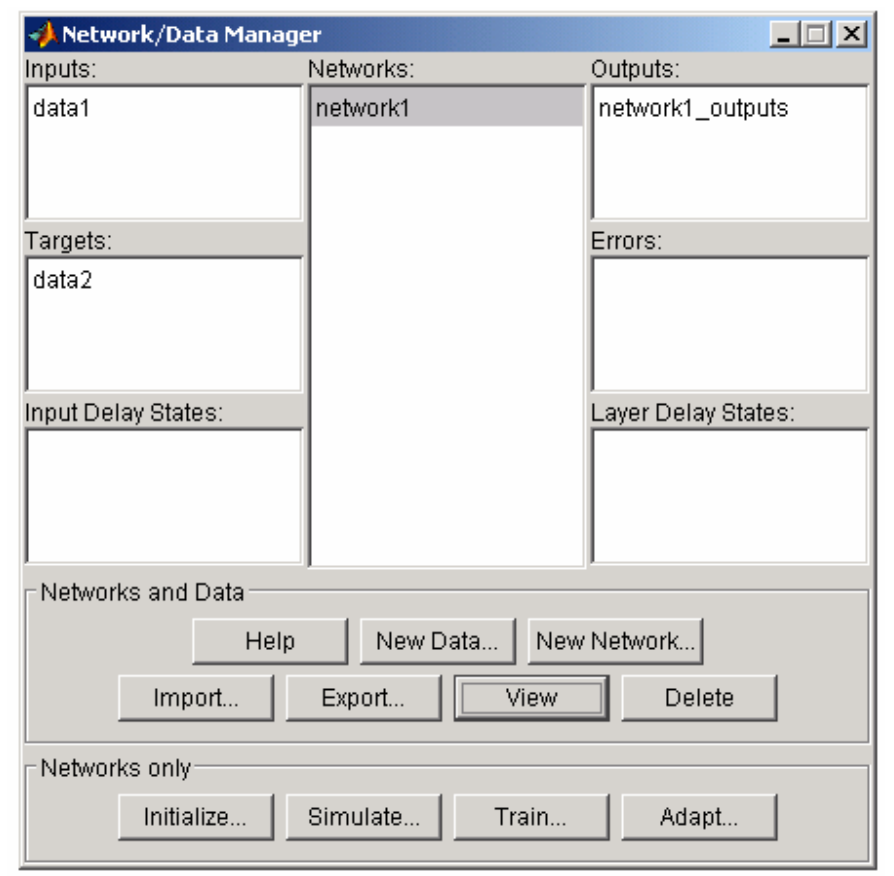

Figura 3-8 - Interface gráfica do Neural Networks Toolbox do MATLAB.

Nessa seção são descritos os parâmetros utilizados na elaboração das redes neurais. Os principais comandos utilizados no software MATLAB encontram-se no ANEXO I.

Para avaliar a generalização dos treinamentos, dividiu-se o conjunto de dados em um conjunto de treinamento e um de teste, sendo mostrado na tabela 3-3 o número de dados utilizado em cada uma das análises. 
Tabela 3-3 - Número de dados utilizados para treinamento e teste das RNAS.

\begin{tabular}{l|cc} 
& Spin Coating & Automontagem \\
\cline { 2 - 3 } Dados & 57 & $1.604(100 \%)$ \\
Treinamento & 50 & $1.283(80 \%)$ \\
Teste & 7 & $321(20 \%)$
\end{tabular}

Para o caso de automontagem, foram obtidos 16.037 pontos experimentais. Isso porque o passo do UV-Vis foi de $5 \mathrm{~nm}$. Para o treinamento e simulação foi diminuído o tamanho do conjunto de treinamento e teste utilizando apenas os dados com um passo de $50 \mathrm{~nm}$ (descartados os intermediários).

A fim de entender o comportamento do treinamento nos diferentes conjuntos, foi calculado um valor de erro médio para o conjunto de treinamento, um para o conjunto de teste e um outro para um conjunto total, segundo a expressão do MSE encontrada na Tabela 2-2.

Para o controle dos parâmetros as interfaces gráficas (Figura 3-9) foram construídas no próprio MATLAB.

Um algoritmo (Figura 3-10) foi gerado para testar diferentes configurações de redes analisando a reprodutibilidade e a influência dos parâmetros nos resultados finais de simulação.
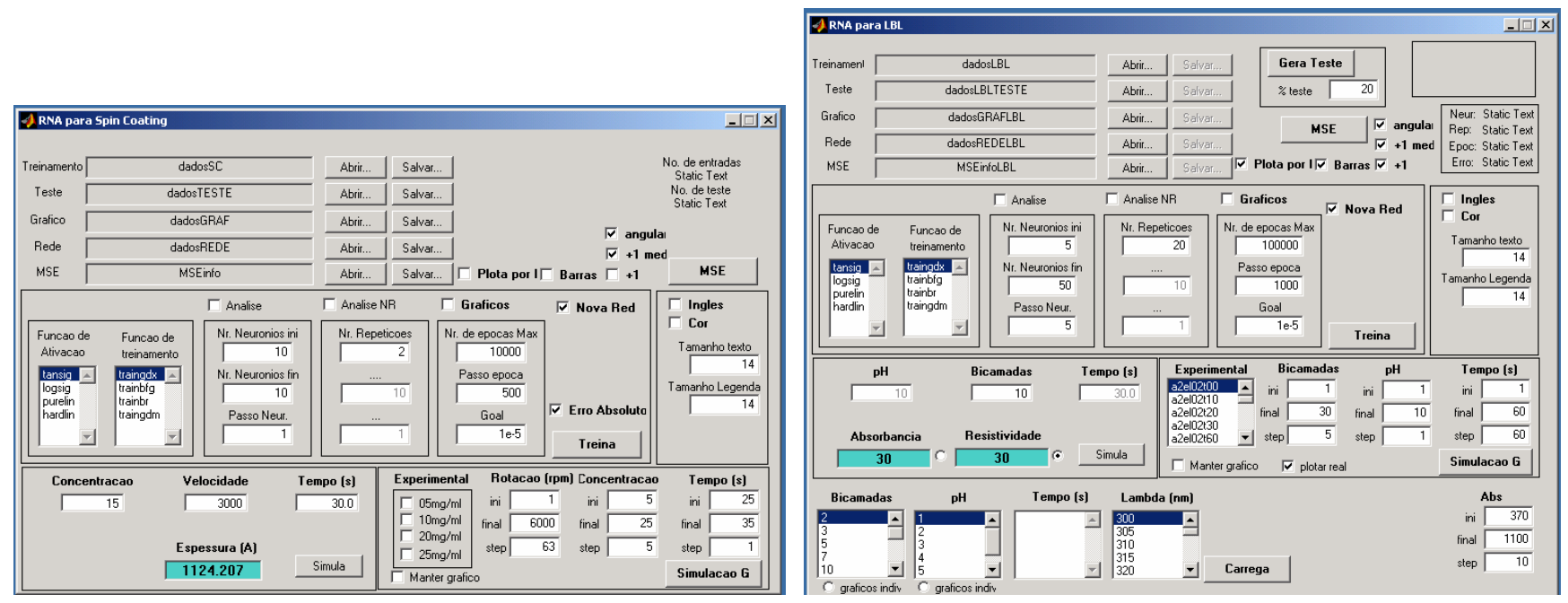

Figura 3-9 - Interfaces gráficas desenvolvidas para estudo de RNAs. 


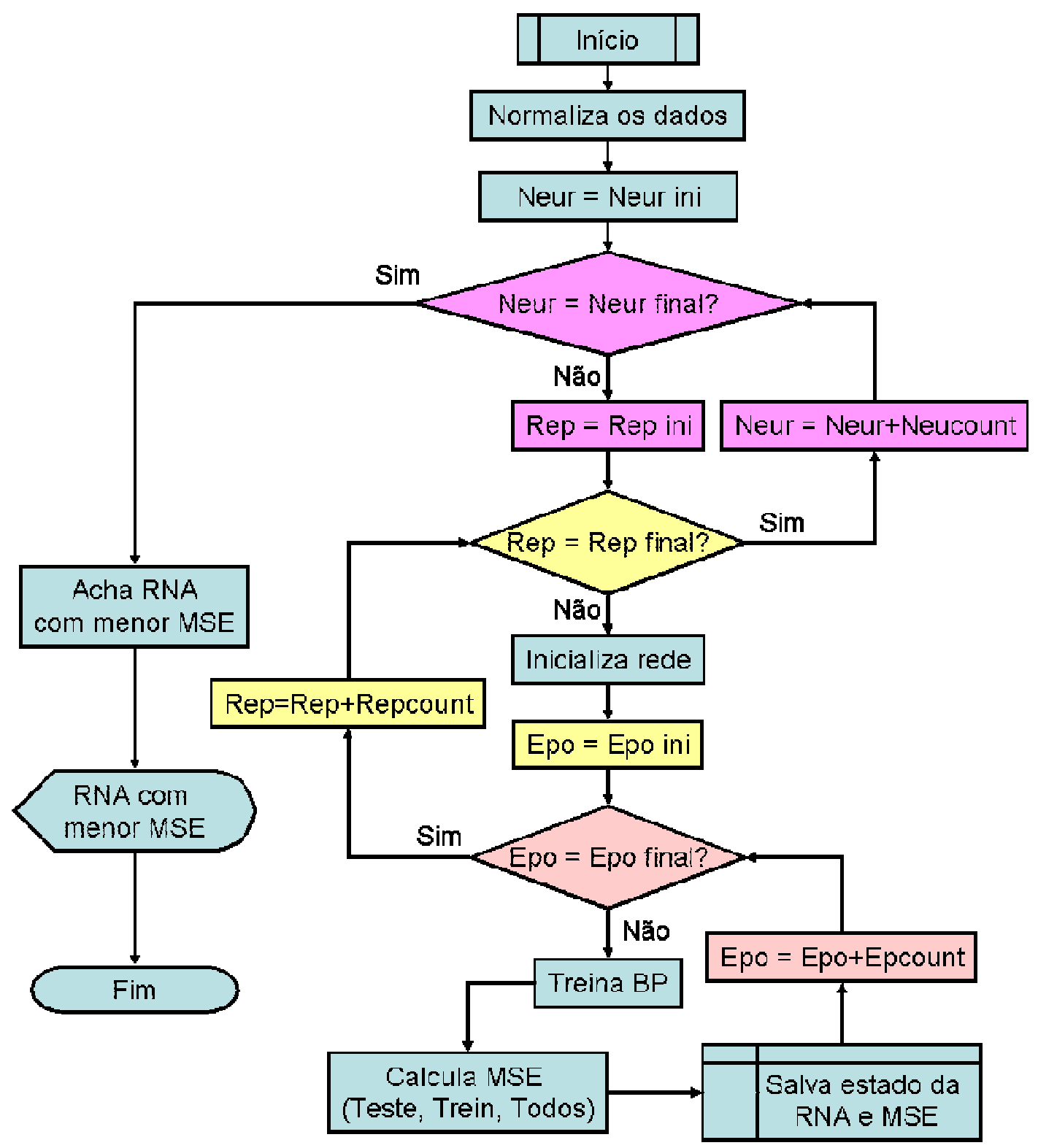

Figura 3-10 - Algoritmo utilizado para treinamento e análise do erro (neur=número de neurônios na camada intermediária; epo=número de épocas, rep= número da repetição (inicialização)).

O algoritmo consiste em se inicializar uma rede neural com um número de neurônios X, treiná-la Y épocas (a cada 1.000 épocas, por exemplo), calcular o erro e salvar o estado da rede em cada instante. Após ter treinado o número de épocas máximo, uma nova rede neural é inicializada com um outro número de neurônios na camada escondida. O procedimento é repetido. Ao fim, esse procedimento é repetido por $Z$ vezes (valor predefinido pelo usuário). Assim, repete-se $Z$ vezes, redes neurais que contenham $\mathrm{X}$ neurônios na camada escondida, por $\mathrm{Y}$ épocas e guardam-se todas as redes (em todos os estados). 
Por fim, o algoritmo encontra a rede que apresentou menor erro e indica para o usuário quem é ela. Associando com a figura 1-14, podemos perceber que o que esse algoritmo faz é gerar diferentes redes iniciais (círculos verdes) com o mesmo número de neurônios, treiná-las por Y épocas salvando cada valor (deslocamento dos círculos) e ao final apresenta qual se aproximou mais do conjunto de treinamento e do conjunto de teste. A normalização dos dados no inicio do algoritmo transforma cada conjunto de dados em valores no intervalo de -1 a 1 . 


\section{RESULTADOS}

As características dos filmes finos poliméricos obtidos por diferentes técnicas de deposição são afetadas pelos parâmetros do processo. Um primeiro resultado esperado foi identificar a importância dos diferentes parâmetros em relação às características finais dos filmes. Foi proposta a utilização de redes neurais artificiais para simular condições de deposição e validar os resultados com experimentos, obtendo a menor diferença possível entre os dois resultados (experimental e simulado).

Nessa seção são descritos os resultados experimentais obtidos, a análise das redes neurais e seus diferentes parâmetros e os melhores resultados conseguidos através da simulação.

\subsection{Filmes finos de POMA obtidos por spin coating}

A Figura 4-1 mostra os dados experimentais coletados para uma primeira série de experimentos de deposição de POMA pelo método de spin coating. Foram utilizadas diversas concentrações de POMA (Tabela 3-1), mantendo o tempo de rotação constante em 30 segundos.

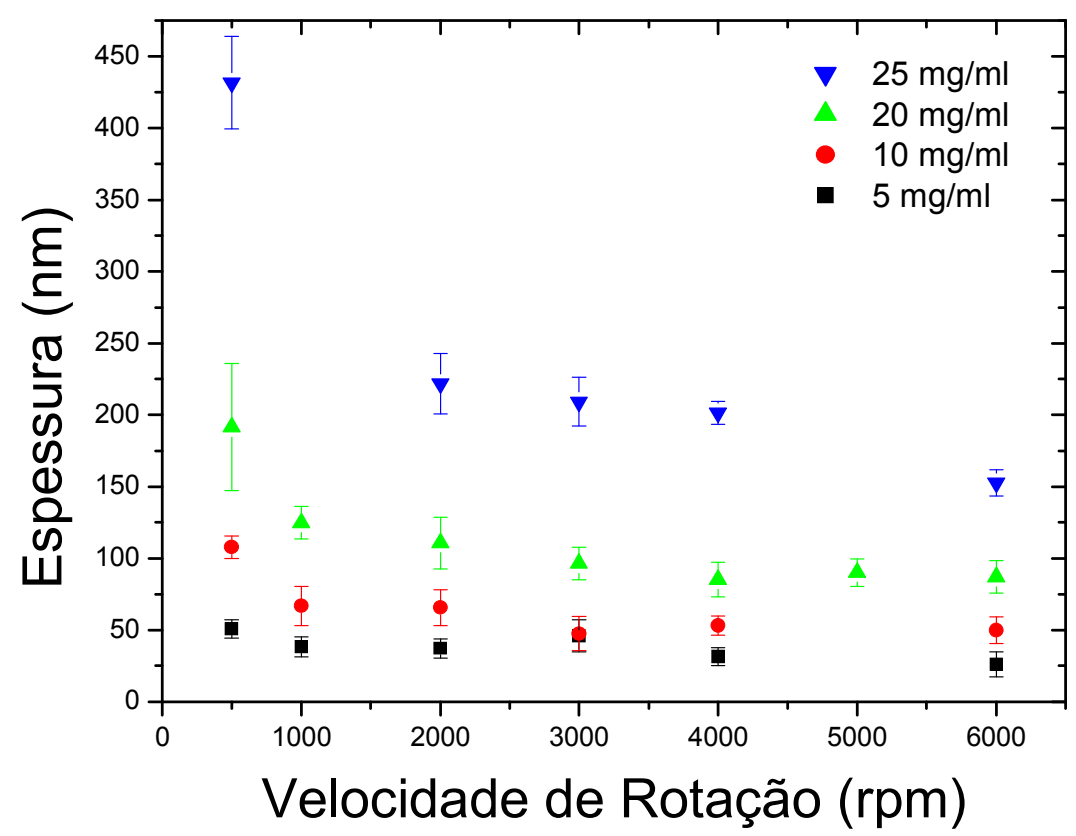

Figura 4-1-Espessura final em função da velocidade de rotação para diferentes concentrações com tempo de rotação igual a 30 segundos. 
Ao se observar o comportamento da espessura, constata-se que quanto maior a velocidade de rotação menor é a espessura final do filme. O fenômeno inverso acontece quando observamos a variação da espessura em função da concentração da solução. Uma concentração maior ocasiona uma espessura também maior, mantidos os outros parâmetros constantes. Esse comportamento é esperado de acordo com o trabalho de SUKANEK ${ }^{55}$ e com o modelo proposto por LAWRENCE ${ }^{54}$.

Apenas para servir de comparação com outros trabalhos de spin coating em polímeros condutores, traçou-se o gráfico log-log e obteve-se a aproximação linear dos dados. Assim, o coeficiente angular foi calculado e está mostrado na Figura 4-2.

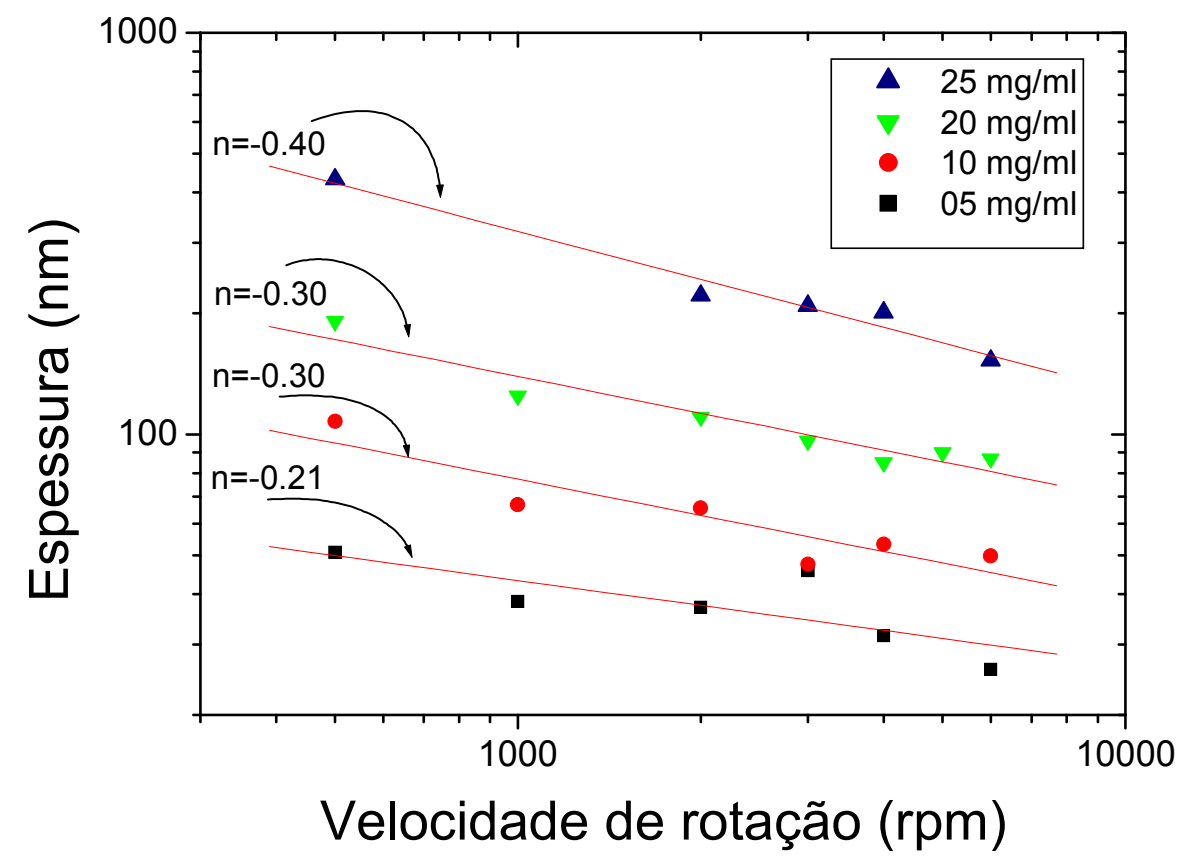

Figura 4-2 - Traçado log-log da espessura em função da velocidade de rotação para diferentes concentrações. Aproximações lineares e coeficiente angular (n).

$\mathrm{CHANG}^{60}$ e seus colaboradores encontraram para o MEH-PPV um coeficiente $n$ que não dependia da concentração. Porém, podemos observar que para o caso da POMA, o coeficiente variou de $-0,21(5 \mathrm{mg} / \mathrm{mL})$ até $-0,40(25 \mathrm{mg} / \mathrm{mL})$. Esses valores são menores do que o encontrado para polímeros como os fotoresistes de DAMON $^{52}(-0,5)$ e as poliimidas $(-0,4$ a $-1,3)$ de SUKANEK $^{55}$ mas são parecidos com o dos polímeros conjugados obtidos por CHANG $(-0,37$ a $-0,49)$ e $\mathrm{CHO}^{93}$ ($0,34)$.

Em seguida, uma segunda série de amostras foi obtida, variando-se o tempo de rotação de 2 a 60 segundos. Os resultados são mostrados na Figura 4-3. 
Para esse conjunto de dados, o tempo de rotação não é um parâmetro importante para a espessura. De acordo com SUKANEK ${ }^{59}$, o tempo de rotação só é importante até um determinado instante. É esperado que para pequenos valores de tempo (i.e. próximo a zero) o processo de spin coating se assemelhe a uma deposição por casting, mas no caso aqui apresentado o tempo não parece ter efeito significativo sobre a espessura.

Para o caso de POMA diluída em clorofórmio na concentração de $20 \mathrm{mg} / \mathrm{mL}$, o tempo para que o regime (estado estacionário onde as variações são desprezíveis) seja obtido deve ser inferior a 2 segundos. É importante perceber que para as amostras obtidas com $500 \mathrm{rpm}$ e entre dois e cinco segundos, a solução não foi completamente espalhada nas bordas dos substratos. Para todos os casos, a espessura foi obtida em cinco pontos diferentes, próximos ao centro do filme onde havia uniformidade visual.

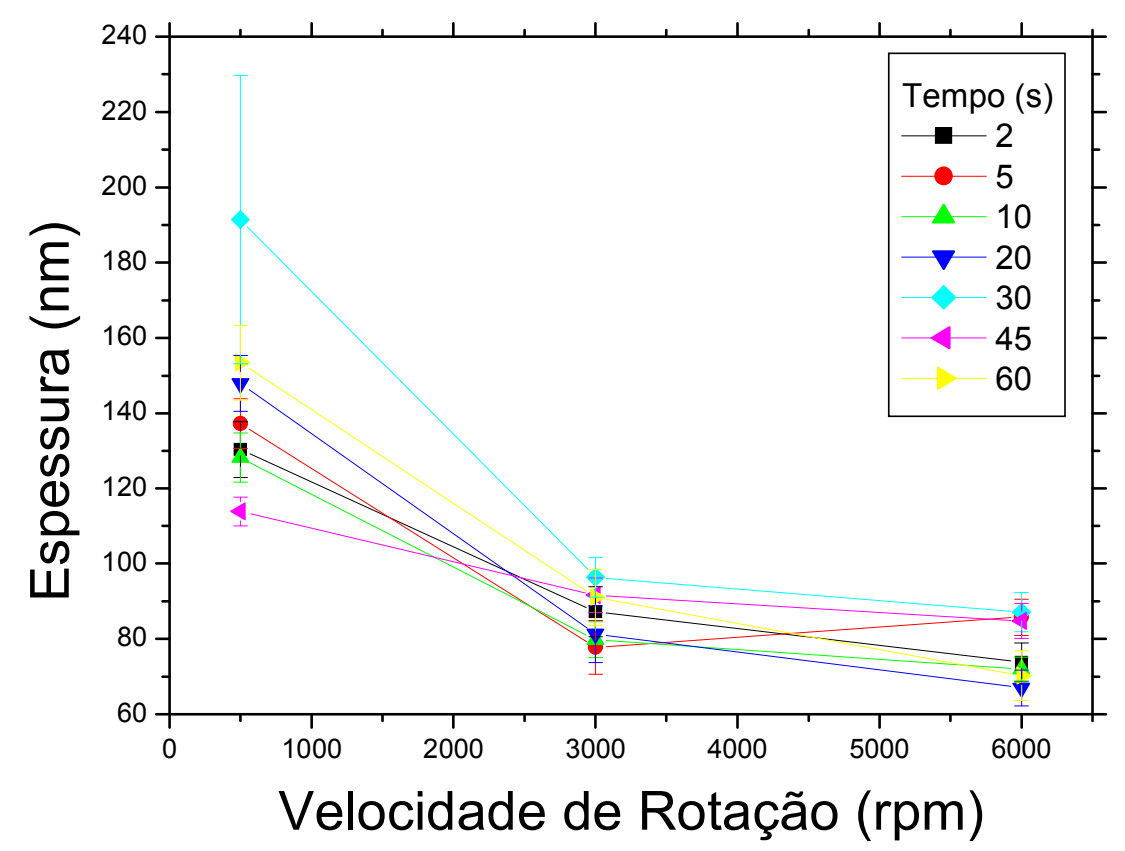

Figura 4-3 - Espessura em função da velocidade de rotação para diferentes tempos de rotação com concentração de $20 \mathrm{mg} / \mathrm{mL}$.

Para aprofundar o estudo morfológico dos filmes de POMA, foram obtidas as imagens de AFM para diferentes velocidades de rotação. Podemos observar que quanto maior é a velocidade de rotação, mais homogêneo é o filme, diminuindo a rugosidade superficial (Figura 4-4). Tal resultado é contrário àquele obtido por MELLO e seus colaboradores ${ }^{61}$, onde após analisar apenas duas velocidades de 
rotação constataram que quanto maior a velocidade maior é a rugosidade final do filme.
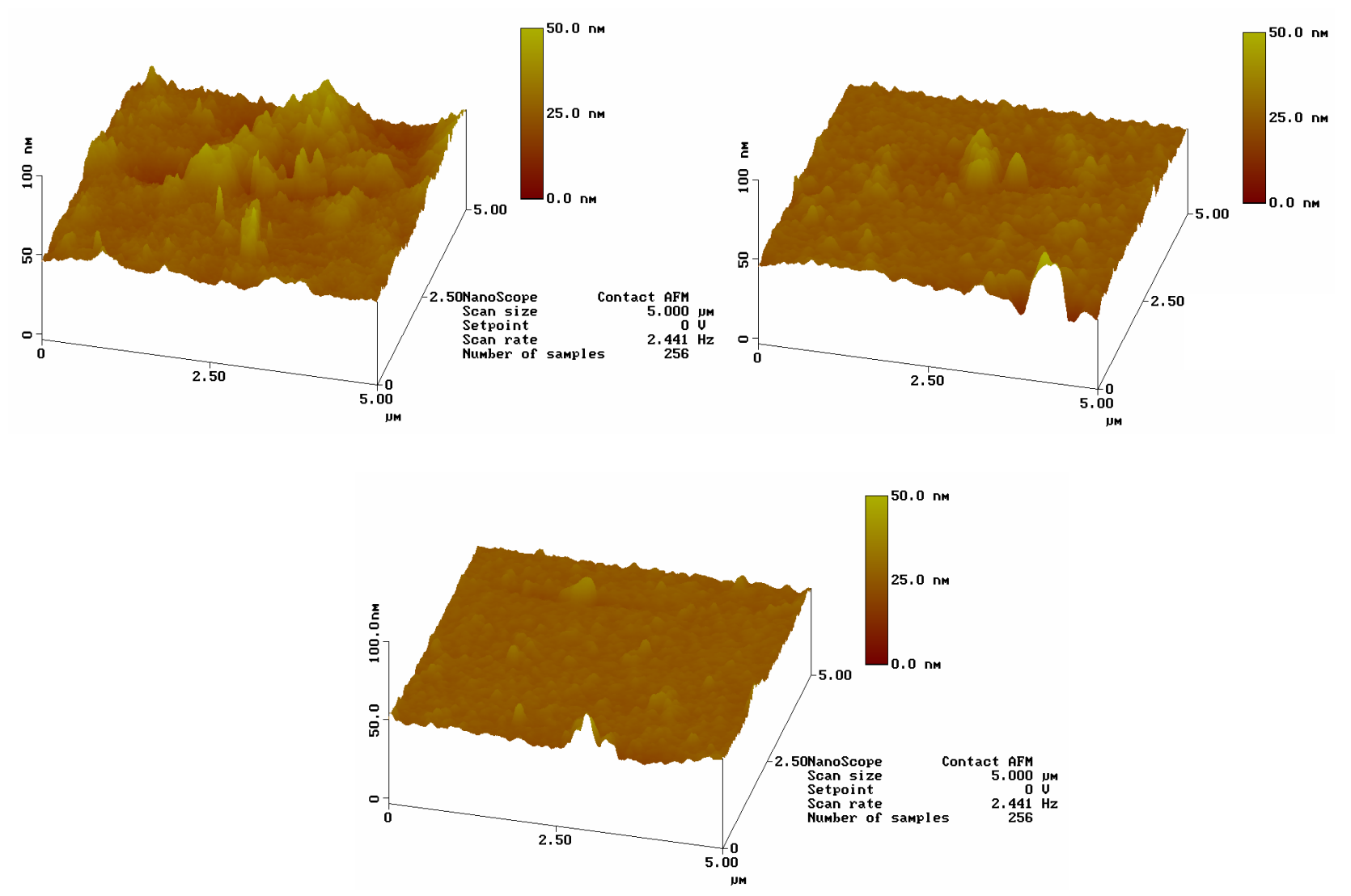

Figura 4-4 - Imagens de AFM da superficie de filmes de POMA obtidos com velocidades de rotação de: a) $500 \mathrm{rpm}$ b) $3.000 \mathrm{rpm}$ c) $6.000 \mathrm{rpm}$, (concentração de $10 \mathrm{mg} / \mathrm{mL}$, tempo de rotação $30 \mathrm{~s}$ ).

Devido a necessidade de uma quantidade de dados significativa, optou-se por treinar as RNAs apenas com os dados relativos ao estudo da espessura dos filmes.

\subsubsection{Reprodutibilidade}

O erro calculado para a espessura nas análises a seguir é dado em angstrons. Para que afirmemos que o treinamento foi ou não eficaz devemos comparar os valores encontrados com a média e o desvio padrão dos valores experimentais. Para os dados de espessura de spin coating temos que a média dos valores experimentais foi de $99 \mathrm{~nm}$, e o desvio padrão igual a $6 \mathrm{~nm}(60 \AA)$.

A primeira análise utilizando as RNAs foi a de reprodutibilidade de uma mesma rede (i.e. mesmo número de neurônios na camada intermediária) frente a diferentes inicializações. A Figura 4-5 apresenta o erro quadrático médio (MSE) em função do número de épocas, com 15 neurônios na camada intermediária, para 100 
diferentes inicializações, para os três conjuntos de dados (conjunto de treinamento, de teste e total).

a)

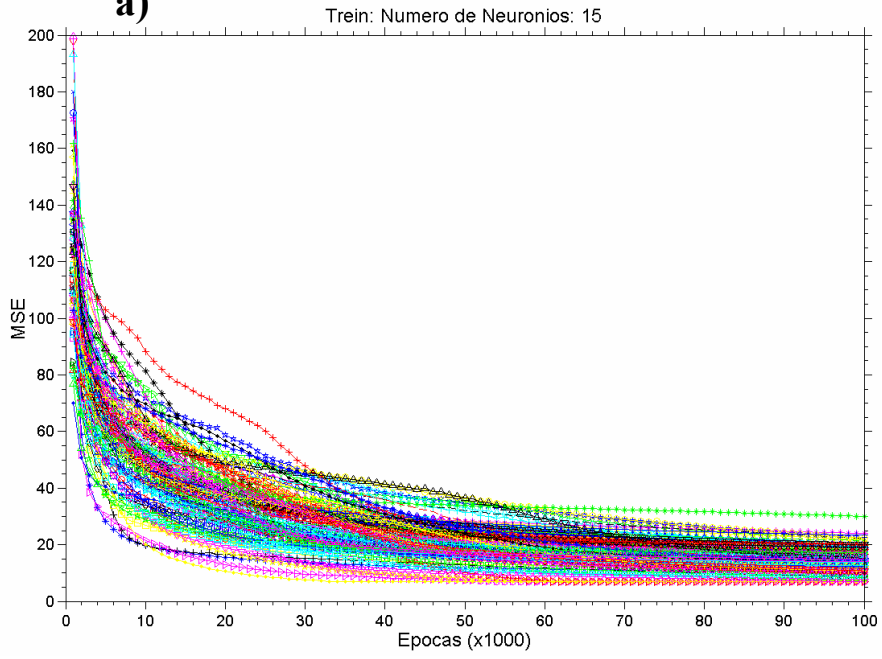

b)

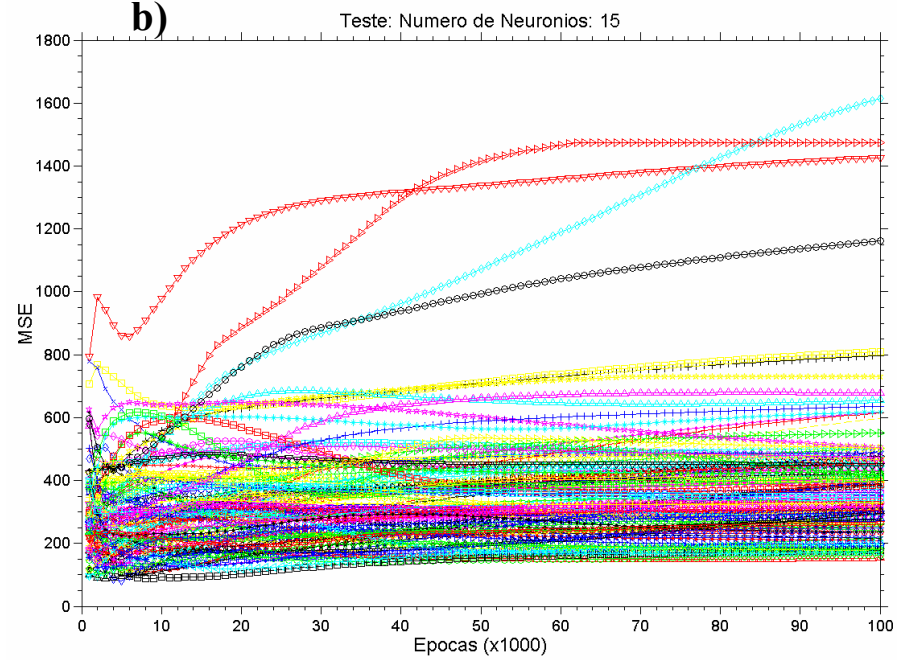

c)

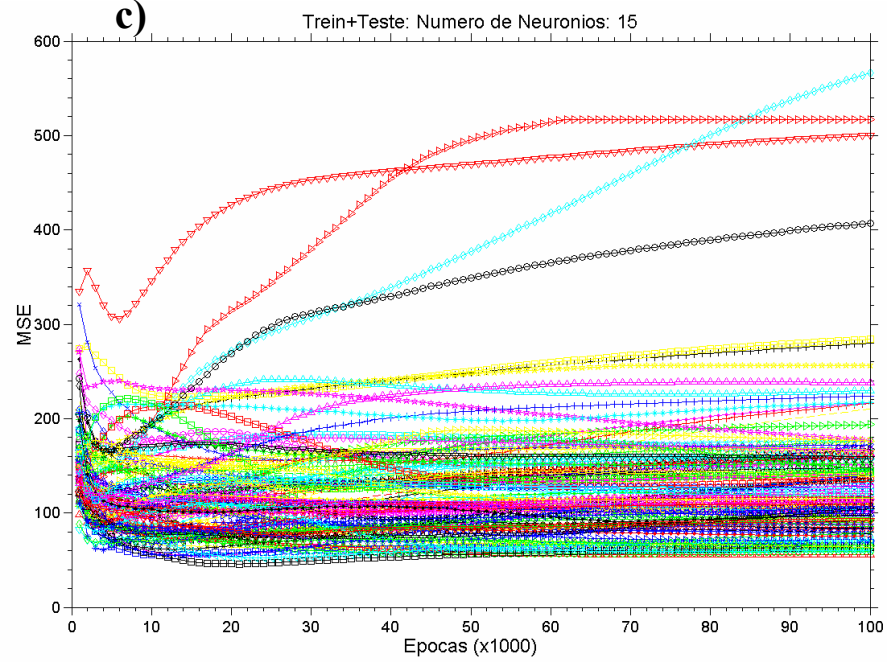

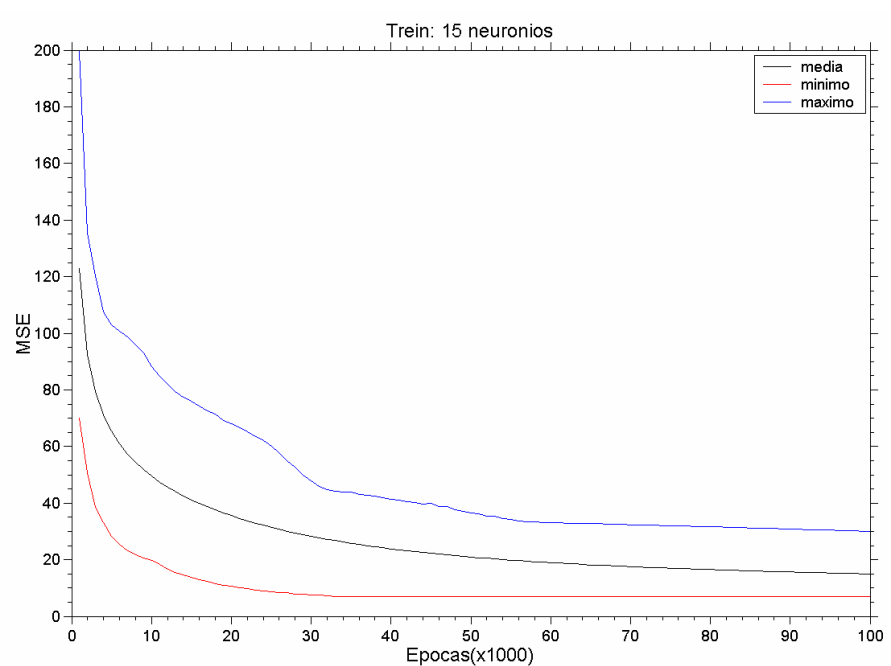
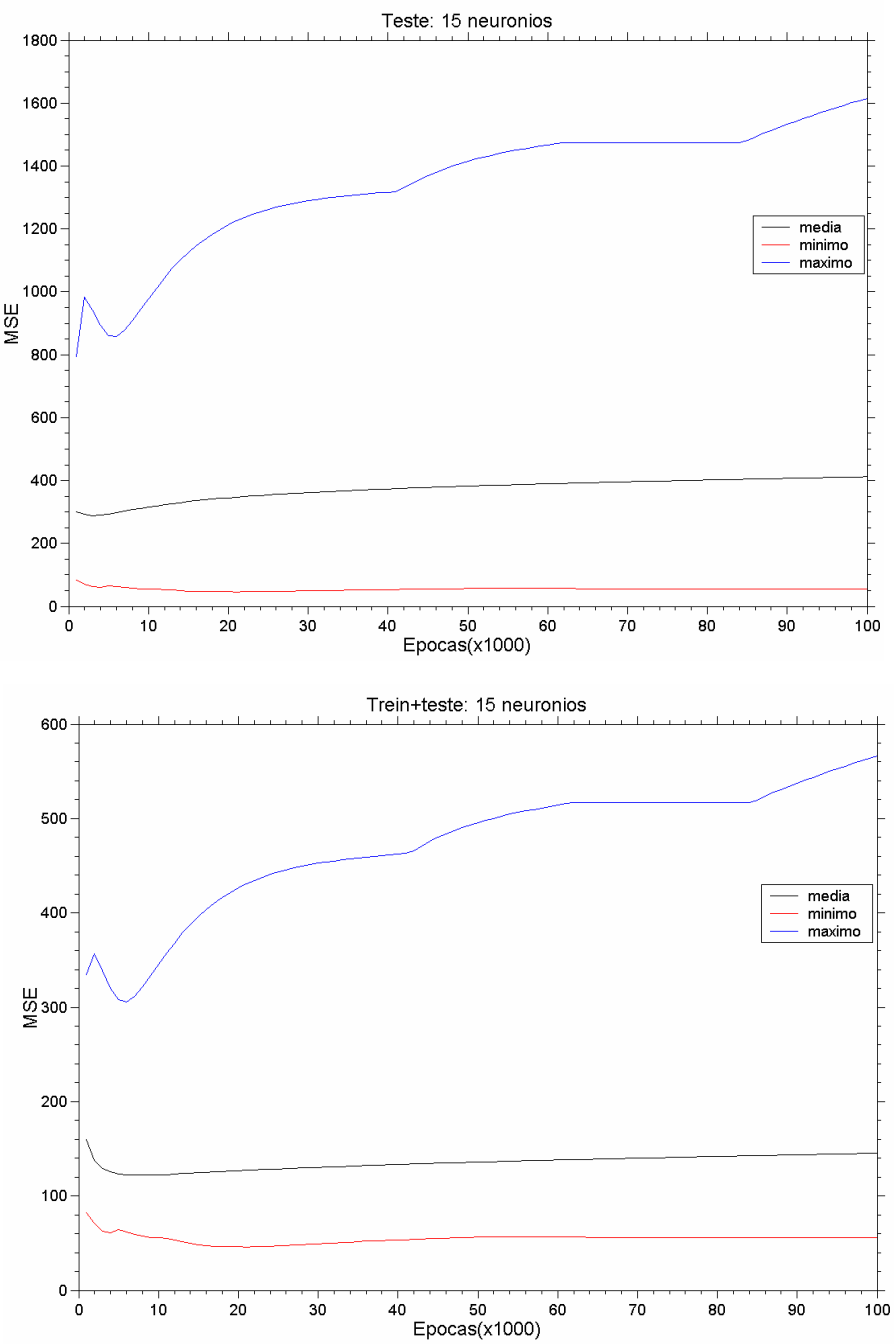

Figura 4-5 - Erro em função do número de épocas para diferentes inicializações. a) conjunto de treinamento b) conjunto de teste c) conjunto total. 
Os gráficos do lado esquerdo mostram todas as 100 diferentes inicializações enquanto que no lado direito, são mostrados apenas a média, os valores máximos e os mínimos dos erros obtidos. Pode-se notar que conforme se treina (aumento do número de épocas) o erro cai para todas as inicializações no conjunto de treinamento. Tal fato deve necessariamente ocorrer se o algoritmo de treinamento for adequado. Caso alguma inicialização não tivesse convergido para um ponto de mínimo, então o algoritmo de treinamento estaria errado.

Por outro lado, quando o erro é observado no conjunto de teste e no conjunto total, notamos que diversas curvas não convergem para um mínimo. Esse resultado não invalida o processo de treinamento na medida em que a rede neural não foi treinada com os valores de teste (Figura 2-16). Mas, se queremos construir um ambiente simulador, que consiga interpolar e extrapolar os resultados de treinamento, então tal efeito sobre o erro é nocivo ao resultado final.

Dessa maneira, apesar de diferentes inicializações não afetar o erro relativo ao conjunto de treinamento, ela afeta o conjunto de teste e conseqüentemente o conjunto total. Assim, algumas medidas devem ser tomadas para se evitar um simulador insatisfatório.

Para se resolver esse problema pode-se, por exemplo, modificar o algoritmo de treinamento e de análise do erro para parar de treinar a rede quando o erro do conjunto de teste começa a se elevar ${ }^{79}$. Outra maneira de reduzir esse problema, e talvez mais eficaz, é utilizar um conjunto maior de dados (de treinamento) já que, observou-se que a rede sempre minimiza o erro sobre esse conjunto.

Sobre o efeito do número de épocas no MSE, observamos que nas curvas da média (gráficos do lado direito na Figura 4-5), mais épocas de treinamento (>10.000) não melhoram o erro sobre o conjunto de teste. Após 20.000 épocas a taxa de aprendizado torna-se pequena para o conjunto de treinamento (inclinação da curva).

De uma forma geral, o algoritmo utilizado não assegura um controle de reprodutibilidade no conjunto de teste (e conseqüentemente no conjunto total). Mesmo assim, a minimização do erro e o aprendizado do conjunto de treinamento permitem que todas as redes treinadas assumam uma forma parecida com aquela encontrada experimentalmente, resultado esse que será apresentado mais adiante. 


\subsubsection{Número de neurônios na camada intermediária}

Para uma boa representação de funções, é necessário utilizar um número adequado de neurônios na camada escondida. Um número muito grande de neurônios tende a representar muito bem os pontos do treinamento, mas mostra uma resposta ruim nos pontos de interpolação. Já um número pequeno de neurônios apresenta um comportamento mais adequado na interpolação, porém pode ocasionar um erro médio quadrático alto em relação ao conjunto de treinamento.

O número de neurônios da camada intermediária foi variado de 1 até 40, sendo que para cada um deles, foram realizadas 30 inicializações diferentes. $\mathrm{O}$ erro mostrado aqui foi computado a cada 1.000 épocas até um total de 50.000 épocas. Esses valores foram escolhidos a fim de analisar uma faixa grande de parâmetros sem gastar tempo demais. Apenas como referência, o tempo de treinamento e análise para a obtenção desses resultados é por volta de $200 \mathrm{~h}$.
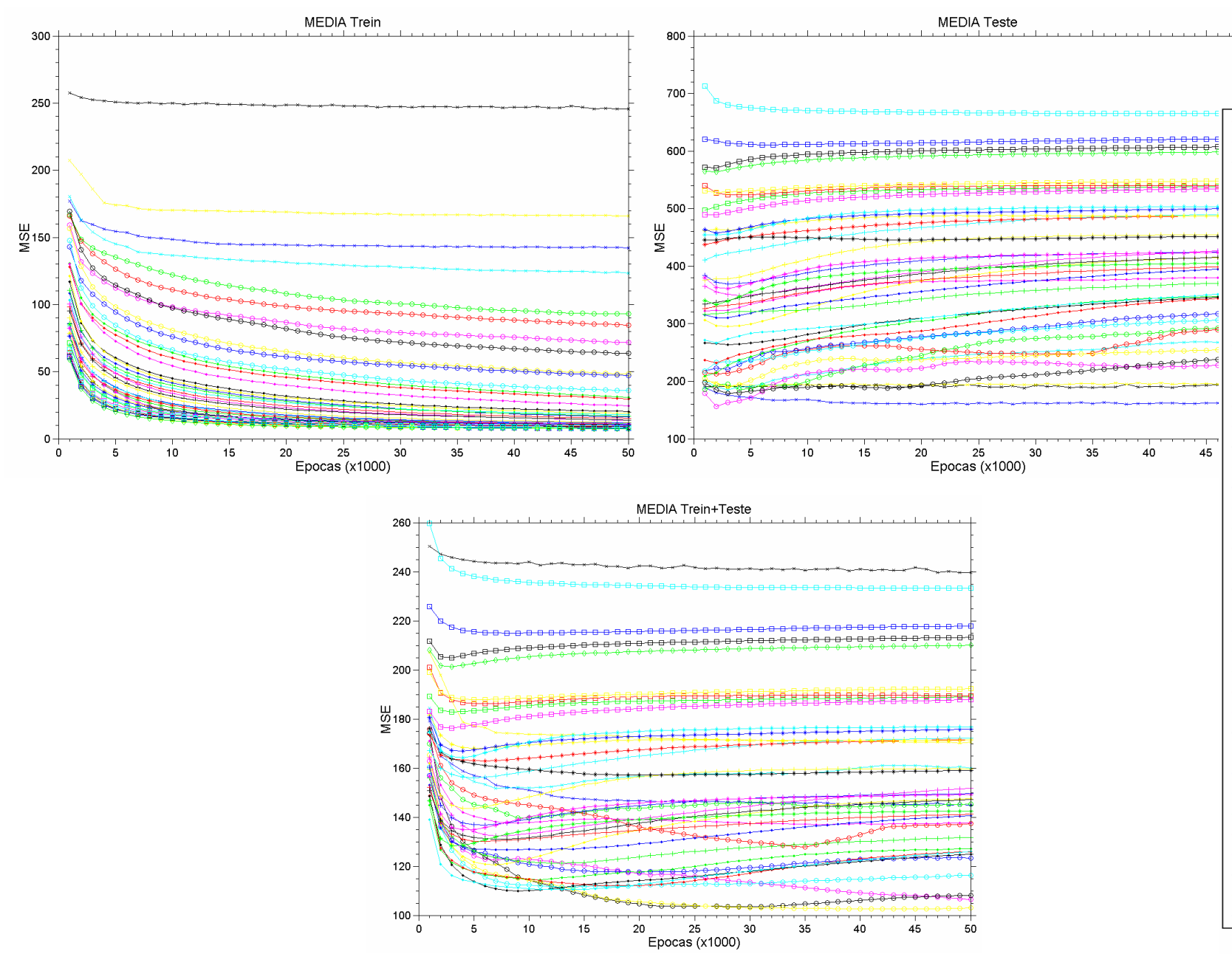

Figura 4-6 - Média do MSE de 30 inicializações em função do número de épocas para diferentes números de neurônios na camada intermediária $(1 \leq \mathrm{N} \leq 40)$. 
A Figura 4-6 mostra os resultados do MSE médio calculado a partir de 30 inicializações diferentes, em função do número de épocas.

Ao se observar os diferentes conjuntos de dados utilizados, é possível perceber que o erro calculado para o conjunto de treinamento, além de sempre convergir para um valor mínimo, é menor do que o encontrado para o conjunto de teste (pode-se perceber pela diferença na escala).

$\mathrm{O}$ erro apresentado na forma gráfica acima, torna difícil a análise devido à quantidade de dados sobrepostos. Para visualizar melhor a influência do número de neurônios na camada intermediária e o número de épocas sobre o erro, foram construídos os gráficos da Figura 4-7. Nessa figura é mostrado o MSE sobre o conjunto de treinamento, em função do número de neurônios para 1.000, $25.000 \mathrm{e}$ 50.000 épocas. Conforme é aumentado o número de neurônios e o número de épocas (gráficos 25.000 e 50.000), o MSE médio diminui. Do ponto de vista do erro sobre o conjunto de treinamento, podemos concluir que quanto maior o número de neurônios, menor é o erro encontrado. Na Figura 4-7, a barra vermelha horizontal mostra o limite para um erro igual a 60 (6,1\% em relação à espessura). Tal erro é igual ao desvio-padrão encontrado nos dados experimentais.

É interessante notar que o erro para um número de neurônios maior do que 25 parece estabilizar após 25.000 épocas enquanto que um numero de neurônios menor ainda apresenta uma queda significativa do erro. 

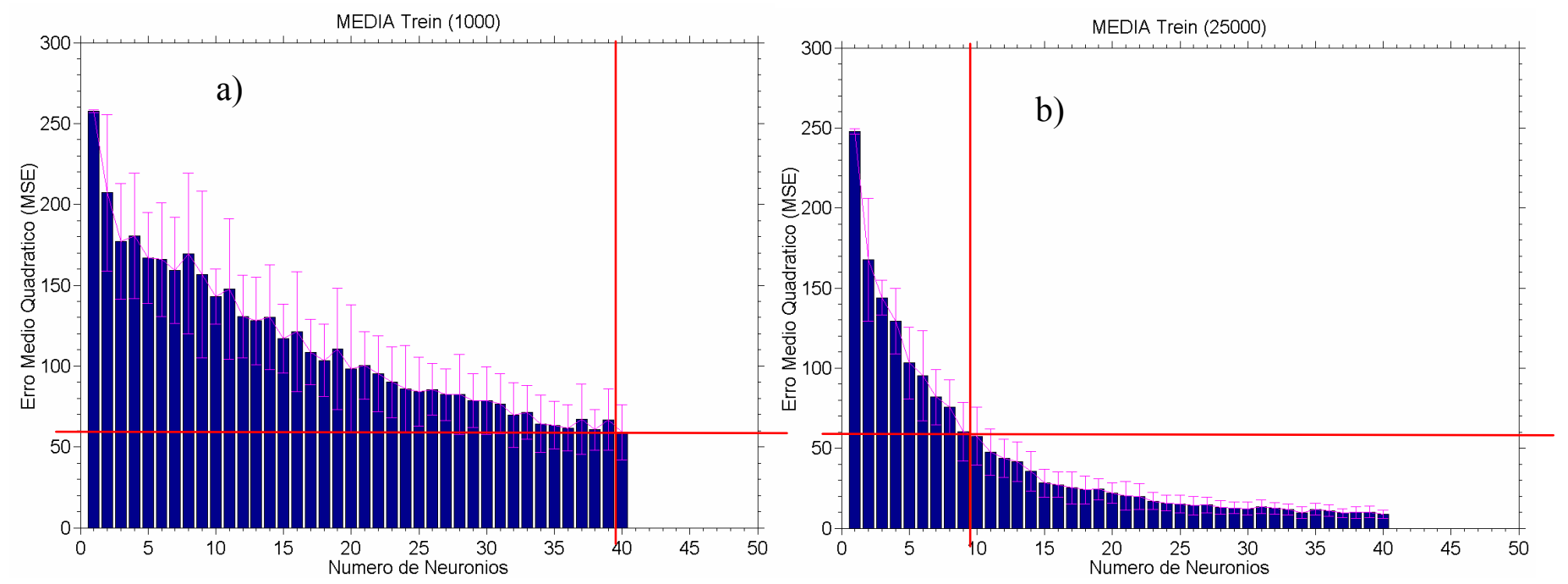

c)

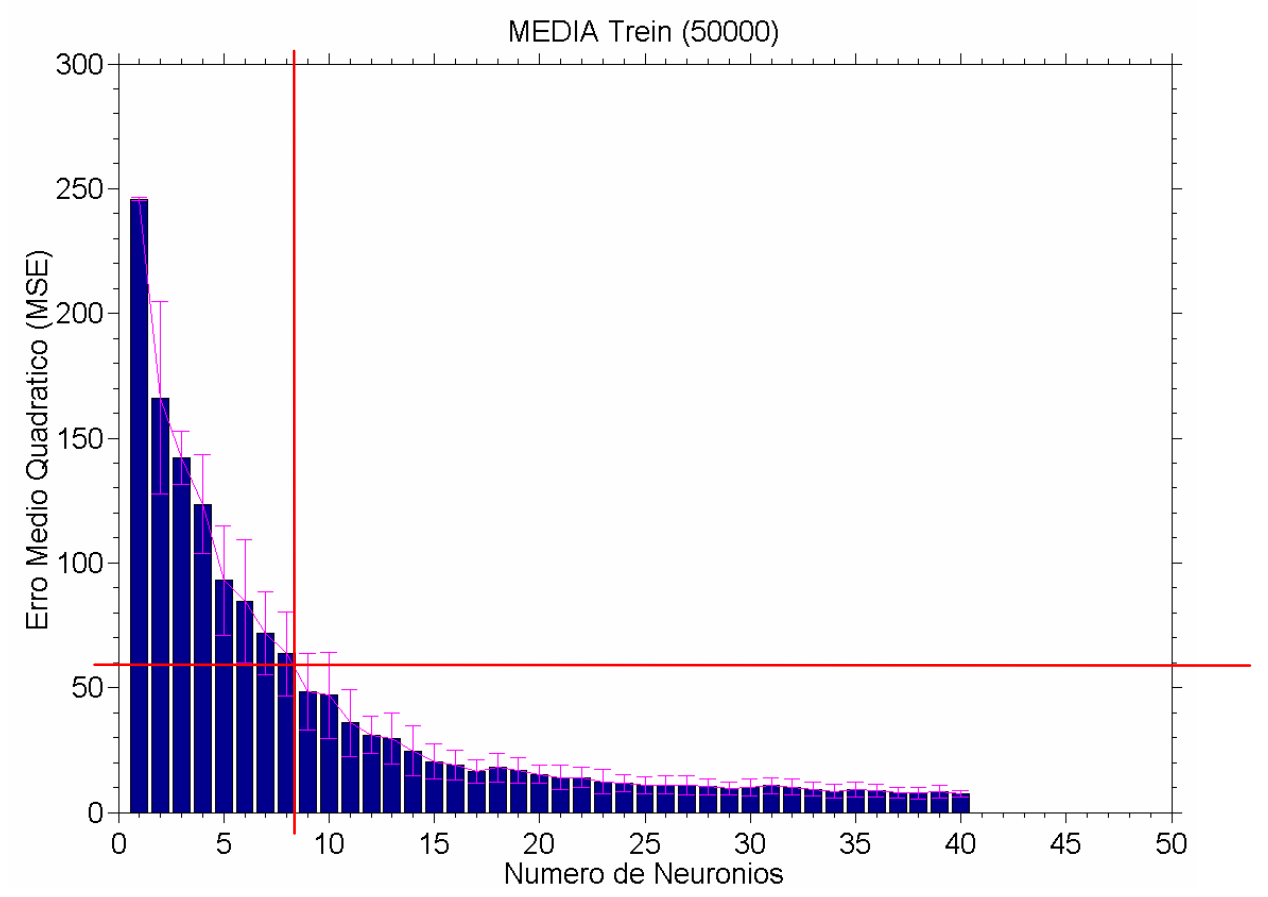

Figura 4-7 - MSE médio para o conjunto de treinamento em função do número de neurônios a) 1.000 épocas b) 25.000 épocas c) 50.000 épocas.

Os mesmos gráficos foram obtidos para o conjunto de teste e são encontrados na Figura 4-8. Diferentemente do que acontece no conjunto de treinamento, o MSE torna-se maior conforme aumentamos o número de neurônios. Conforme a explicação dada no início desse tópico, um número grande de neurônios tende a tornar a interpolação e extrapolação ruim, pois esses se especializam apenas nos dados apresentados no treinamento. Assim, podemos perceber que deve haver um número de neurônios intermediário onde o erro é minimizado em ambos os conjuntos. 
Ao se aumentar o número de épocas, não se nota uma mudança muito significativa em relação ao erro nesse conjunto.
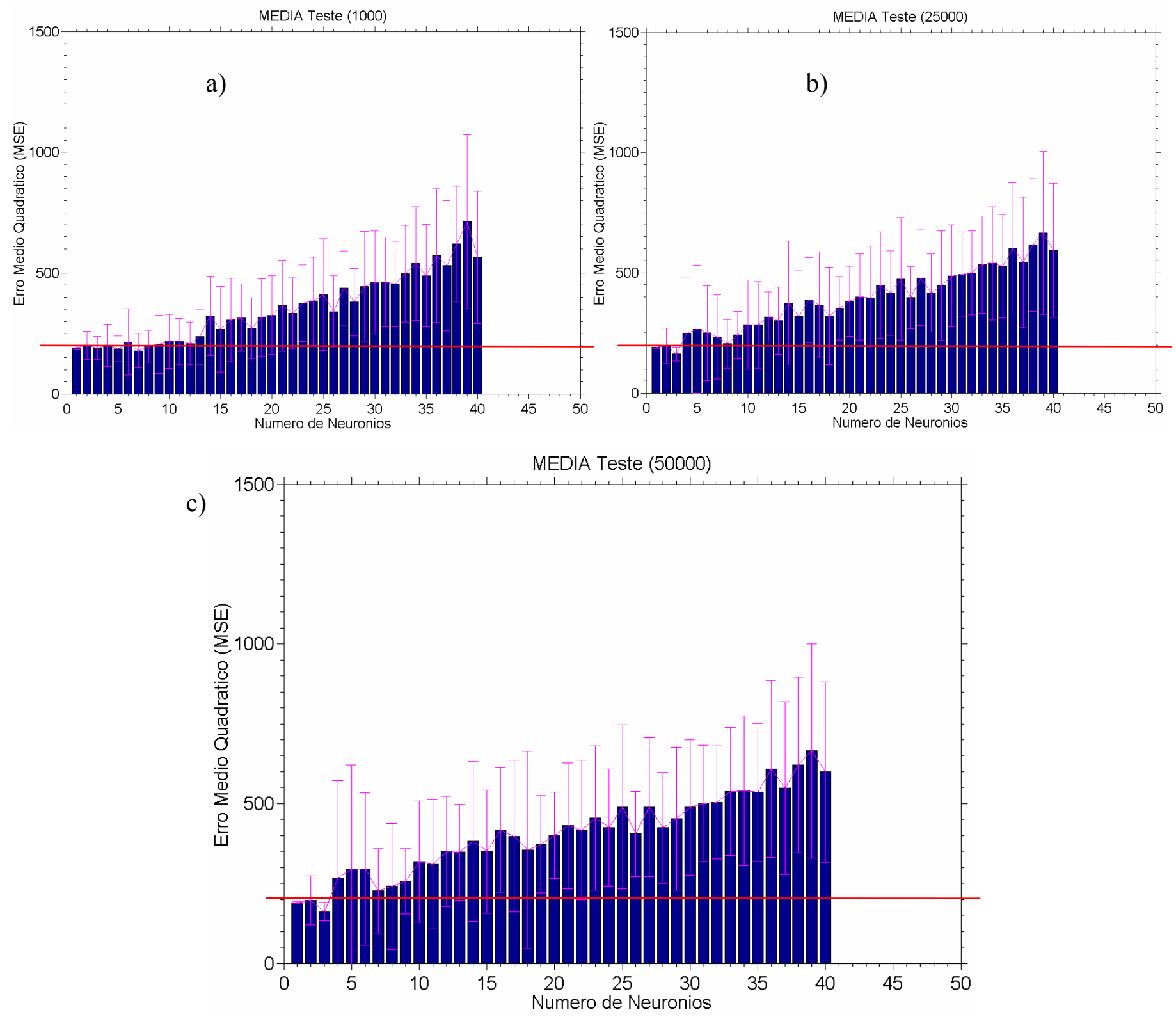

Figura 4-8 - MSE médio para o conjunto de teste em função do número de neurônios a) 1.000 épocas b) 25.000 épocas c) 50.000 épocas.

A Figura 4-9 mostra a mesma análise do MSE, porém, para o conjunto total. Aqui, há a união do efeito sobre o erro do conjunto de treinamento e do conjunto de teste. Apesar deste último conjunto possuir uma menor quantidade de valores ( 7 contra 50 do de treinamento), o erro médio elevado causa o aparecimento do mesmo padrão no erro do conjunto total. Assim, mesmo que no conjunto de treinamento o erro diminua para um aumento do número de neurônios e um aumento do número de 
épocas, quando o erro é avaliado sobre o conjunto total esse padrão é sobreposto pelo erro do conjunto de teste.
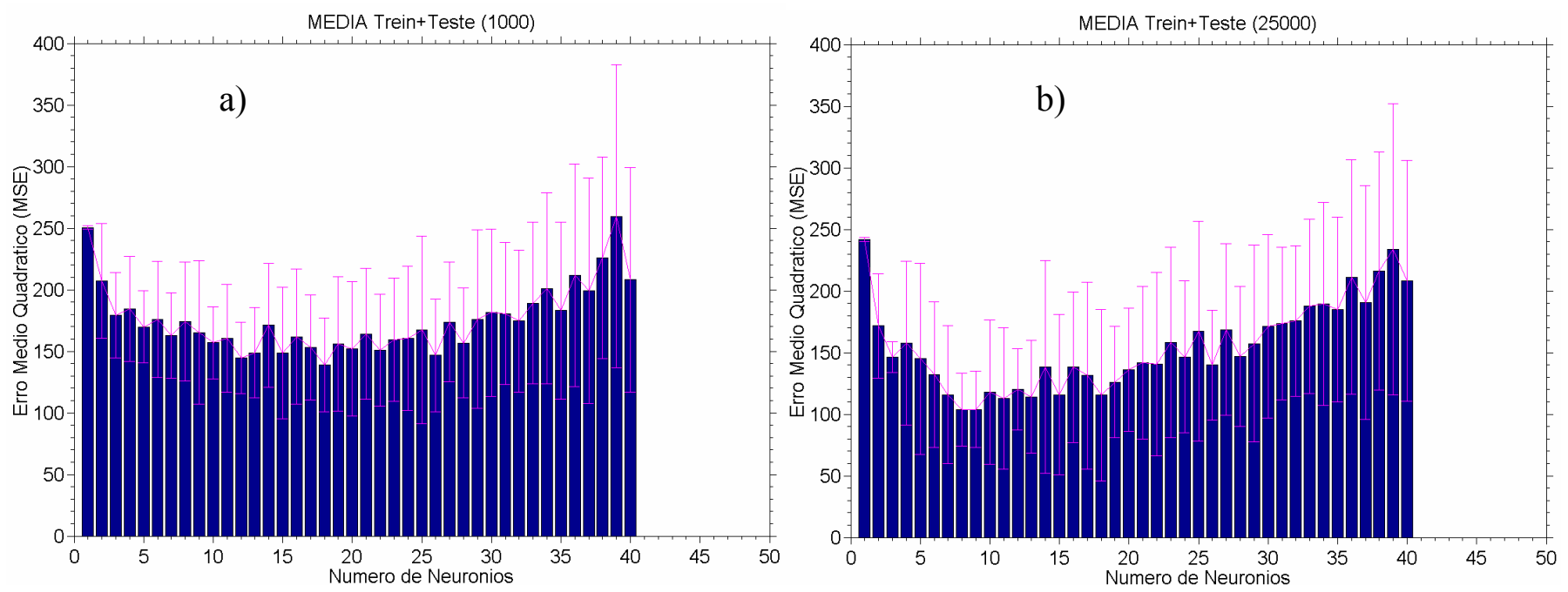

c)

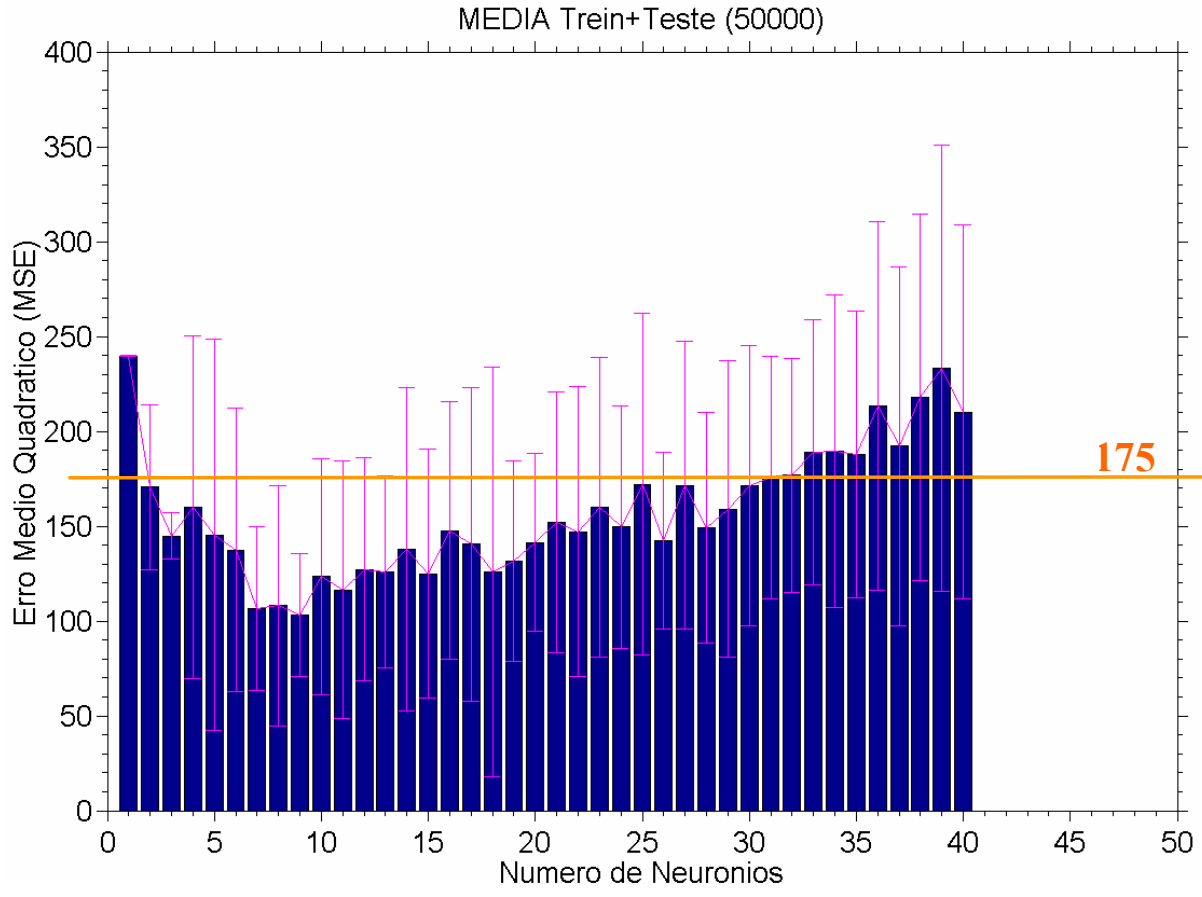

Figura 4-9 - MSE médio para o conjunto total (treinamento + teste) em função do número de neurônios a) 1.000 épocas b) 25.000 épocas c) 50.000 épocas.

Ao se observar o valor médio para 50.000 épocas no conjunto total, podemos afirmar que um número de neurônios entre 6 e 10 fornece a melhor resposta em relação ao erro. Para estes casos, o erro é menor do que 11,5\% em relação a média da espessura. Já para 1 neurônio na camada intermediária e para valores maiores que 30 neurônios o erro torna-se maior do que 175 , o que do ponto de vista de processo 
equivaleria a um erro da ordem de $17 \mathrm{~nm}$ na espessura. Se pensarmos que a média das espessuras é $99 \mathrm{~nm}$, então, $17 \mathrm{~nm}$ seria equivalente a um erro de 17,7\%.

Uma outra forma de avaliar o erro foi proposta utilizando um gráfico de construção circular. Para esse gráfico, primeiro foi traçado o MSE calculado na época seguinte em função do MSE na época atual, como mostra a Figura 4-10.
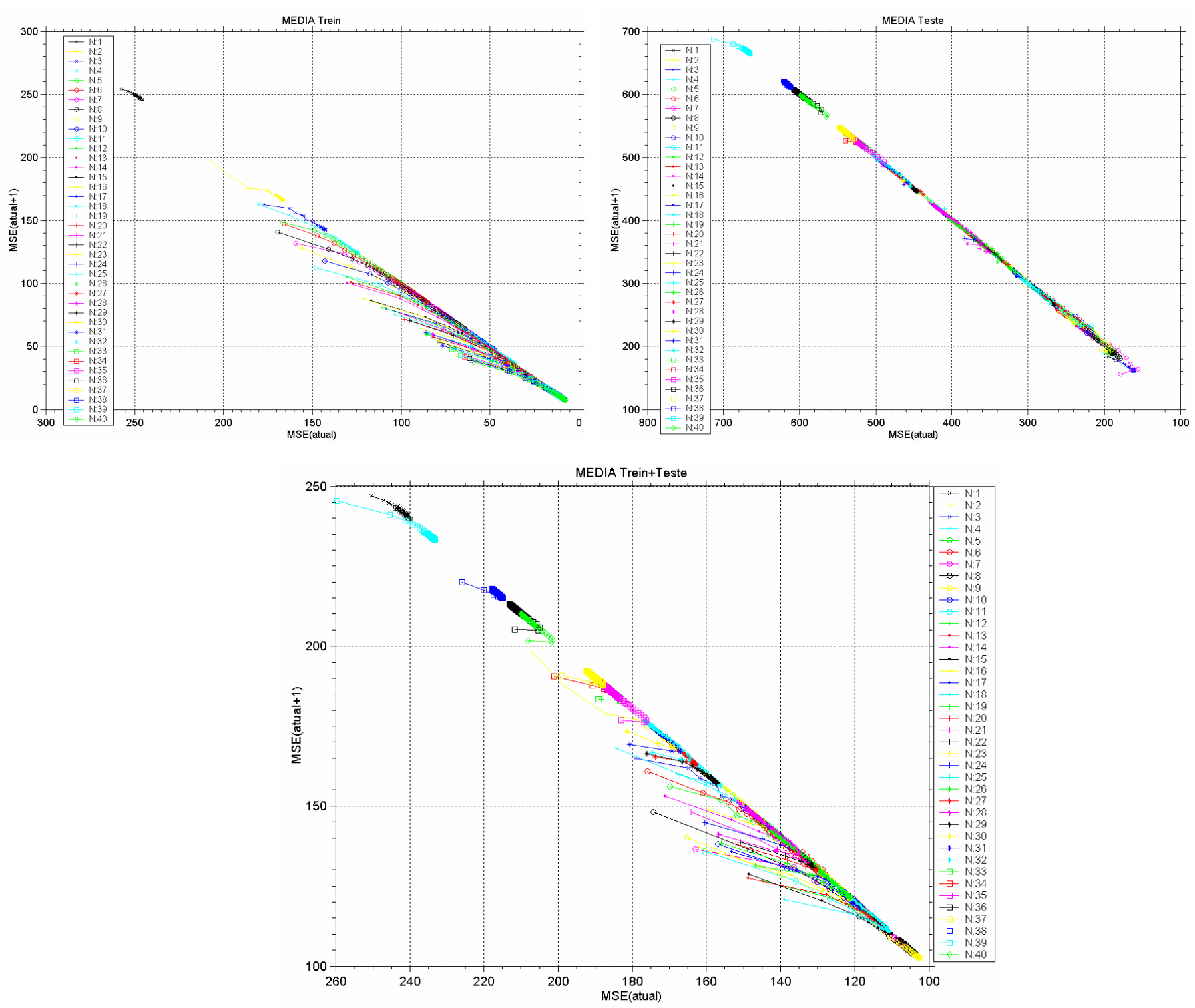

Figura 4-10 - MSE atual+1 em função do MSE atual para diferentes números de neurônios.

Como pode ser visto, as curvas se sobrepõem e tornam difícil a análise. Para dirimir esse efeito, as curvas correspondentes a cada número de neurônios diferentes foram rotacionadas em torno do 0 , de acordo com as equações (12), onde MSE atual corresponde ao valor do X, enquanto que o MSE seguinte corresponde ao valor do Y. 


$$
\begin{aligned}
& \text { Xfinal }=\cos \left(a \tan \left(\frac{Y 1}{X 1}\right)-\theta\right) \cdot \sqrt{X_{1}^{2}+Y_{1}^{2}} \\
& \text { Yfinal }=\operatorname{sen}\left(a \tan \left(\frac{Y 1}{X 1}\right)-\theta\right) \cdot \sqrt{X_{1}^{2}+Y_{1}^{2}}
\end{aligned}
$$

Onde $\theta$ é o ângulo que se deseja deslocar a respectiva curva.

Dessa forma as curvas foram separadas e tornou-se possível analisar diversos parâmetros simultaneamente.
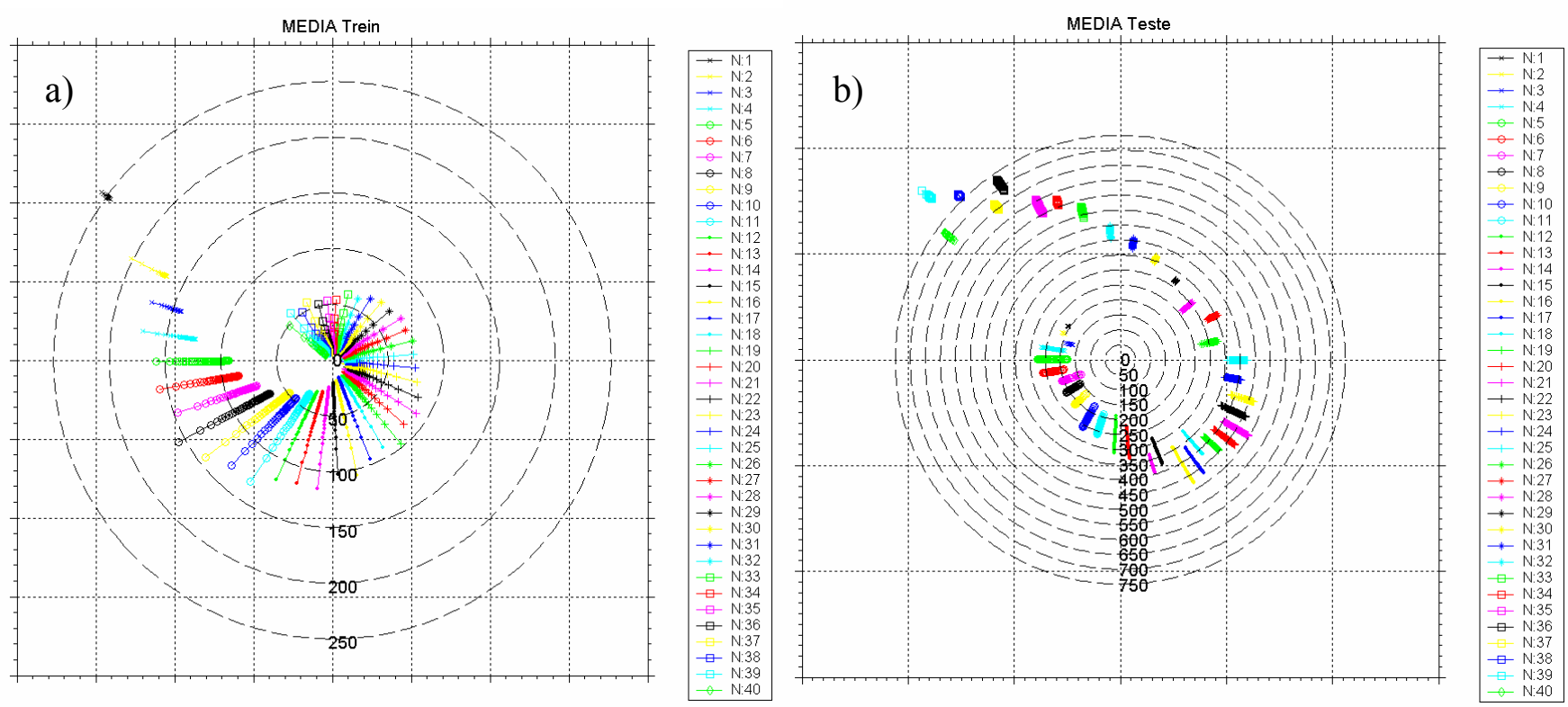

c)
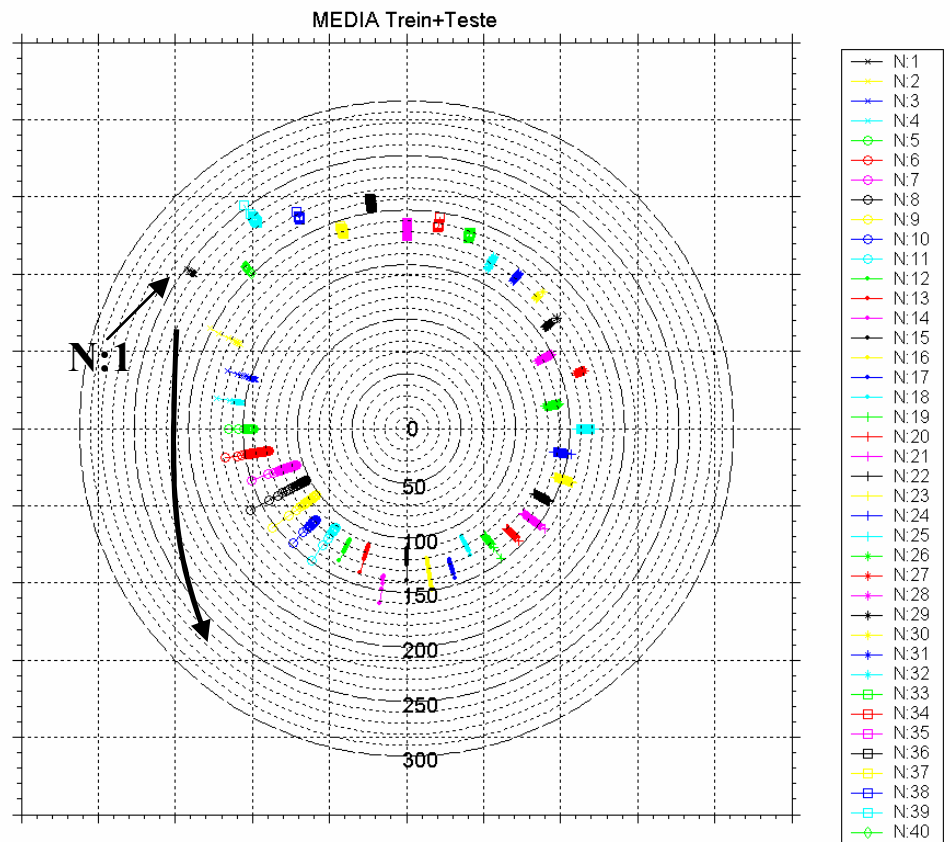

Figura 4-11 - Visualização circular do MSE a) conjunto de treinamento b) conjunto de teste c) conjunto total. 
A Figura 4-11 a) mostra um comportamento encaracolado em direção ao centro conforme o número de neurônios é elevado. Tal formato indica que um aumento do número de neurônios faz com que o erro seja minimizado no conjunto de treinamento. Na Figura 4-11 b) observa-se um padrão diferente do primeiro caso. Nessa figura as curvas começam relativamente próximas ao centro e conforme se aumenta o número de neurônios, o erro acaba crescendo.

Esse método de visualização permite extrair não só a informação sobre o MSE (distância do ponto até o centro 0) como também a taxa de aprendizagem (distância entre dois pontos da curva) e a influência do número de épocas (muitos pontos sobrepostos significa que tais épocas não melhoram significativamente o MSE).

Como já dito anteriormente, os números de neurônios que obtiveram as melhores respostas na média foram os entre 6 e 10, o que pode ser facilmente visto na Figura 4-11 c), onde apenas esses três números de neurônios conseguiram um erro menor do que $110(11 \mathrm{~nm})$.

\subsubsection{Simulação das curvas experimentais}

Depois de realizada a análise do erro, apresentamos aqui a simulação de alguns estados da rede.

A Figura 4-12 mostra os resultados da simulação para uma rede formada por 15 neurônios (inicialização 12 e épocas como indicado na própria figura). 

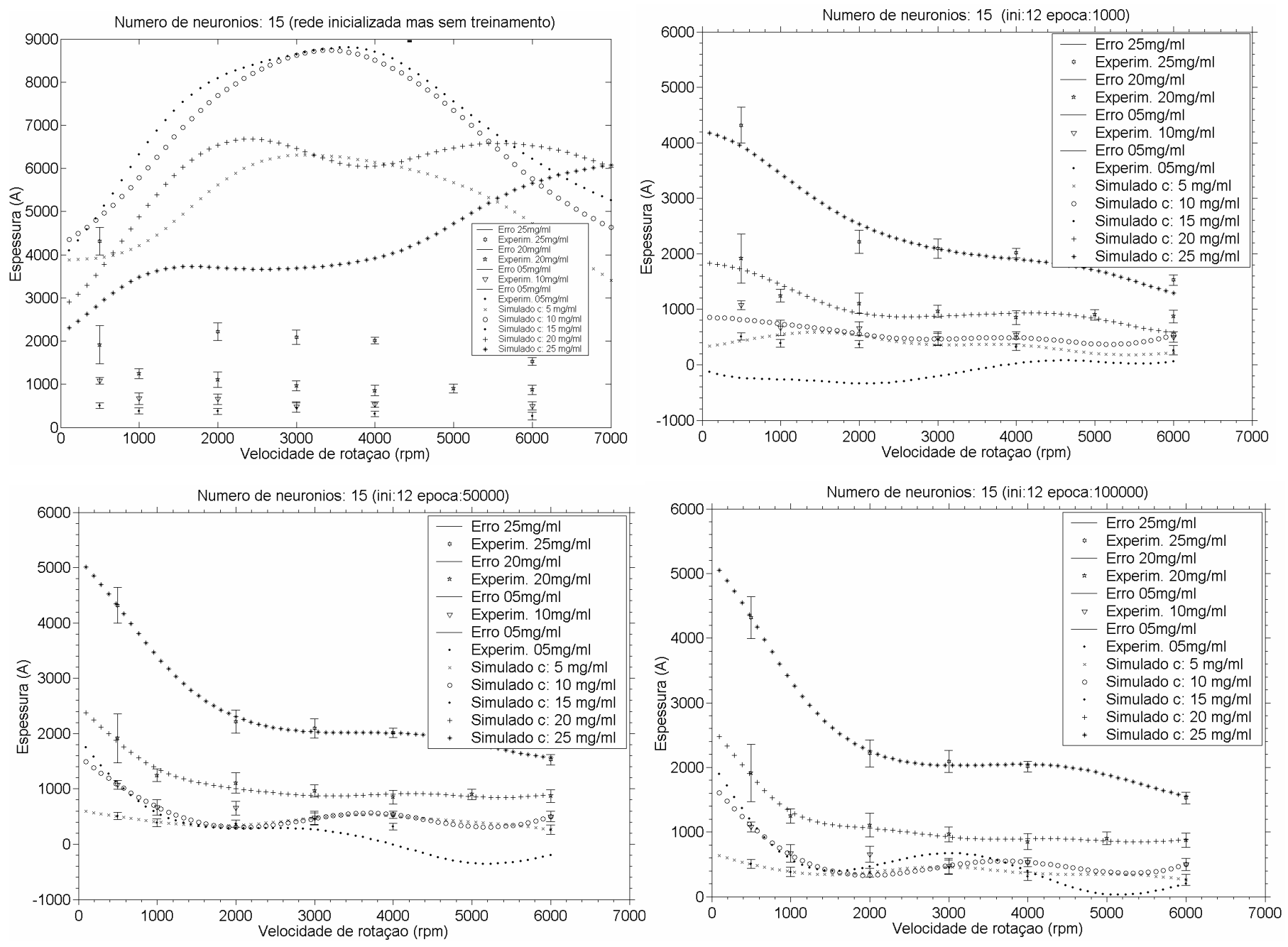

Figura 4-12 - Simulação da espessura em função da velocidade de rotação e da concentração para uma rede treinada com diferentes épocas.

O primeiro gráfico mostra o resultado de uma rede inicializada aleatoriamente (sem treinamento). Os valores simulados encontram-se totalmente em desacordo quando comparados aos valores experimentais. Após 1.000 épocas de treinamento, as curvas simuladas já começam a acompanhar as curvas experimentais. Porém, as curvas de concentração 5 e $10 \mathrm{mg} / \mathrm{mL}$ apresentam um resultado muito insatisfatório. Quanto mais se treina, por exemplo, 50.000 e 100.000 épocas), mais as curvas simuladas se aproximam dos valores experimentais.

De acordo com a análise do MSE sobre o conjunto total, as redes que apresentaram menor erro na média foram aquelas entre 6 e 10 neurônios. Porém, esse resultado é obtido pela média e ao se escolher uma rede para simulação, não é possível compará-la com outra formada por um número diferente de neurônios. 
Assim, caso fosse necessário escolher um número de neurônios para a formação de uma rede para treinamento e simulação, deveria ser escolhido um valor entre 6 e 10 neurônios. $\mathrm{O}$ algoritmo aqui proposto consegue localizar a rede com o menor MSE sobre o conjunto total. Assim, apresentamos aqui a rede com 18 neurônios, inicializacao: 21; época: 21.000, escolhida como a melhor (menor erro geral) entre todas as analisadas (Figura 4-13).
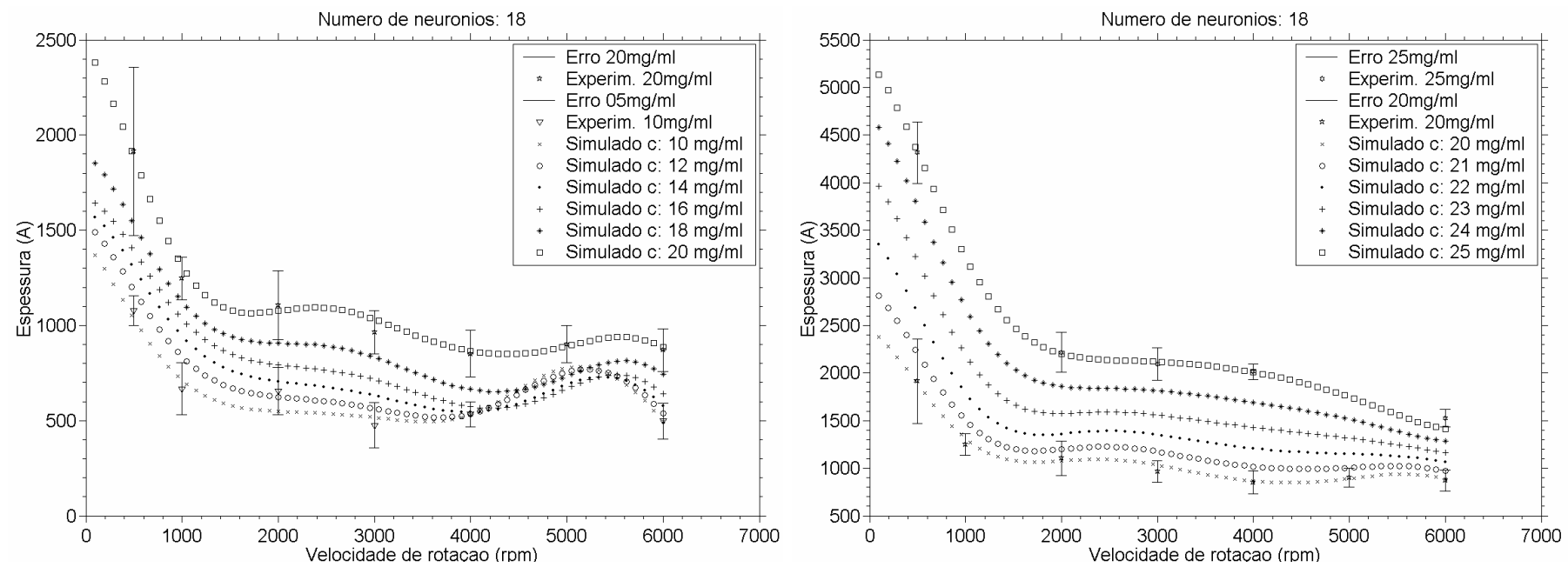

Numero de neuronios: 18

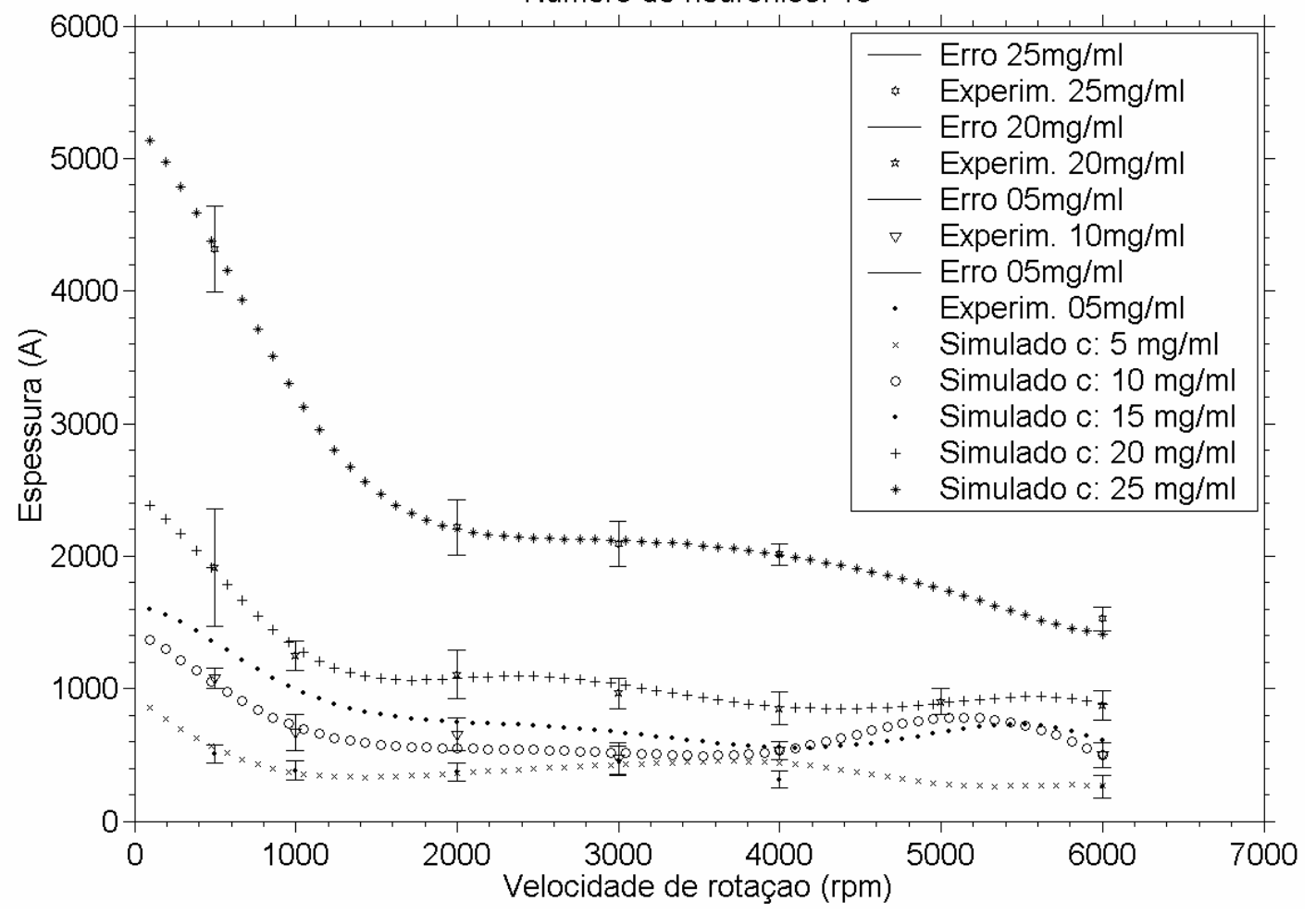

Figura 4-13 - Simulação da espessura em função do número de épocas para diferentes concentrações, para tempo igual a $30 \mathrm{~s}$. Simulação a partir da melhor rede neural obtida ( número de neurônios: 18 , inicialização: 21 , época: 21.000 ). 
Podemos notar que a simulação fornecida apresenta um comportamento de acordo com o esperado. As curvas se ajustam muito bem sobre os pontos experimentais apresentando um erro (em relação a esses pontos) bem menor do que a incerteza experimental. $\mathrm{O}$ fato da curva de $10 \mathrm{mg} / \mathrm{mL}$ apresentar uma elevação em torno de $5.000 \mathrm{rpm}$ deve-se ao fato de que para essa velocidade, há apenas o ponto de $20 \mathrm{mg} / \mathrm{mL}$, fazendo com que a rede interprete que há um ponto de subida em tal região.

De uma forma geral, a simulação por redes neurais artificiais apresenta uma boa resposta para esse processo, tornando possível a previsão de valores a partir de um pequeno número de dados experimentais.

\subsection{Filmes de PAni/PVS obtidos por automontagem (ESA-LBL)}

A variação da espessura em função do número de bicamadas para as amostras da série 1 foi obtida por perfilometria e é mostrada na Figura 4-14.

Podemos ver que a espessura aumenta linearmente com o número de bicamadas, como esperado ${ }^{64}$, a uma taxa de aproximadamente $5 \mathrm{~nm}$ por bicamada ( $\sim 55 \mathrm{~A} /$ por bicamada). É importante ressaltar que a equação da Figura 4-14 apresenta um coeficiente linear negativo, porém, tal valor é impraticável. Apenas é deixado na figura devido à aproximação linear obtida pelo método dos mínimos quadrados.

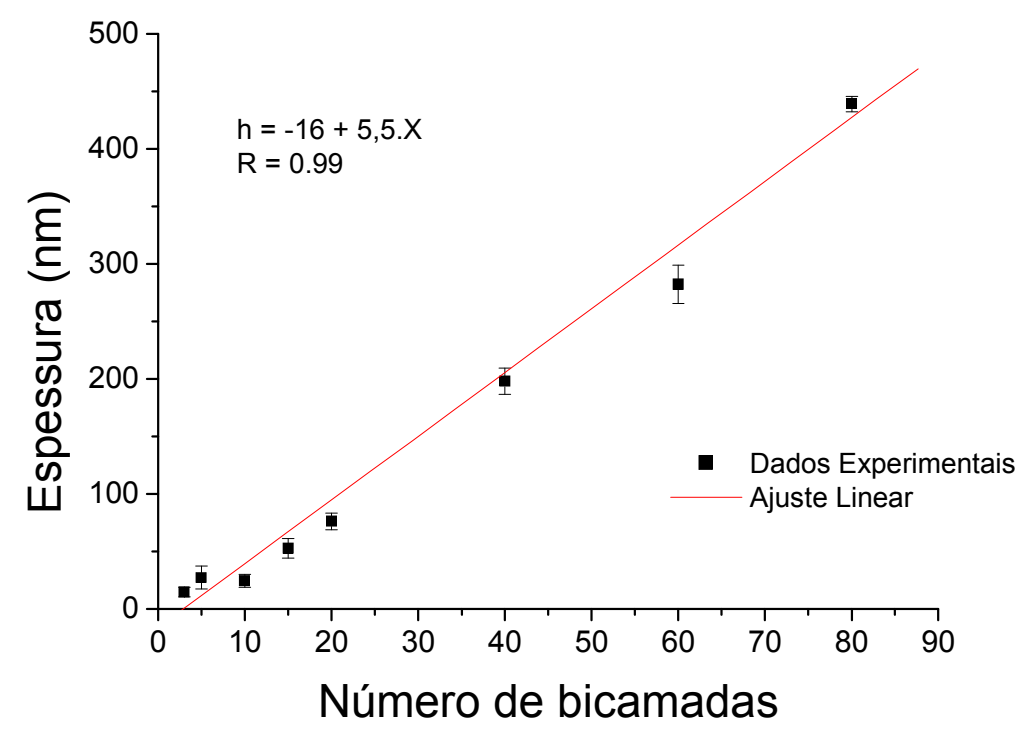

Figura 4-14 - Espessura em função do número de bicamadas para as amostras da série 1. 
Utilizando os filmes automontados obtidos sobre eletrodos de ouro, foi levantada a curva de dopagem, mostrada na Figura 4-15. São mostrados os diferentes valores de condutância elétrica obtidos para diferentes números de bicamadas e diferentes tempos de mergulho em solução de $\mathrm{HCl}$ (pH 3) (amostras da série 2).

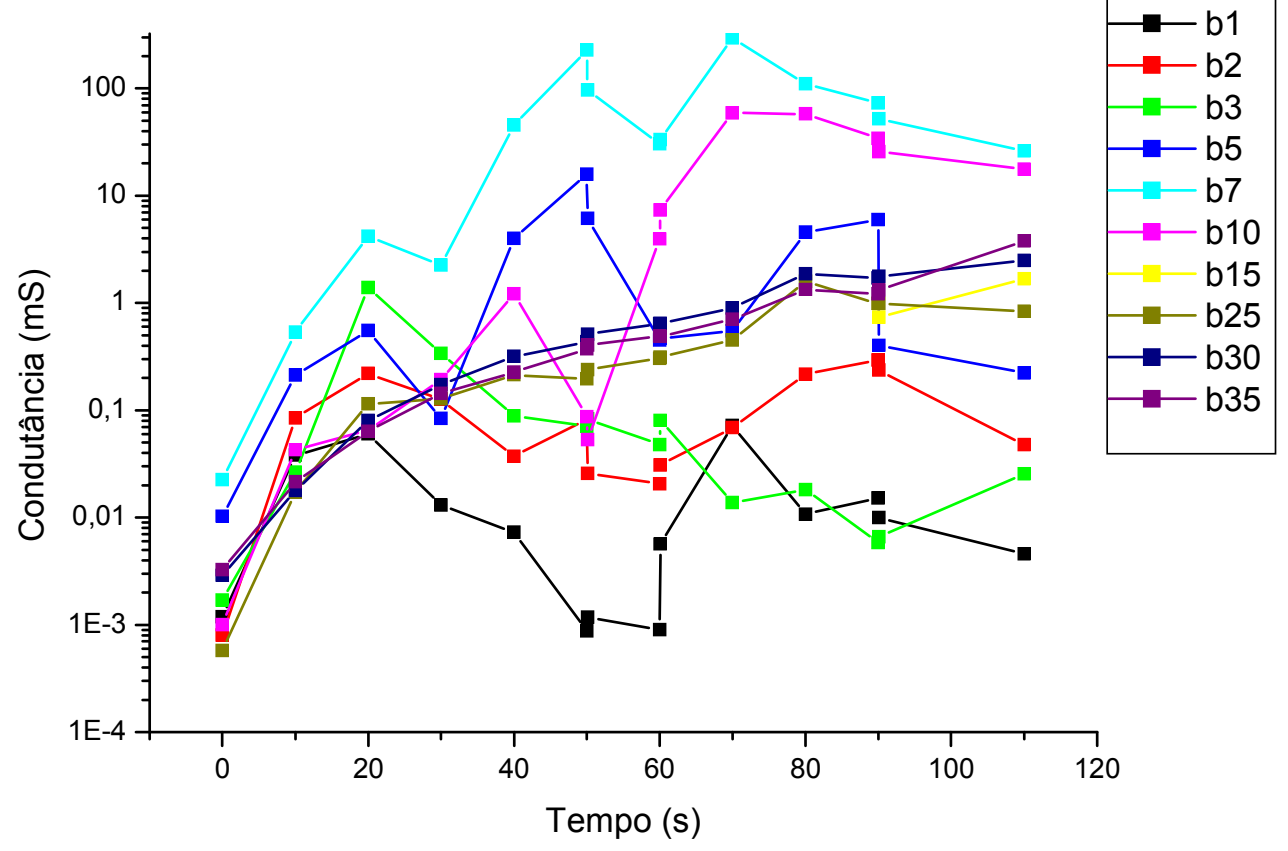

Figura 4-15 - Condutância elétrica em função do tempo de dopagem em HCl para diferentes números de bicamadas.

O comportamento da condutância segue o esperado pela literatura, quanto maior o tempo de dopagem, mais condutiva fica a amostra. A queda de alguns valores de condutância conforme se aumenta o tempo de dopagem ainda não está explicada e será alvo de análise em trabalhos posteriores.

Uma das possibilidades é que a diferença do número de bicamadas dos filmes, e consequentemente da espessura, faz com que haja uma distribuição diferente de dopantes entre eles. Os filmes mais finos atingem rapidamente a saturação de dopagem enquanto que os filmes mais espessos tendem a demorar mais até que os dopantes se distribuam uniformemente ao longo do filme. Por não obter um comportamento regular na resposta da condutância em função do tempo, optouse por não utilizar esses dados na simulação de redes neurais. 
Para analisar a influência da dopagem no espectro de absorção, após as amostras serem obtidas, elas foram desdopadas através do mergulho em solução com $\mathrm{pH} 10\left(\mathrm{NH}_{4} \mathrm{OH}, 0,1 \mathrm{~N}\right)$ por 10 minutos. A seguir, elas foram deixadas sobre papel toalha por 15 minutos a fim de secar antes de serem levantados os primeiros espectros de absorção.

$\mathrm{O}$ processo de dopagem ocorreu utilizando soluções de $\mathrm{HCl}$ com diferentes pHs, deixando por 30 segundos as amostras nelas mergulhadas. Os espectros foram obtidos após 15 minutos de secagem.

Os espectros são apresentados na Figura 4-16.
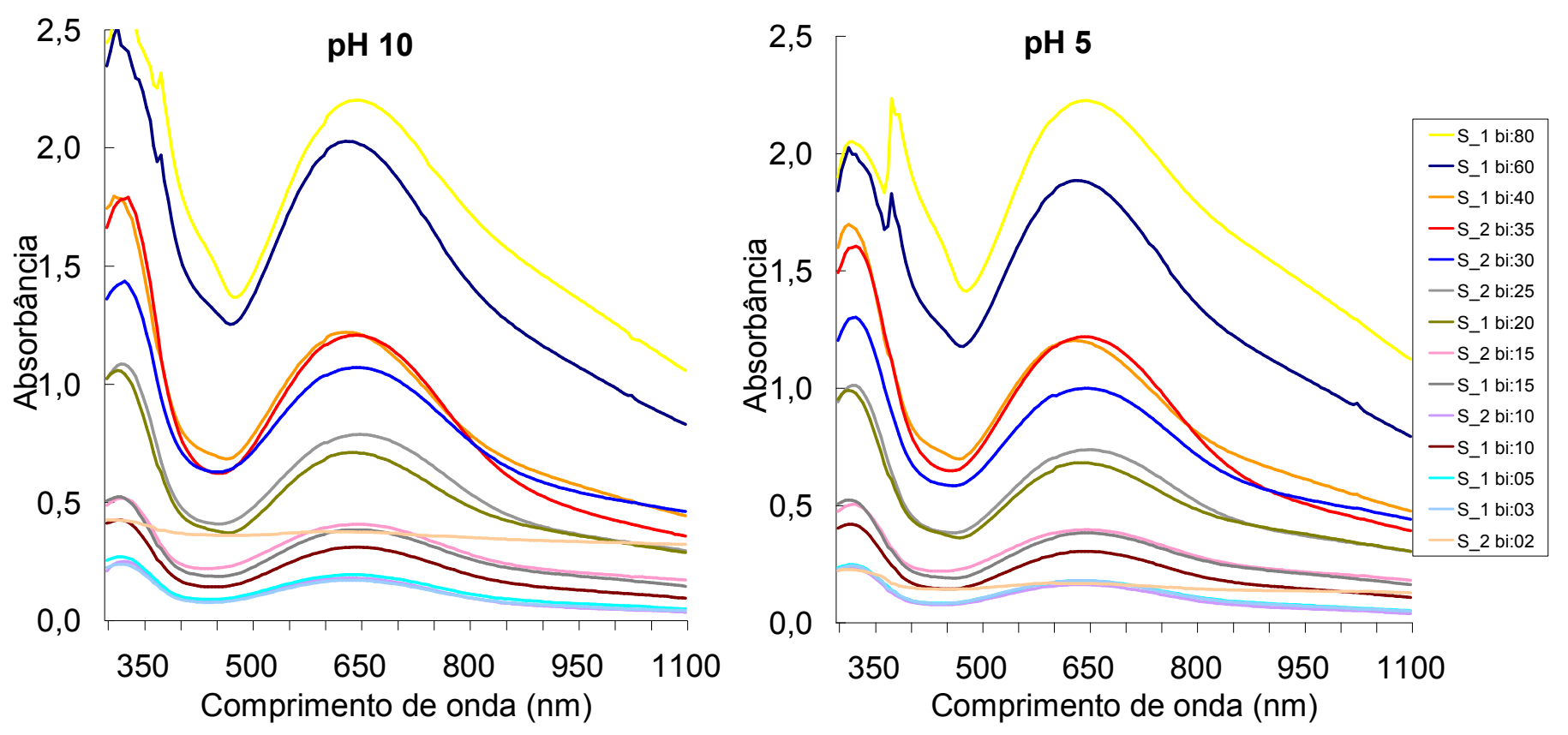

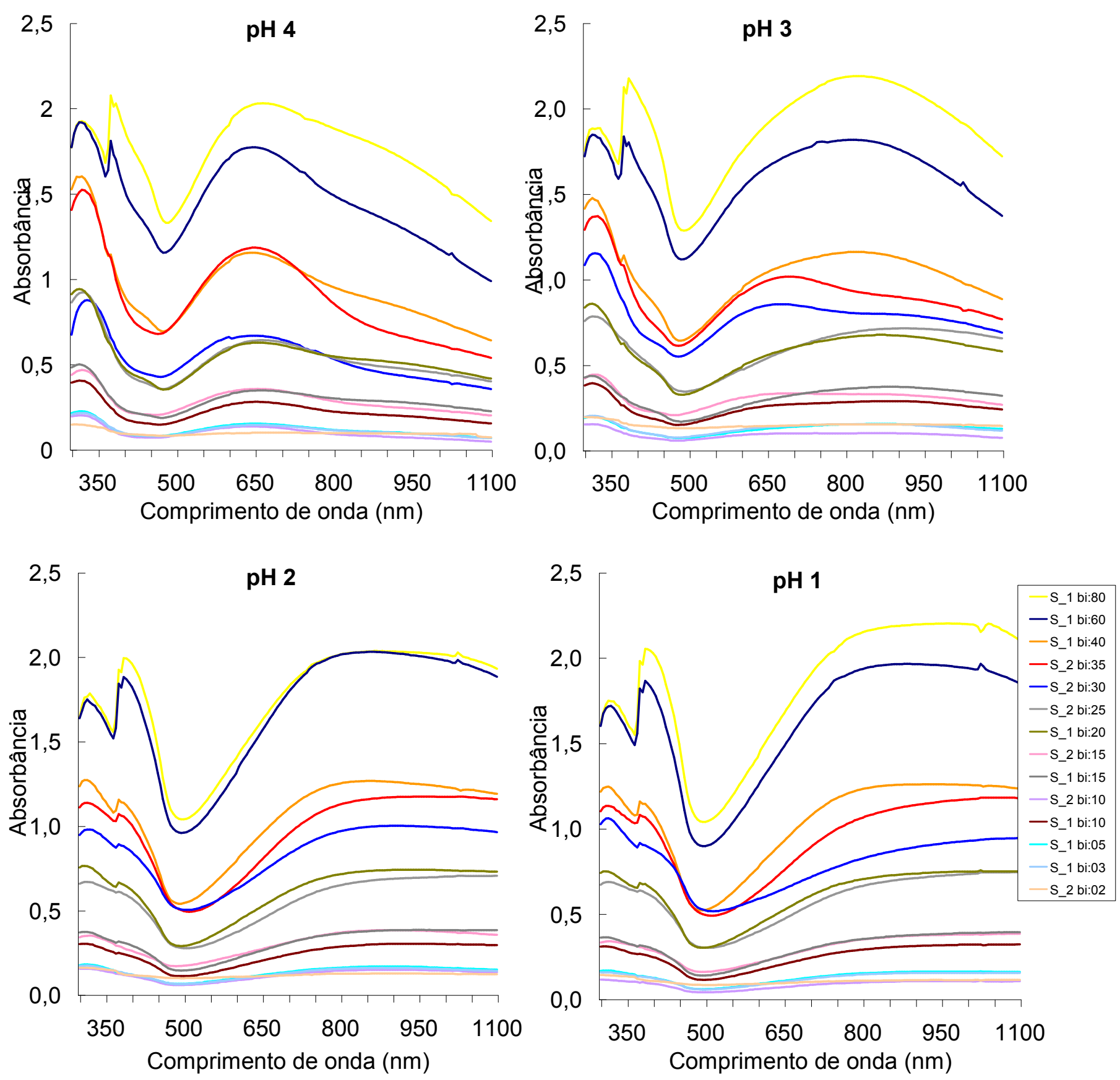

Figura 4-16 - Espectros de absorção em função do comprimento de onda para diferentes números de bicamadas em diferentes pHs.

Para efeito de comparação com a análise do erro, apresentada a seguir, foi traçado o histograma da distribuição dos dados utilizados para o treinamento e análise do erro (Figura 4-17). O histograma apresenta uma média de 0,589. 


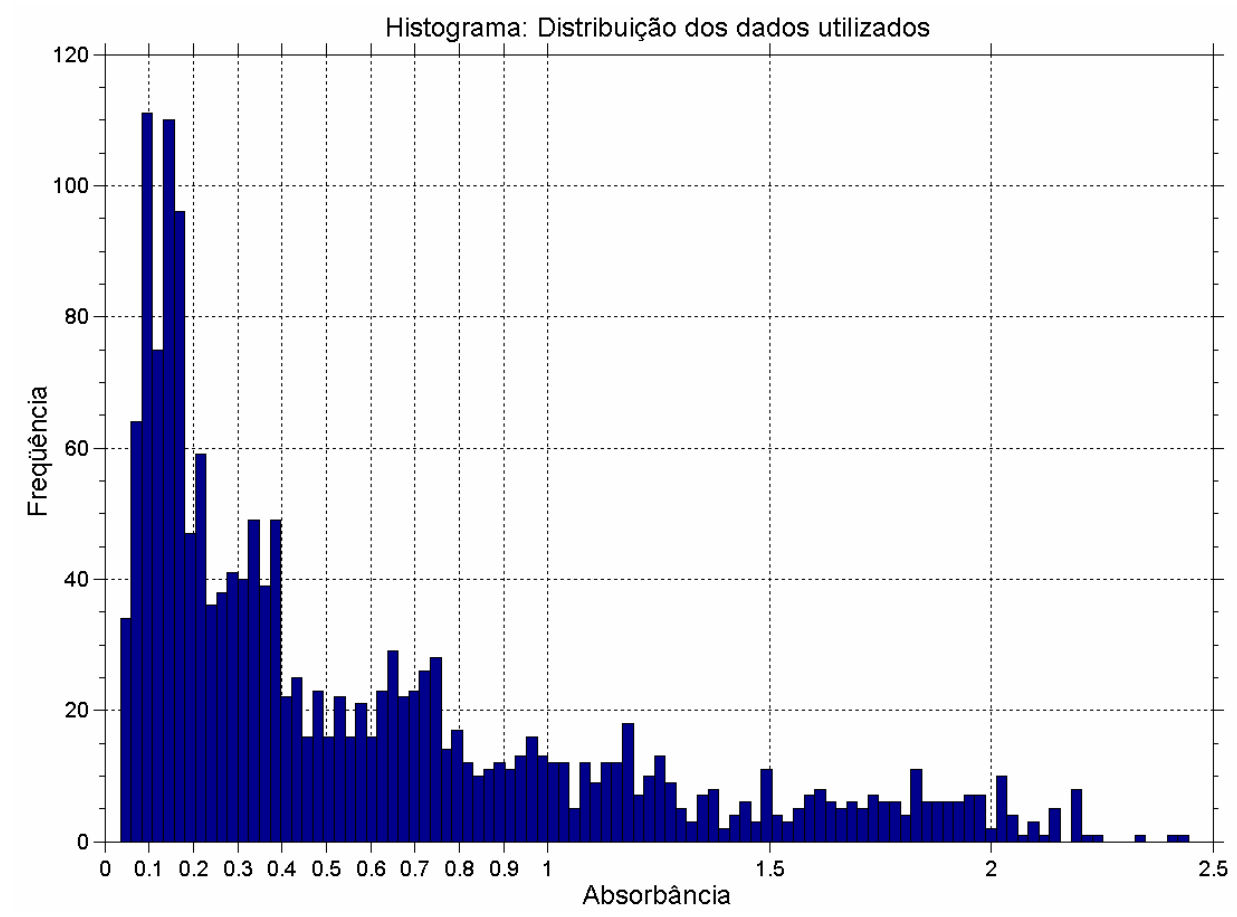

RNAs.

Figura 4-17 - Distribuição do conjunto de saída utilizado para treinamento e teste das

\subsubsection{Reprodutibilidade}

Do mesmo modo como analisado para o caso do spin coating foram traçados os gráficos do erro em função do número de épocas, para diferentes inicializações. Porém, devido a maior quantidade de dados utilizados para o treinamento e teste, as faixas exploradas aqui foram diferentes. Variou-se de 20.000 a 100.000 com passo de 20.000 o número de épocas, enquanto que foram realizadas 50 diferentes inicializações para uma rede formada por 100 neurônios na camada intermediária.
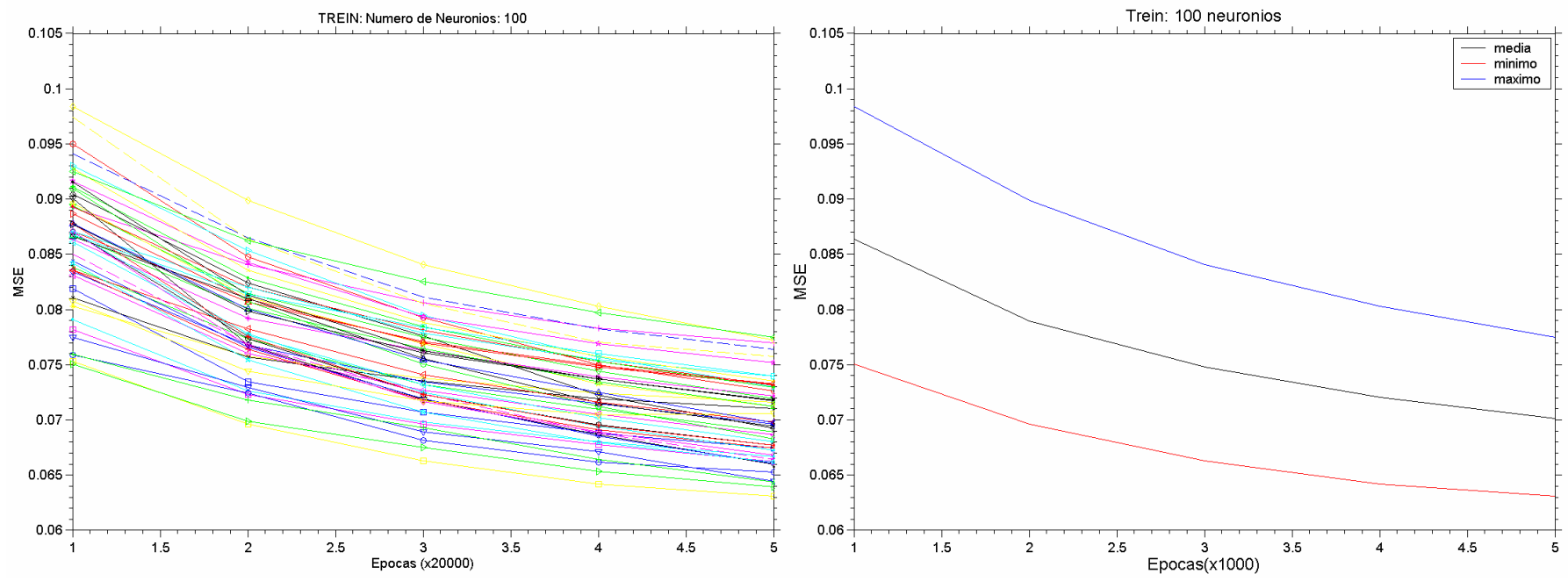

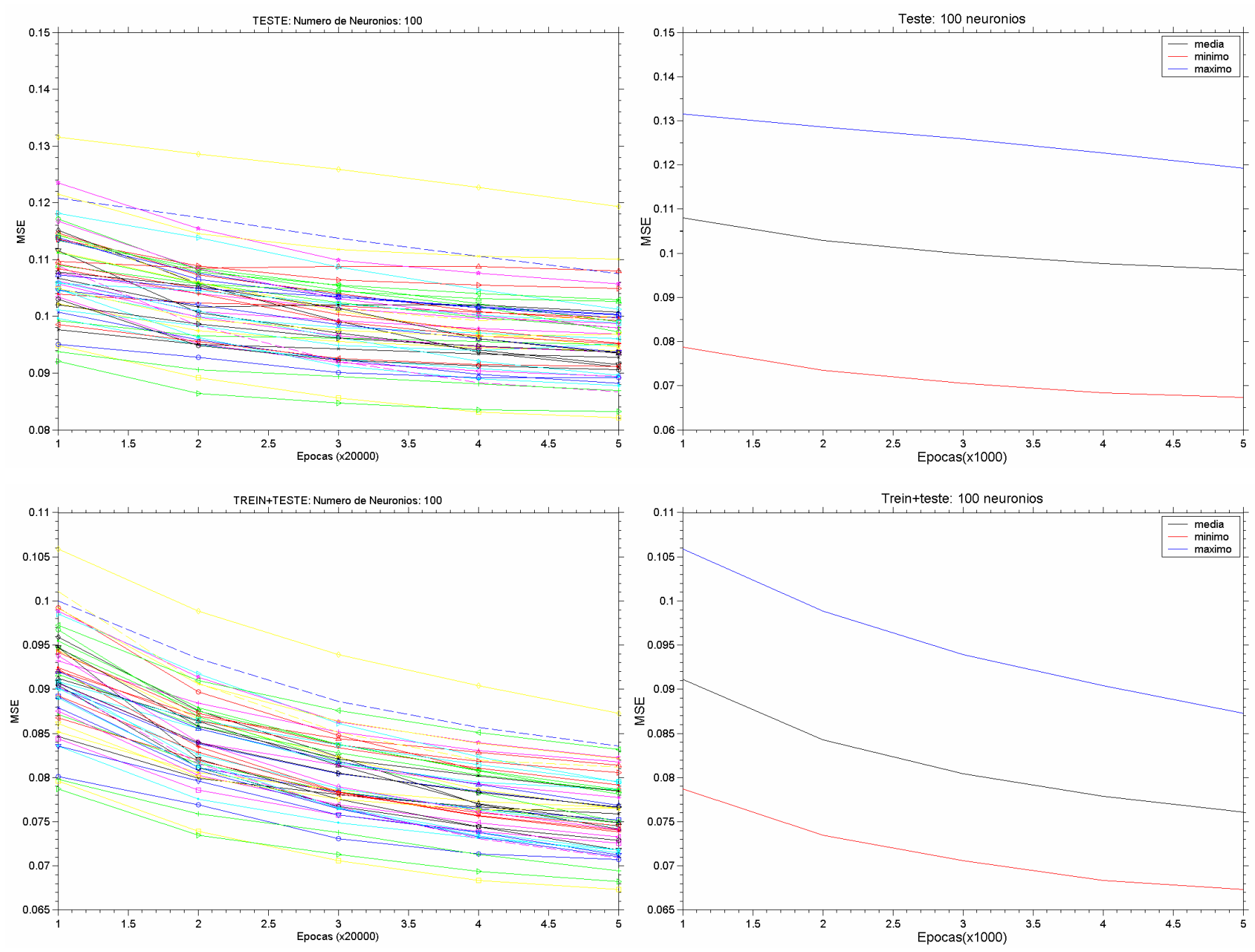

Figura 4-18 - Erro em função do número de épocas para diferentes inicializações. a) conjunto de treinamento b) conjunto de teste c) conjunto total.

A Figura 4-18 apresenta o erro para as 50 inicializações obtidas no lado esquerdo e os valores máximo, mínimo e a média no lado direito.

$\mathrm{O}$ aumento do número de épocas leva sempre a uma diminuição do erro, em todos os conjuntos estudados. Tal resultado é diferente do obtido para o caso anterior. A grande diferença entre os dois casos consiste no número de dados utilizados para simulação e análise. Para esse segundo caso, o número de dados é muito superior ao número de neurônios utilizado e, portanto, parece que apesar dos neurônios aprenderem sobre o conjunto de treinamento eles não se especializam demais, permitindo que o erro sobre o conjunto de teste continue sempre melhorando (i.e. diminuindo). 
Ao se observar a variação do erro sobre o conjunto total, podemos ver que, para 100 neurônios, os valores possuem uma diferença entre o máximo e o mínimo de 0,027 em 20.000 épocas e diminuem para 0,020 em 100.000 épocas. Uma variação de 0,020 sobre uma média de 0,589 equivale a apenas $3,4 \%$. O valor médio para esse mesmo número de épocas foi de 0,077 , fornecendo assim um erro igual a $13,1 \%$ em relação a média dos dados.

É mostrada na Figura 4-19 a representação circular dos MSE calculados para as 50 diferentes inicializações. Fica claro que a variação entre diferentes inicializações é pequena, apresentando apenas algumas curvas fora do padrão quando observadas no conjunto de teste.
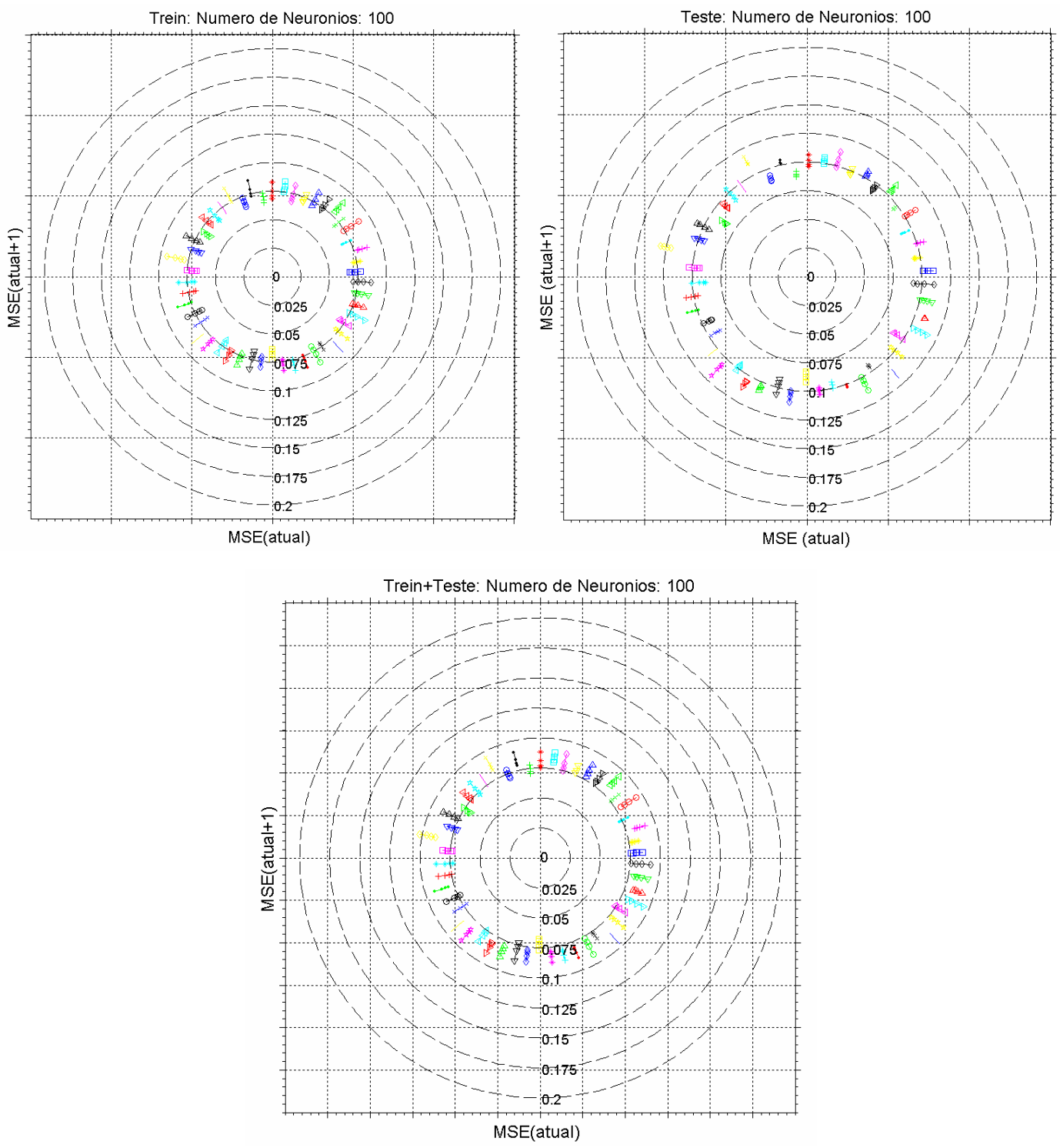

Figura 4-19 - Representação circular do MSE para 50 diferentes inicializações a) conjunto de treinamento b) conjunto de teste c) conjunto total. 
Para esse caso estudado, pode-se afirmar que o sistema é reprodutivo, isso é, diferentes inicializações fornecem praticamente a mesma resposta aos conjuntos analisados.

\subsubsection{Número de neurônios na camada intermediária}

A Figura 4-20 apresenta o MSE médio em função do número de épocas para diferentes números de neurônios. Devido a enorme quantidade de dados utilizada e o tempo gasto para simular e treinar as redes, foram analisados apenas alguns números de neurônios e épocas diferentes.
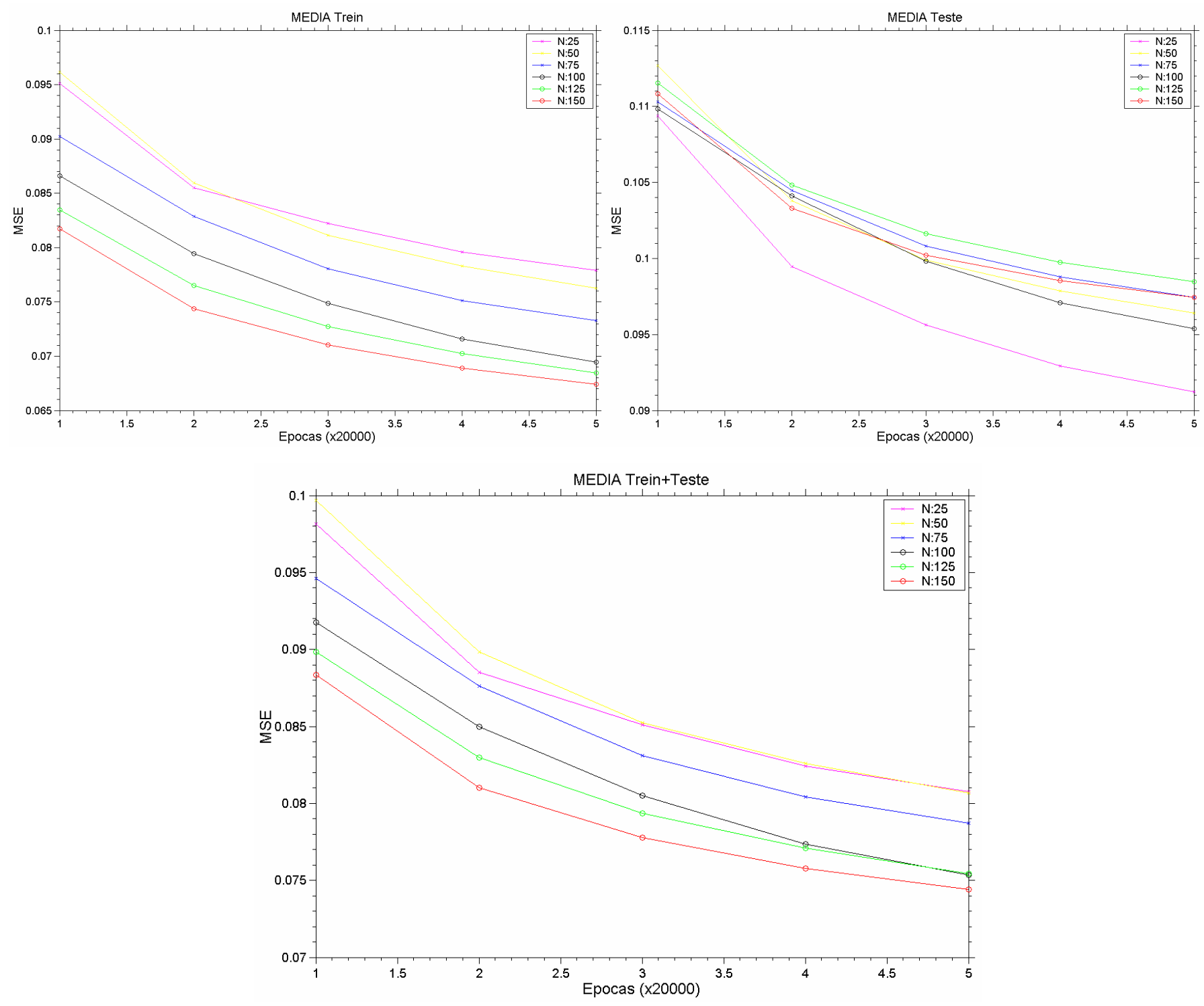

Figura 4-20 - MSE médio em função do número de épocas para diferentes números de neurônios a) conjunto de treinamento b) conjunto de teste c) conjunto total. 
Podemos ver claramente que em todos os casos, mesmo atingindo 100.000 épocas, o erro ainda continua a decair. Diferentemente do caso obtido para o spin coating, o erro cai em todos os três conjuntos. Tal resultado deve-se ao fato de que o número de dados para treinamento e para teste é muito maior do que no caso anterior. Assim, um número pequeno (quando comparado ao número de dados) de neurônios na camada intermediária consegue aprender sobre o conjunto de treinamento, mas não se especializa em valores específicos.

A Figura 4-21 mostra o MSE seguinte (atual +1) em função do MSE atual para diferentes números de neurônios, para os três conjuntos diferentes.
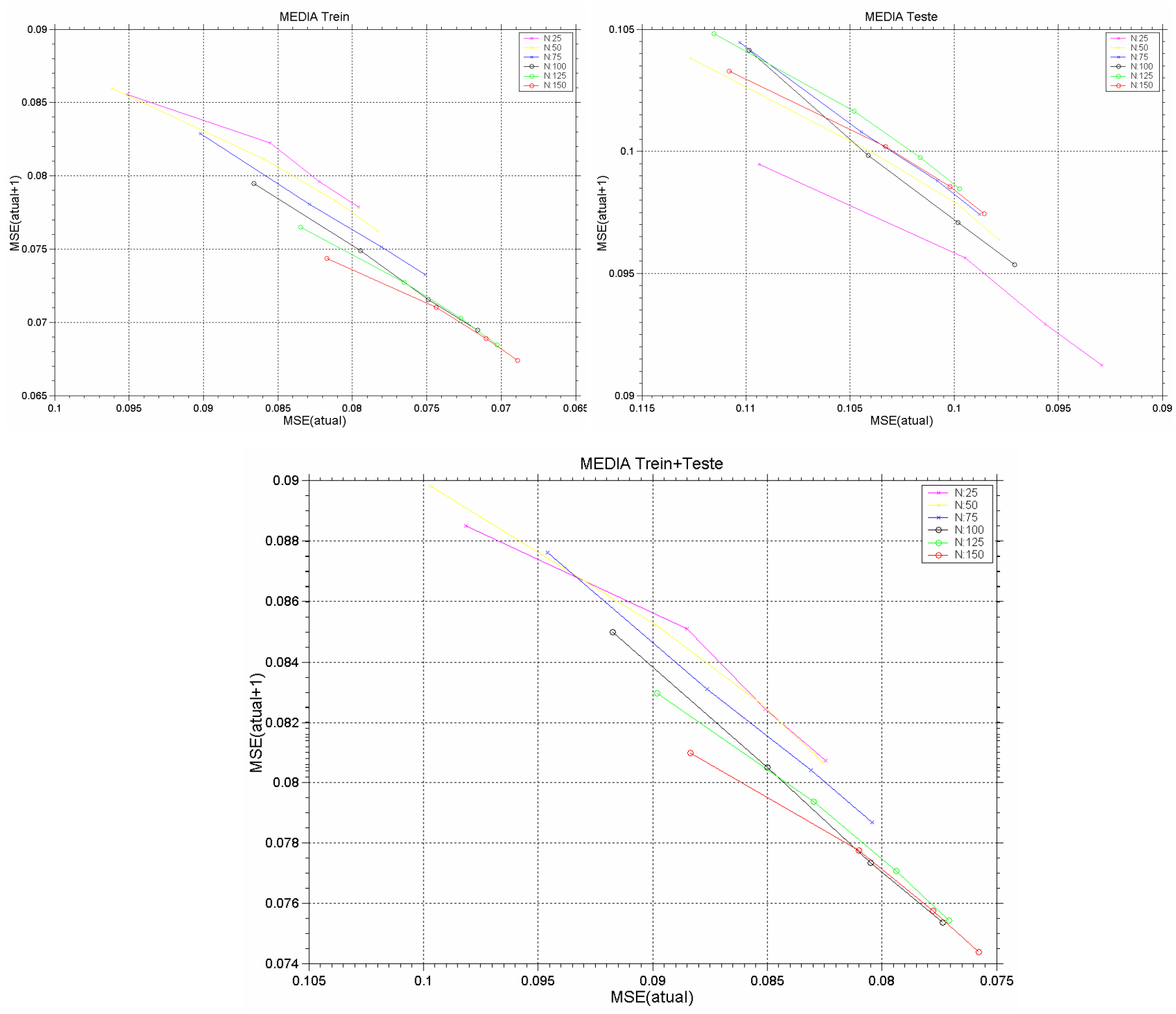

Figura 4-21 - MSE atual+1 em função do MSE atual para diferentes números de neurônios a) conjunto de treinamento b) conjunto de teste c) conjunto total. 
Para o caso de spin coating haviam muitos dados diferentes e essa representação ficava confusa e poluída. Para esse caso, porém, podemos utilizá-la sem perda de informação.

No conjunto de treinamento, o aumento no número de neurônios provoca uma diminuição no MSE, tendo para 150 neurônios o menor erro final. Já no conjunto de teste, mesmo ocorrendo a minimização com o aumento do número de épocas, o número de neurônios não mostra ter relação direta com o erro. $\mathrm{O}$ menor erro é encontrado para 25 neurônios, mas para os outros números de neurônios, ocorre uma sobreposição das curvas. Na união dos dois conjuntos, acaba prevalecendo que um maior número de neurônios acarreta um menor MSE médio. Mas, devemos lembrar que apesar dessas conclusões, a variação do erro nessa análise é relativamente pequena.

Podemos dizer que, para esse conjunto de dados utilizado, um maior número de neurônios e de épocas tende a melhorar o MSE médio. Porém, utilizar uma quantidade muito grande de neurônios na camada intermediária faria com que o tempo de treinamento fosse elevado tornando inviável a análise e a utilização dessa ferramenta para a simulação.

\subsubsection{Simulação das curvas experimentais}

A Figura 4-22 mostra a simulação dos espectros de absorção dos filmes automontados para diferentes pHs, utilizando a melhor rede encontrada (18 neurônios, inicialização: 6, época: 100.000). Podemos ver claramente o mesmo comportamento encontrado na Figura 4-16, onde são apresentados os valores experimentais.

Para um $\mathrm{pH}$ igual a 10 o pico é estreito e centrado em $650 \mathrm{~nm}$. Conforme ocorre a dopagem, o pico se desloca para $950 \mathrm{~nm}$, ficando mais largo. 

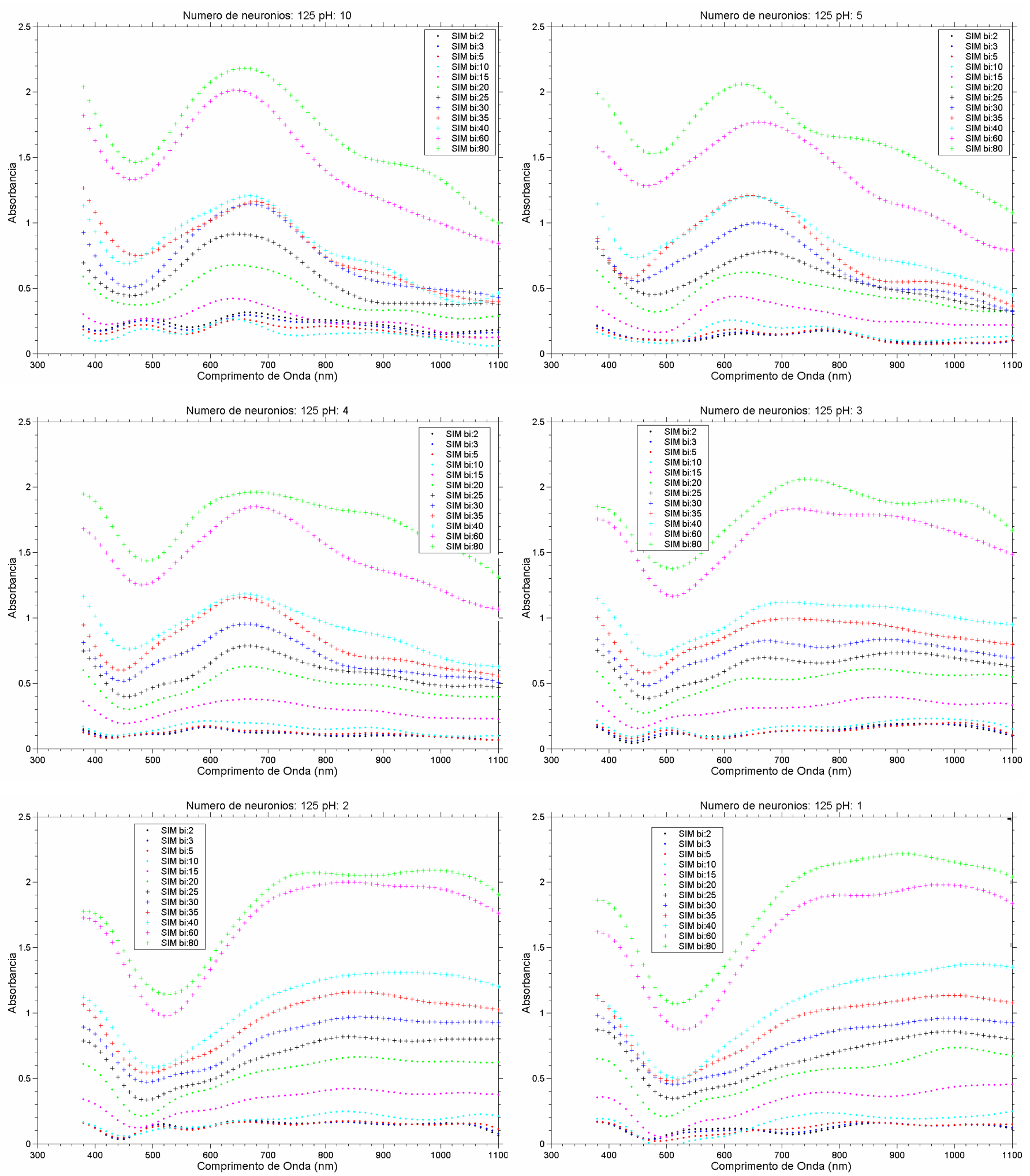

Figura 4-22 - Simulação dos espectros de absorção em função do comprimento de onda para diferentes números de bicamadas em diferentes pHs. Rede neural formada por 125 neurônios, inicialização: 6 época: 100.000. 
Para efeito de comparação entre os valores experimentais e simulados, são apresentados na Figura 4-23 a simulação dos espectros e os valores experimentais (passo de 5 em $5 \mathrm{~nm}$ e não de $50 \mathrm{em} 50$ os quais foram utilizados para o treinamento e teste) sobrepostos.

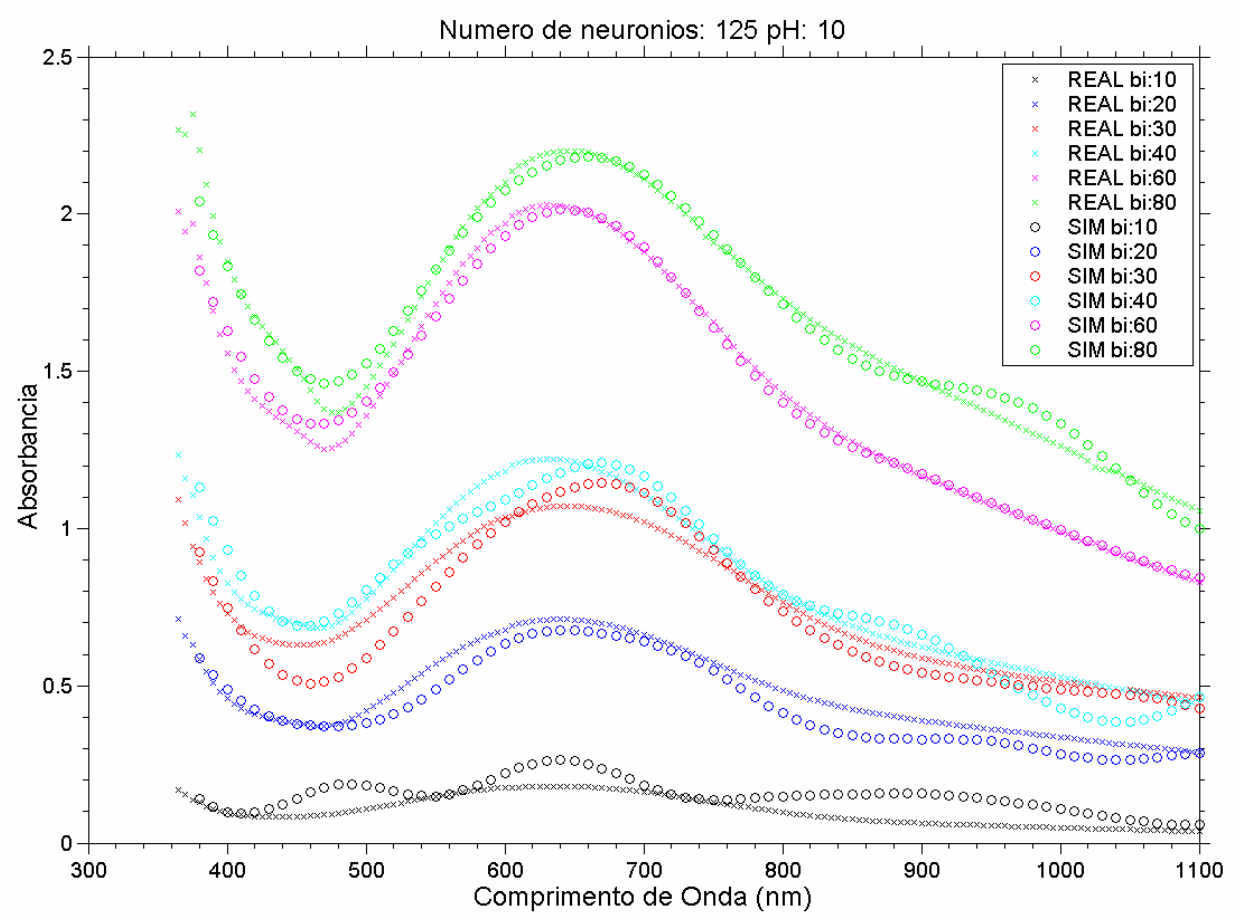

Figura 4-23 - Espectros de absorção simulados e reais para diferentes bicamadas com pH 10 e rede "número de neurônios:125, inicialização: 6, época: 100.000".

Podemos ver que para um número grande de bicamadas os espectros tornamse muito semelhantes, porém, para um número pequeno de bicamadas, ocorre uma variação grande entre eles. Tal resultado acontece devido à quantidade de informações contidas nos conjuntos de treinamento. Tal quantidade só pode ser aprendida com uma quantidade também grande de número de neurônios. O que deve ficar claro é que o importante é delimitar um universo de simulação e então realizar medidas experimentais que extrapolem esse universo. Assim, assegura-se que os dados simulados internos contenham também a sutileza das informações externas. 


\section{CONCLUSÕES}

Mostrou-se nesse trabalho que a utilização de redes neurais artificiais permite aos pesquisadores da área de processamento de materiais e dispositivos criar sistemas que simulem e reproduzam os processos de deposição de filmes finos.

Foram abordadas muitas etapas na confecção de dispositivos que utilizam diferentes processos e materiais, os quais são fortes candidatos à utilização de treinamentos e simulações por redes neurais artificiais.

Através do estudo de dois processos de obtenção de filmes finos poliméricos distintos, spin coating e automontagem, dados experimentais foram levantados, préprocessados e utilizados para treinamento e avaliação das redes neurais.

Nas deposições por spin coating, do ponto de vista morfológico, mostrou-se que a espessura final dos filmes de POMA obedece a um comportamento exponencial decrescente, com um expoente variável com a concentração da solução polimérica. Tal resultado difere do encontrado na literatura e abre novas perspectivas para a explicação do comportamento desses sistemas na formação dos filmes. $\mathrm{Na}$ análise da rugosidade, mostrou-se um comportamento também diferente do encontrado na literatura onde a rugosidade diminui com o aumento da velocidade de rotação e não o contrário.

A análise do MSE no treino das redes neurais artificiais mostrou que a reprodutibilidade pode ser um problema, mas que, como proposto, um aumento no número de dados de treinamento ou a utilização de um algoritmo específico pode fazer com que o resultado final seja aquele onde o MSE é mínimo.

Foi demonstrado também que o número de neurônios na camada intermediária provoca dois comportamentos distintos quando o erro é medido sobre o conjunto de treinamento ou sobre o conjunto de teste. Para o primeiro conjunto, quanto maior é o número de neurônios, menor é o erro final obtido. Enquanto que no conjunto de teste o fenômeno inverso ocorre. Tal fato, como explicado anteriormente, está associado a uma especialização dos neurônios nos dados experimentais apresentados no treinamento. Dessa forma, ao se fornecer dados de teste, a rede não consegue simular eficazmente fornecendo um erro superior a aqueles encontrados para um numero menor de neurônios. Assim, obteve-se um 
valor ótimo entre os erros sobre o conjunto de treinamento e sobre o conjunto de teste, onde um número entre 6 e 10 neurônios conseguiu o melhor resultado.

A análise do número de épocas mostrou que mais épocas não influenciam significativamente o MSE sobre o conjunto de teste, e em alguns casos, até faz com que haja uma piora. Por outro lado, no conjunto de treinamento, o número de épocas faz com que a rede melhor sua resposta. Com o aumento do número de épocas, a taxa de aprendizado cai exponencialmente, tendendo a um mínimo, fato que mostra que as primeiras iterações são as mais significativas para o processo de treinamento.

As simulações mostram que mesmo redes que não apresentaram o menor erro aprendem o comportamento das curvas experimentais. Já a rede que obteve o menor erro sobre o conjunto total, aquela formada por 18 neurônios na camada intermediária mostrou uma resposta muito satisfatória, ajustando sobre os pontos experimentais com diferença entre a curva e os pontos abaixo de $6 \mathrm{~nm}$.

Nas amostras depositadas por automontagem, foi obtido um crescimento linear do filme com o aumento do número de bicamadas depositadas, fato esse já muito conhecido na literatura.

A análise da condutância elétrica em função do tempo de mergulho de filmes automontados numa solução protonante $(\mathrm{pH} 3)$, forneceu uma resposta como esperada (i.e. aumento da condutância conforme se aumenta o tempo de exposição), porém, com um comportamento irregular. Tal comportamento pode ser fruto de diversos fatores como a diferença na espessura dos filmes. Devido a esse comportamento irregular, redes neurais artificiais não foram treinadas com tais dados experimentais e sua análise será feita em trabalhos posteriores.

O estudo da absorção dos filmes em diferentes comprimentos de onda, para diferentes dopagens, forneceu um comportamento similar ao encontrado em outros trabalhos com PAni. Tais dados foram utilizados para o treinamento e teste de redes neurais artificiais.

A análise do MSE mostrou que diferentemente do ocorrido para spin coating, um maior número de épocas faz com que o MSE sempre diminua em todos os conjuntos analisados. Tal fato deve-se ao número elevado de dados utilizados para o treinamento e para o teste, quando comparados ao número de neurônios encontrados 
na camada intermediária. Ao se treinar as redes, os neurônios aprendem sobre o conjunto de treinamento, mas não se especializam em um determinado valor.

Segundo as análises feitas, as redes treinadas apresentam um elevado grau de reprodutibilidade, fornecendo uma variação de apenas 3,4\% em relação à média dos dados experimentais.

A análise dos números de neurônios na camada intermediária mostrou que um aumento nesse número provoca uma diminuição no MSE. Tal fato ocorre não apenas para o conjunto de treinamento, mas para o conjunto de teste e consequentemente para o conjunto total. Como já dito anteriormente, a grande quantidade de dados é o fator responsável por tal comportamento. Um número maior de neurônios poderia levar a uma melhora nos resultados, porém, a relação tempo/diminuição do erro, torna tal ação inviável. É importante notar que a diferença no número de neurônios melhora o MSE, porém, tal melhora não é tão grande quando comparada à média.

Os espectros simulados pelas RNAs treinadas apresentaram um comportamento muito parecido com os experimentais. As RNAs aprenderam sobre o comportamento em diferentes pHs e diferentes números de bicamadas, tornando possível agora a simulação de espectros com características de processo diferentes. Apenas os espectros de filmes com poucas bicamadas apresentaram uma variação grande. Tais espectros possuem valores de absorção muito pequenos e ficam próximos a extremidade do conjunto analisado.

Outra conclusão obtida nesse trabalho refere-se à nova forma de visualizar os dados sobre o erro, a chamada representação circular. A construção de tais gráficos possibilita a leitura de muitas variáveis simultaneamente. O erro final, o número de neurônios, o número de épocas, a taxa de aprendizado são algumas das informações que se concentram em tais gráficos. A geometria formada também revela comportamentos relacionados aos diferentes parâmetros citados.

Como trabalhos futuros, podem-se estudar outros parâmetros desses processos, analisar novos materiais e novos comportamentos e até mesmo outros processos e variáveis. O algoritmo desenvolvido aqui é de uso genérico e permite não só obter o melhor simulador por ele encontrado como também analisar do ponto 
de vista de redes neurais artificiais a influência dos mais variados parâmetros sobre o erro. 


\section{ANEXO I}

\subsection{Procedimento e comandos usados no MATLAB para a construção das redes neurais artificiais}

Para criar, treinar e simular as RNAs, foi utilizado o software MATLAB da Mathworks e a ferramenta Neural Networks Toolbox. Essa ferramenta permite que uma série de tipos diferentes de RNAs seja criada e fornece um grau de liberdade relativamente grande para a alteração dos parâmetros dessas redes. Apesar desta ferramenta permitir sua utilização via interface gráfica (Figura 6-7), optou-se por utilizar o acessório de programação do MATLAB, devido à sua maior robustez e facilidade na confecção de testes e análises semiautomáticas. A programação em MATLAB pode ser encontrada em livros ${ }^{92}$ ou no próprio software.

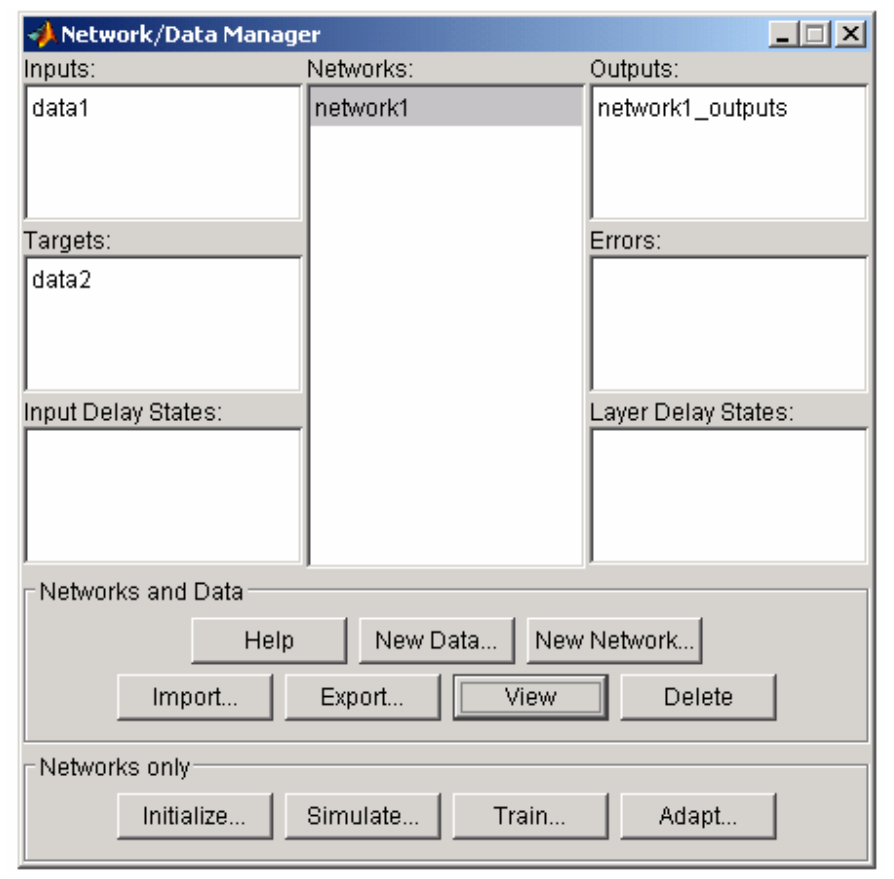

Figura 6-7 - Neural Networks toolbox do Matlab.

Após os dados serem carregados no MATLAB, um pré-processamento é necessário. Devido à natureza diferente de cada entrada e saída, os dados devem ser normalizados para que os pesos da rede não saturem. Para descobrir os valores máximos e mínimos e normalizar os valores, utiliza-se o comando:

$[$ [pn,minp, maxp,tn,mint,maxt $]=\operatorname{premnmx}(p, t)$ 
Onde $p$ é o conjunto de dados de entrada e $t$ é o conjunto de saída (experimental). $P n$ é a matriz de entrada já normalizada (entre -1 e 1), $\min p$ o valor mínimo da entrada, maxp o máximo de entrada, e da mesma forma o conjunto $t n$, mint e maxt.

Com os dados já normalizados, o próximo passo consiste em se definir uma matriz de $n$ (numero de entradas) por 2 onde irá conter os valores máximos e mínimos de cada entrada. O comando

\section{$p r=\operatorname{minmax}(p n)$}

gera essa matriz a partir do conjunto de dados $p n$. Nesse caso, como pn já é um conjunto normalizado, os valores de máximos e mínimos serão -1 e 1 .

A próxima etapa consiste em se definir como será formada a rede neural. Dentro do neural network toolbox, diversas são as possibilidades de criação da rede. O comando usado nesse trabalho foi o newff, um comando que gera uma rede neural do tipo feed-forward com retropropagação.

Netn $=$ newff(pr,[s1 s2...sn1],\{tf1 tf2...tfn1\},btf, blf, pf) onde,

pr é a matriz de máximos e mínimos definida acima.

$\mathrm{S}$ i - contém o número de neurônios da camada $\mathrm{i}$

Tf i - define a função de transferência de todos os neurônios da camada i

btf - Define a função de treinamento da rede,

blf -Define a função de aprendizagem da rede

$\mathrm{pf}$ - define a função que mede a performance

Esse comando gera toda a arquitetura da rede neural, já estabelecendo os máximos e mínimos, o número de camadas e neurônios por camada, as funções de transferência, a função de aprendizagem e a de desempenho. Após esse comando, uma variável é criada (Netn) contendo todas as informações da arquitetura. A rede é criada e os pesos são automaticamente inicializados. Em seguida, devem-se estabelecer alguns parâmetros, como o critério de parada, o número máximo de épocas, etc. 
Netn.trainParam.epochs = 10000;

Netn.trainParam.goal = 1e-5;

$\mathrm{O}$ comando de treinamento realiza o treinamento enquanto o número de épocas não for atingido ou quando o erro for inferior ao estipulado.

\section{Netn2=train(netn,pn,tn);}

Nesse comando, a rede netn é treinada utilizando o conjunto de entrada $p n$ e o de saída $t n$. No final, a rede treinada é colocada em netn2.

Após ter sido treinada a rede pode ser simulada utilizando o comando $\operatorname{sim}(n e t, p)$. A simulação dos parâmetros foi gerada a partir de 500 pontos abrangentes da faixa de trabalho empregada nesse trabalho.

$$
\operatorname{An}=\operatorname{sim}(\text { netn,pn); }
$$

A simulação fornece a matriz $A n$. Como esses dados estão normalizados, $A n$ deve ser pós-processado e para isso, faz-se uso do comando postmnmx (an,mint,maxt)

$$
A=\operatorname{postmnmx}(\text { an,mint,maxt })
$$




\section{BIBLIOGRAFIA}

${ }^{1}$ http://skepdic.com/science.html em 10/11/2004.

2 EISBERG, R.; RESNICK, R.; Quantum physics of atoms, molecules, solids, nuclei, and particles, vol 2. 4 ed., John Wiley \& Sons (1974).

${ }^{3}$ DIRANI, E. A. T.; Películas de silício microcristalino hidrogenado depositadas a baixa temperatura pela técnica PECVD, tese de doutorado, EPUSP, São Paulo (1998).

${ }^{4}$ EDER, F.; et al.; Organic electronic on paper, Applied Physics Letters, 84, 14 (2004) 26732675.

5 HALIK, M.; et al.; High-mobility organic thin-film transistors based on a,a'didecyloligothiphenes, Journal of Applied Physics, 93, 5 (2003) 2977-2981.

${ }^{6}$ MEIJER, E.; et al.; Scaling behavior and parasitic series resistance in disordered organic field-effect transistors, Applied Physics Letters, 82, 25 (2003) 4576-4578.

${ }^{7}$ KAWABE, Y.; et al.; A numerical study of operational characteristics of organic lightemiting diodes, Journal of Applied Physics, 84, 9 (1998) 5306-5314.

${ }^{8}$ KUMAR, D.; SHARMA, R. C.; Advances in conductive polymers, European Polymer Journal, 34, 8 (1998) 1053-1060.

${ }^{9}$ AKCELRUD, L.; Electroluminescent polymers, Progress in Polymer Science, 28 (2003) $875-962$.

${ }^{10}$ FRIEND, R. H.; et al.; Electroluminescence in conjugated polymers, Nature, 397 (1999) 121-128.

11 SAXENA, V.; MALHOTRA, B. D.; Prospects of conducting polymers in molecular electronics, Current Applied Physics, 3 (2003) 293-305.

${ }^{12}$ ADHIKARI, B.; MAJUMDAR, S.; Polymer in sensor applications, Progress in Polymer Science, 29 (2004) 699-766.

${ }^{13}$ PESRUAD, K. C.; Polymers for Chemical Sensing, Materials Today, Abril (2005) 38-44

${ }^{14}$ GALBÁN, J.; et al.; Sensor film for Vitamin $C$ determination based on absorption properties of polyaniline, Talanta, 65 (2005) 1045-1051

15 MIRSKY, V. M.; et al.; Nanometer thick SPR sensor for gaseous $\mathrm{HCl}$, Sensors and Actuators B, 106 (2005) 369-372

${ }^{16}$ SAKANOUE, T.; et al.; Visible light emission from polymer-based field-effect transistors, Applied Physics Letters, 84, 16 (2004) 3037-3039.

${ }^{17}$ CHAWDHURY, N.; et al.; The effects of $\mathrm{H}_{2} \mathrm{O}$ and $\mathrm{O}_{2}$ on the photocurrent spectra of MEHPPV, Synthetic Metals, 102 (1999) 871-872.

18 http://www.plastiquarian.com/stauding.htm em 04/11/2004.

${ }^{19}$ GREENE, R. L.; STREET, G. B.; SUTER, L. J.; Supercondutivity in polysulfur nitride $(S N)_{x}$, Physical Review Letters, 34 (1975) 577-579. 
${ }^{20}$ SHIRAKAWA, H.; et al.; Electrical conductivity in doped polyacetylene, Physical Review Letters, 39, 17 (1977) 1098-1101.

${ }^{21}$ Editado por HADZIIOANNOU, G.; VAN HUTTEN, P.F.; Semiconducting Polymers Chemistry, Physics and Engineering, Wiley-VCH, Alemanha (1999).

${ }^{22}$ KRUMHANSL, J. A.; SCHRIEFFER, J. R.; Dynamics and statistical mechanics of a onedimensional model Hamiltonian for structrual phase transitions, Physical Review B, 11, 9 (1975) 3535-3545.

${ }^{23}$ SU, W. P.; SCHRIEFFER, J. R.; HEEGER, A. J.; Solitons on polyacetylene, Physical Review Letters 42, 25 (1979) 1698-1701.

${ }^{24}$ SU, W. P.; SCHRIEFFER, J. R.; HEEGER, A. J.; Solitons excitations in polyacetylene, Physical Review B 22, 4 (1980) 2099-2111.

${ }^{25}$ ÖSTERBACKA, R.; et al.; Excitons, Polarons and laser action in poly(p-phenylene vinylene) films, Journal of Chemical Physics 118, 19 (2003) 8905-8916.

${ }^{26}$ MIRANDA, P.; MOSES D.; HEEGER, A. J.; Ultrafast photogeneration of charged pólarons on conjugated polymer chains in dilute solution, Physical Review B, 70, (2004) 085212.

${ }^{27}$ BIANCHI, R. F.; Estudo das propriedades eletrônicas e ópticas de filmes e dispositivos poliméricos, Tese de Doutorado, IFSC-USP, São Carlos (2002).

${ }^{28}$ BRAUN, D.; Electronic Injection and Conduction Processes for Polymer Devices, Journal of Polymer Science Part B: Polymer Physics, 41 (2003) 2622-2629.

${ }^{29}$ WÜNSCH, F.; et al.; Charge Carrier injection via semiconducting electrodes into semiconducting/electroluminescent polymers, Surface Science, 489 (2001) 191-199.

${ }^{30}$ FLEMING, R. J.; Space Charge Polymers, Particularly Polyethylene, Brazilian Journal of Physics, 29, 2 (1999) 280-294.

31 BORSENBERGER, P.M.; PAUTMEIER, L.; BÄSSLER, H.; Charge transport in disordered molecular solids, Journal of Chemical Physics 94, 8 (1991) 5447-5454.

${ }^{32}$ PARKER, I. D.; Carrier tunneling and device characteristics in polymer light-emitting diode, Journal of Applied Physics, 75 (1994) 1656-1666.

${ }^{33}$ BRAUN, D.; HEEGER, A. J.; Visible Light emission from semiconducting polymer diodes, Applied Physics Letters, 58 (1991) 1982-1984.

${ }^{34}$ MATTOSO, L.H.C.; RIUL, A. Jr.; SOTO, A.M.G.; et al.; An electronic tongue using polypyrrole and polyaniline, Synthetic Metals, 132 (2003) 109-116.

${ }^{35}$ MATTOSO, L.H.C.; MALMEGRIM, R.R.; FONSECA, F. J.; et al.; An Artificial sensor based on conducting polymers, Biosensors and Bioelectronics, 18 (2003) 1365-1369.

${ }^{36}$ YANG, Y.; HEEGER, J.; Polyaniline as a transparent electrode for polymer light-emitting diodes: lower operating voltage and higher efficiency, Applied Physics Letters, 64, 10 (1994) 12451247. 
${ }^{37}$ MACDIARMID, A. G.; Synthetic Metals: a novel role for organic polymers, Synthetic Metals, 125 (2002) 11-22.

${ }^{38}$ ZOPPEI, R. T.; Polianilina: Síntese, Dopagem e Condução DC, Dissertação. IFSC-USP, São Carlos (1999).

${ }^{39}$ NECHTSCHEIN, M.; et al.; On the nature of the conducting state of polyaniline, Synthetic Metals, 29 (1989) 211-218.

${ }^{40}$ BIANCHI, R. F.; ONMORI, R.K.; GONÇALVES, D.; ANDRADE, A.M.; FARIA, R.M.; IRENE, E.A.; An electrical study of a thin film poly(o-methoxyaniline) field effect transistor, Synthetic Metals, 121 (2001) 1687-1688.

41 MERGULHÃO, S.; FARIA, R.M.; LEAL FERREIRA, G.F.; SWORAKOWSKI, J.; Transport of holes in uniformly and non-uniformly protonated poly(-o methoxyaniline), Chemical Physics Letters, 269 (1997) 489-493.

${ }^{42}$ BURROUGHES, J. H.; et al.; Light-emitting diodes based on conjugated polymers, Nature, 347 (1990) 539-541.

${ }^{43}$ NISHIO, M.; NISHIOKA, A.; TANIGUCHI, T.; et al.; Rheological properties of ethylene ionomer neutralized with binary metal cation, Polymer, 46 (2005) 261-266.

44 TADA, K.; et al., Hole injection from diamond into conducting polymer, Journal of Applied Physics, 84 (1998) 5635-5643.

${ }^{45}$ MARKS, T. J.; Progress in high work function TCO OLED anode alternatives and OLED nanopixelation, Synthetic Metals, 127 (2002) 29-35.

${ }^{46}$ SEOUL, C.; et al.; Preparation of light-emitting devices with poly(p-phenylenevinylene): effects of thermal elimination conditions and polymer layer thickness on device performance, Synthetic Metals 99 (1999) 35-43.

${ }^{47}$ GRANT, P. S.; MCSHANE, M. J.; Development of Multilayer Fluorescent Thin Film Chemical Sensors Using Electrostatic Self-Assembly, IEEE Sensors Journal, 3, 2 (2003) 139-146.

${ }^{48}$ VAN DER PAUW, L. J.; A method of measuring the resistivity and Hall coefficient of lamellae of arbitrary shape, Philips Technical Review, 20 (1958) 220-224

49 MITZL, D. B.; et al., High-mobility ultrathin semiconducting films prepared by spin coating, Nature, 428 (2004) 299-303.

${ }^{50}$ EMSLIE, A.G.; BONNER, F. T.; Peck, L. G.; Flow of a viscous liquid on a rotating disk, Journal of Applied Physics, 29, 5 (1958) 858-862.

${ }^{51}$ MEYERHOFER, D.; Characteristics of resist films produced by spinning, Journal of Applied Physics, 49 (1978) 3993-3997.

52 DAMON, G. F.; Proceedings of Second Kodak Seminar on Microminiaturization, Eastman Kodak Co., Rochester, NY, (1967) 36. 
${ }^{53}$ FLACK, W. W.; SOONG, D. S.; BELL, A. T.; HESS, D. W.; A mathematical model for spin coating on polymer resists, Journal of Applied Physics, 56 (1984) 1199-1206.

${ }^{54}$ LAWRENCE, C. J.; The mechanics of spin coating of polymer films, Physics of Fluids, $\mathbf{3 1}$, 10 (1988) 2786-2795.

55 SUKANEK, P. C.; Dependence of film thickness on speed in spin coating, Journal of Eletrochemical Society, 138, 6 (1991) 1712-1719.

${ }^{56}$ LUURTSEMA, G. A.; Spin coating for rectangular substrates, dissertação de mestrado, University of Califórnia, Berkeley (1997).

${ }^{57}$ SUKANEK, P. C.; A model for spin coating with topography, Journal of Electrochemical Society, 136, 10 (1989) 3019-3026.

${ }^{58}$ BULlWINKEL, M. D.; GU, J.; CAMPBELL, G. A.; SUKANEK, P. C.; The effect of polymer molecular weight and solvent type on the planarization of spin-coated films, Journal of Electrochemical Society, 142, 7 (1995) 2389-2394.

${ }^{59}$ SUKANEK, P. C.; “Anomalous” speed dependence in polyimide spin coating, Journal of Electrochemical Society, 144, 11 (1997) 3959-3962.

${ }^{60}$ CHANG, C. C.; PAI C. L.; CHEN, W. C.; et al.; Spin coating of conjugated polymers for electronic and optoelectronic applications, Thin Solid Films, 479 (2005) 254-260.

${ }^{61}$ MELLO, R. L.; SIMÃO, R. A.; COELHO, L. F.; FERREIRA, M.; Mesoscopic Patterns in POMA spin-coated films: a systematic study; Molecular Crystals and Liquid Crystals, 374 (2002) 179184.

${ }^{62}$ STANGE, T. G.; MATHEW, R.; EVANS, D. F.; Scanning tunneling microscopy and atomic force microscopy characterization of polystyrene spin-coated onto silicon surfaces, Langmuir, 8 (1992) 920-826.

63 ZUCOLOTTO, V.; Compósitos poliméricos nanoestruturados de azocorantes, ftalocianinas e polímeros luminescentes, Tese de doutorado, IFSC-USP, São Carlos (2003).

${ }^{64}$ FERREIRA, M.; RUBNER, M.F.; Molecular-level processing of conjugated polymers. 1. Layer-by-layer manipulation of conjugated polyions, Macromolecules, 28 (1995) 7107-7114.

${ }^{65}$ FOU, A.C.; RUBNER, M.F.; Molecular-level processing of conjugated polymers. 2.Layerby-layer manipulation of in-situ polymerized p/type doped conducting polymers, Macromolecules, 28 (1995) 7114-7120.

${ }^{66}$ CHEUNG, J.H.; STOCKTON, W. B.; RUBNER, M.F.; Molecular-level processing of conjugated polymers. 3. Layer-by-layer manipulation of polyaniline via electrostatic interactions, Macromolecules, 30 (1995) 2712-2716.

${ }^{67}$ STOCKTON, W. B.; RUBNER, M.F.; Molecular-level processing of conjugated polymers. 4. Layer-by-layer manipulation of polyaniline via hydrogen-bonding interactions, Macromolecules, 30 (1995) 2717-2725. 
${ }^{68}$ PATERNO, L. G.; MATTOSO, L.H.C.; OLIVEIRA, O.N.; Filmes poliméricos ultrafinos produzidos pela técnica de automontagem: preparação, propriedades e aplicações, Química Nova, 24, 2 (2001) 228-235.

${ }^{69}$ OLIVEIRA, O.N.; HE, J.A.; ZUCOLOTTO, V.; el al.; Layer-by-Layer Polyelectrolyte Films for Electronic and Photonic Applications. em: KUMAR, J.; NALWA, H. S.; Handbook of Polyelectrolytes And Their Applications, $1^{\mathrm{a}}$ ed., Los Angeles, CA, American Scientific Publishers (2002), capitulo 1,1 .

${ }^{70}$ DECHER, G.; Fuzzy Nanoassemblies: toward layered polymeric multicomposites, Science, 277 (1997) 1232-1237.

${ }^{71}$ DECHER, G.; HONG, J.-D.; Buildup of ultrathin multilayer films by a self-assembly process: I. consecutive adsorption of anionic and cationic bipolar amphiphiles, Makromolekulare Chemie-Macromolecular Symposia, 46 (1991) 321-327.

${ }^{72}$ LVOV, Y.; DECHER, G.; MÖHWALD, H.; Assembly, Structural Characterization, and Thermal behavior of Layer-by-Layer deposited ultrathin films of poly(vinyl sulfate) and poly(allylamine), Langmuir, 9 (1993) 481-486.

${ }^{73}$ KOETSE, M.; LASCHEWSKY, A.; JONAS, A.M.; et al.; Influence of charge density and distribution on the internal structure of electrostatically self-assembled polyelectrolyte films, Langmuir, 18 (2002) 1655-1660.

${ }^{74}$ ARYS, X.; LASCHEWSKY, A.; JONAS, A.M.; Ordered polyelectrolyte "multilayers”. 1. mechanisms of growth and structure formation: a comparison with classical fuzzy "multilayers", Macromolecules, 34 (2001) 3318-3330.

75 LEE, S.S.; LEE, K.B.; HONG, J. D.; Evidence for Spin Coating Electrostatic SelfAssembly of Polyelectrolyte, Langmuir, 19 (2003) 7592-7596.

${ }^{76}$ JIANG, C.; MARKUTSYA, S.; TSUKRUK, V. V.; Collective and Individual Plasmon Resonances in Nanoparticle Films Obtained by Spin-Assisted Layer-by-Layer Assembly, Langmuir, 20 (2004) 882-890.

${ }^{77}$ LI, W.; et al.; Fabrication and Characterization of Optically Active Multilayer Thin Films Based on Polyaniline Colloids, Langmuir, 19 (2003) 4639-4644.

${ }^{78}$ HAYKIN, S.; Neural Networks: A comprehensive foundation, Second Edition, Prentice Hall (1998).

${ }^{79}$ MEHROTRA, K; MOHAN, C. K., RANKA, S.; Elements of Artificial Neural Networks, MIT press (1997).

${ }^{80}$ MCCULLOCH, W.S.; PITTS, W.; A logical calculus of ideas immanent in nervous activity, Bulletin of Mathematical Biophysics, 5 (1943) 115-133.

${ }^{81}$ HEBB, D. O.; The Organization of Behavior: a Neuropsychological Theory, New York, Willey (1949). 
${ }^{82}$ ROSENBLATT, F.; The Perceptron: A probabilistic model for information storage and organization in the brain, Psychological Review, 65 (1958) 386-408.

${ }^{83}$ WIDROW, B.; adaptive switching circuits, Western Electronic Show and Convention, Convention Record, 4, Institute of Radio Engineers (1960) 96-104.

${ }^{84}$ MINSKY, M. L.; PAPERT, S. A.; Perceptrons, Cambridge, MA, MIT Press (1969).

${ }^{85}$ RUMELHART, D. E.; HINTON, G. E.; WILLIAMS, R. J.; Learning representations of back-propagation errors, Nature, 323 (1986) 533-536.

${ }^{86}$ THOMSEY, J. M.; SMITH, A. E.; Performance Measures, Consistency, and power for artificial neural network models, Mathematical Computation Modeling, 21 (1995) 243-258.

${ }^{87}$ KOLMOGOROV, A. N.; On the representation of continuous functions of many variables by superposition of continuous functions of one variable and addition, Doklady Akademii Nauk USSR, 114 (1957) 953-956.

${ }^{88}$ CYBENKO, G.; Approximation by superpositions of a sigmoidal function, Mathematics of Control, Signals and Systems, 2 (1989) 303-314.

${ }^{89}$ GALLANT, S. I.; WHITE, H.; There exists a neural network that does not make avoidable mistakes. Proceedings of the International Conference on Neural Networks, 1 (1988) 657-664.

90 SILVERT, W.; BAPTIST, M.; Can neural networks be used in data-poor situations?, Artificial Neuronal Networks; application to ecology and evolution, editado por S. Lek e J. F. Guégan, Berlin, Springer-Verlag (1998) 241-248.

91 SKOOG, D.; LEARY, J.; Principles of instrumental analysis, $4^{\mathrm{a}}$ ed., Saunders College Publishing (1992), Capitulos 7 e 8.

${ }^{92}$ HANSELMAN, D.; LITTLEFIELD, B.; Matlab 6 - Curso Completo, Prentice Hall (2003).

$93 \mathrm{CHO}$, J.; et al.; Quantitative analysis on the adsorbed amount and structural characteristics of spin self-assembled multilayer films; Polymers, 44 (2003) 5455-5459. 